\title{
KwaZulu-Natal Department of Health policy and guidelines for integrated ante and postnatal care at district hospital community health centre and clinic level
}

Population Council

Follow this and additional works at: https://knowledgecommons.popcouncil.org/departments_sbsr-rh

Part of the Demography, Population, and Ecology Commons, Domestic and Intimate Partner Violence Commons, Family, Life Course, and Society Commons, Gender and Sexuality Commons, International Public Health Commons, Medicine and Health Commons, Sexuality and the Law Commons, and the Women's Health Commons How does access to this work benefit you? Let us know!

\section{Recommended Citation}

"KwaZulu-Natal Department of Health policy and guidelines for integrated ante and postnatal care at district hospital community health centre and clinic level." Johannesburg: Population Council, 2009. 


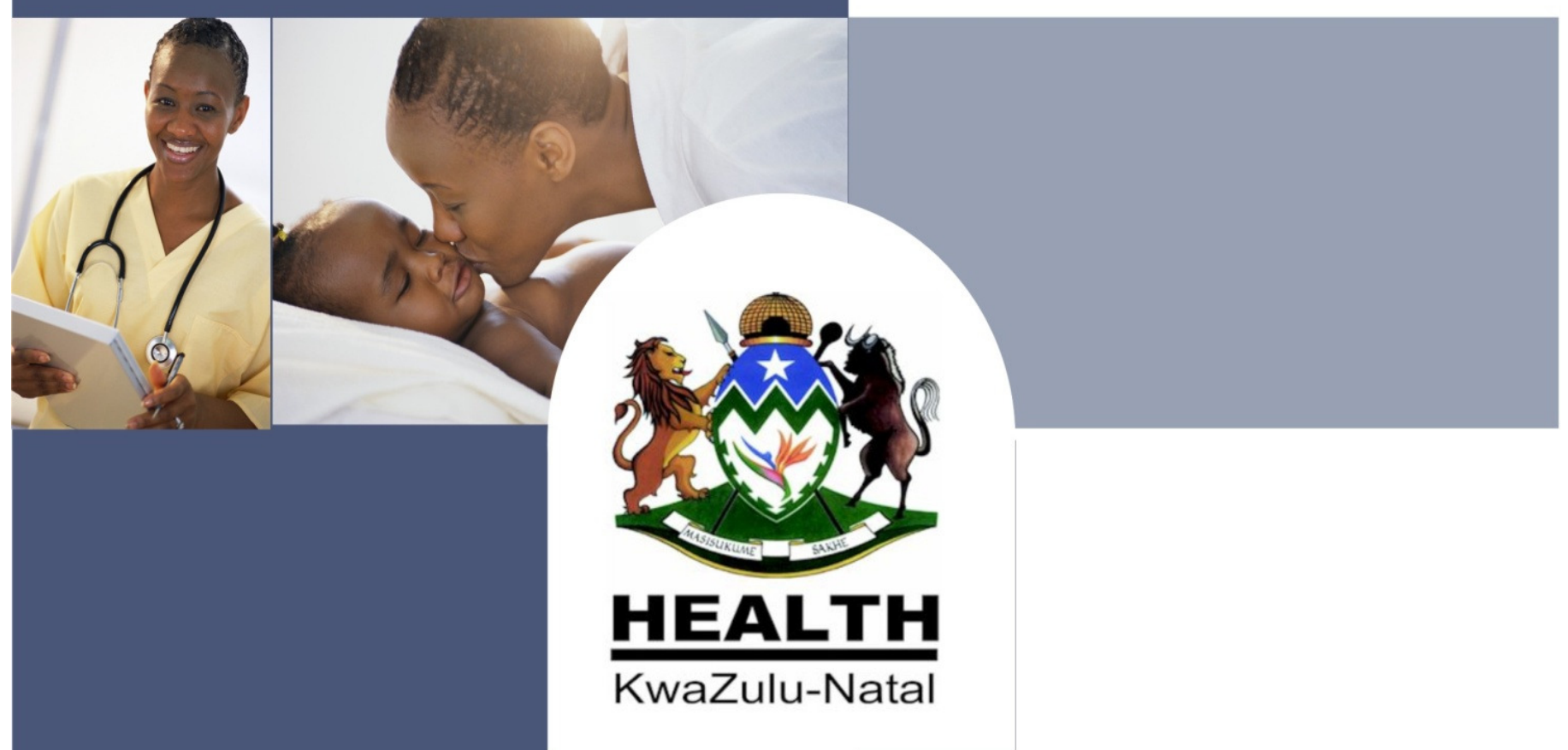

KwaZulu-Natal

Department of Health

Policy and Guidelines

for Integrated

Ante and Post Natal Care

at District Hospital

Community Health Centre and Clinic Level 


\section{Acknowledgements}

We would like to thank those who have participated in the policy and guideline development process in KwaZulu-Natal. Particular appreciation goes to Ms Janet Dalton and Ms Dolly Nyasulu from the KZN Provincial MCWH programme for their leadership and commitment to the process.

We would also like to thank the many nurses and programme managers from the eleven districts in KZN for participating in the stakeholders meetings and for their inputs as the various drafts of the guidelines were developed. Special thanks also go to the various key informants who provided their expert opinions for the various topic areas.

Thanks go to all the pregnant women and postpartum women who participated in the study.

This Policy and Guidelines for Integrated Ante-Natal and Post-Natal Care is made possible by the President's Emergency Plan for AIDS Relief (PEPFAR) and the generous support of the American people through the United States Agency for International Development (USAID). The contents are the responsibility of Population Council and KwaZulu Natal Department of Health and do not necessarily reflect the views of USAID or the United States Government. 


\section{Table of Contents}

1. Introduction 1

2. Policy Development Process 2

3. Context of the Integrated and Evidence-Based Antenatal and Postnatal Policy and Guidelines for KwaZulu-Natal 3

4. Justification for an Integrated Antenatal and Postnatal Policy with Guidelines 5

5. Vision 6

6. Goals 7

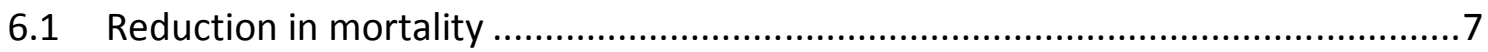

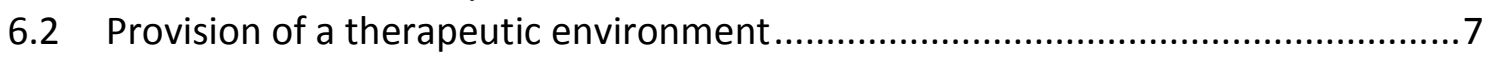

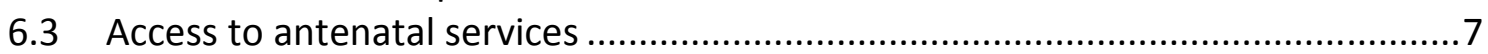

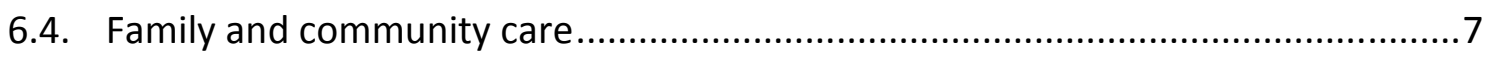

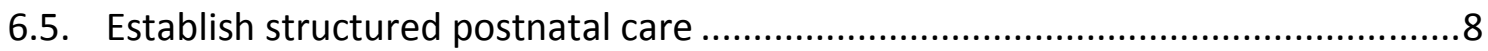

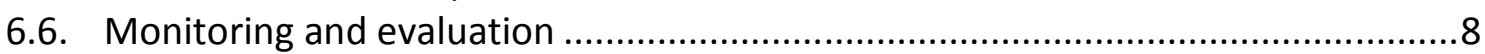

7. Indicators to be Measured 9

8. Guiding Principles 11

9. Underlying Assumptions 12

10. Strategies for Implementation $\quad 14$

10.1. Increasing the knowledge base for all health care providers .............................14

10.2 Increasing the skills base for all health care providers .........................................14

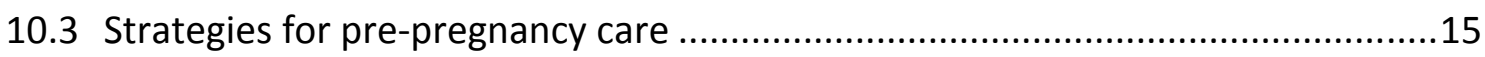

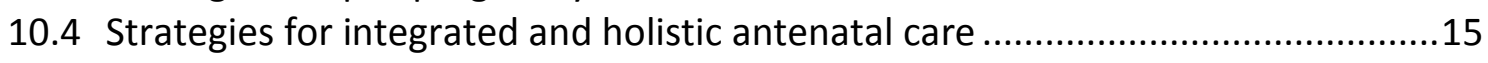

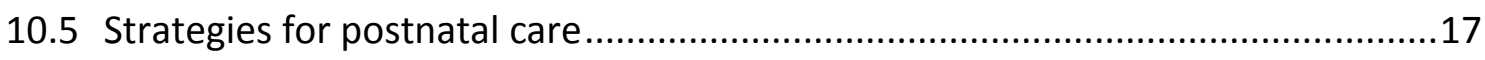

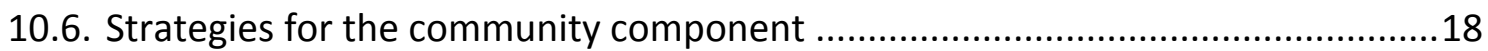

11. Implementation Plan 19

12. Introduction to the Antenatal and Postnatal Care Policy Guidelines 30

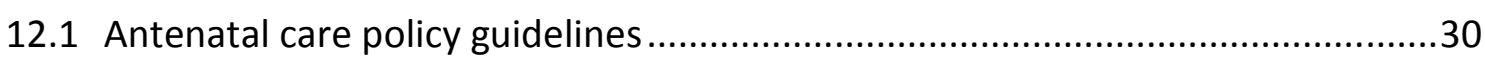

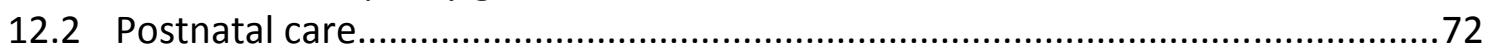




\section{Abbreviations and Acronyms}

\begin{tabular}{|c|c|}
\hline ANC & Antenatal care \\
\hline ARVs & Antiretroviral Drugs \\
\hline BANC & Basic Antenatal care \\
\hline DOTS & Directly Observed Treatment used for Tuberculosis \\
\hline $\mathrm{IMCl}$ & Integrated management of Childhood Illnesses \\
\hline KZN & KwaZulu-Natal \\
\hline MCWH & Maternal Child and Women's Health \\
\hline NMR & Neonatal mortality rate \\
\hline RHRU & Reproductive Health Research Unit \\
\hline PHC & Primary Health Care \\
\hline РMTCT & Prevention of Mother to Child Transmission \\
\hline PNC & Postnatal care \\
\hline TB & Tuberculosis \\
\hline VCT & Voluntary Counselling and Testing \\
\hline WHO & World Health Organisation \\
\hline CTG & Cardiotacogram \\
\hline BCG & Bacillus Calmette-Guerin (TB vaccine) \\
\hline CD4 & Cluster designation 4 cells \\
\hline JACCOL & Jaundice, Anaemia, Blubbing, Cyanosis, Oedema and Lymphadenopathy \\
\hline LNMP & Last Normal Menstrual Period \\
\hline EDD & Estimated Date of Delivery \\
\hline PROM & Premature Rupture Of Membranes \\
\hline
\end{tabular}




\section{Introduction}

The Preamble to the South African Constitution (1994) states: that the Constitution was adopted to "Improve the quality of life of all citizens and free the potential in each person; ...." The Constitution is founded on the value placed in human dignity, equality, human rights and freedoms, as well as non-sexism. Many of the same values are enshrined in the Nurses Pledge and the Hippocratic Oath.

The Bill of Rights in the South African Constitution:

- Is the foundation for the development of all policies to ensure that people can access health services for their needs.

- $\quad$ Ensures that policies do not impinge on their rights, but uphold the Rights of all citizens in South Africa.

- Section 9 (3) declares that the state may not "unfairly discriminate" against anyone on the "...grounds of race, gender, sex, pregnancy, marital status, ethnic or social origin, colour, sexual orientation, age disability, religion conscience, belief, culture, language and birth."

- Section 10 states "Everyone has inherent dignity and the right to have their dignity respected and protected."

- All persons in South Africa have the right to decide about their own reproductive health, ".... security in and control over their own body."

- The right to privacy is clearly fundamental to the Bill of Rights in the South African Constitution.

In the first State of the Nation Address on 24 May 2005, the first democratic President, Nelson R. Mandela gave a precious gift to the Nation of Health Services to all pregnant women (including the puerperium) and children under five years old at no cost to the client. He asked that we build a people-centred society that guarantees human rights and dignity.

The Antenatal and Postnatal Policy for KwaZulu-Natal will be based on these ideals to ensure that all women in KwaZuluNatal attending provincial services will be afforded humane, confidential, safe, informed, integrated and holistic care during their pregnancies and postpartum period.

The Policy and Guidelines - which should be used in conjunction with other relevant guidelines - .focus on a client-centred approach, and on enhancing opportunities for health service providers to gain job satisfaction. Health workers are pivotal in ensuring both a physical and emotional environment in health services that is conducive to the health of pregnant women, mothers and newborn children.

This Policy includes pre-pregnancy care, antenatal care and postnatal care. Postnatal care being defined as the period from six hours postpartum to six weeks postpartum. 


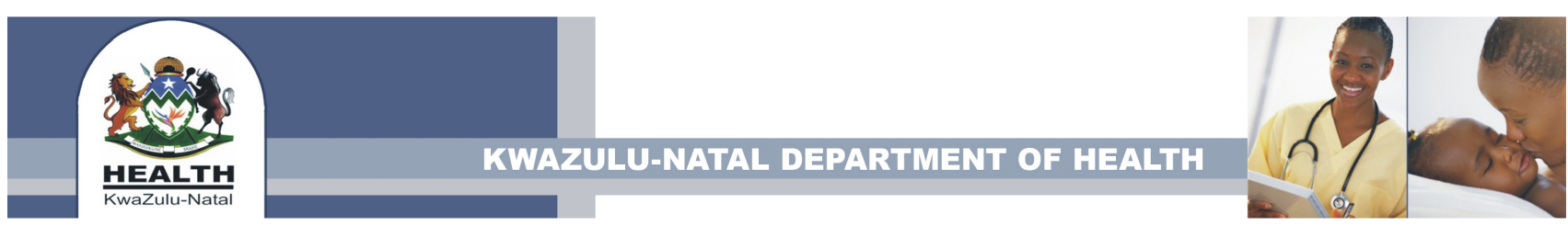

\section{Policy Development Process}

The KwaZulu-Natal Department of Health (Maternal Child and Women's Health Programme), with the technical support of the Population Council and Reproductive Health Research Unit, has undertaken a systematic process in the development of the Antenatal and Postnatal Policy and Guidelines. This has not only ensured that local, national and international research-based evidence has fed into the development but that buy-in and ownership have been generated at all levels through the involvement of all key stakeholders.

Priority areas for inclusion in the policy and guidelines were identified through a stakeholders' meeting and a series of key informant meetings. The stakeholders' meeting was attended by the District Medical Officers, Advanced Midwives, a Primary Health Care nurses and the District level Maternal, Child and Women's Health co-ordinators from each of the 11 districts and professional nurses from the local governments of Durban and Pietermaritzburg. The initial key informants' meeting was attended by participants from academia and programme management in various government departments. Individual follow-up visits were conducted after the key informants' meeting with the meeting attendees and additional key informants to generate buy-in and support and identify key lessons learnt from research and programmatic experience.

The need for a policy and guidelines that support a continuum of care for women from pre-conception to postpartum and family planning as well as one that comprehensively addresses a woman's needs no matter at what point she enters into the system was emphatically emphasised by all. Participants identified a set of areas as needing in-depth review by task teams: preconception, family planning; antenatal care; postnatal care; health systems; community participation and health promotion.

Participants recommended that task teams be created to focus on health systems and community participation. They also stressed the importance of paying sufficient attention to supportive systems (health information systems, supervision, equipment, correct placement and to utilisation of staff, hours of service and resource allocation/utilisation, etc.). Emphasis was also placed on addressing the role of the community and the need to focus on community involvement in both the development process and implementation of the policy and guidelines.

The task teams worked over a period of two years to conduct critical reviews of the existing guidelines, review latest evidence, prepare draft wording for the revised guidelines, make recommendations on language for the policy, and propose key indicators for monitoring. Input from all task teams has been reviewed and incorporated into the policy and guidelines. Pre-field tests were conducted in representative clinics in the province to review relevance, layout, content, user-friendliness, and appropriate local adaptation before finalisation of the documents. 


\section{Context of the Integrated and Evidence-Based Antenatal and Postnatal Policy and Guidelines for KwaZulu-Natal}

KwaZulu-Natal has a rising maternal mortality rate:

\begin{tabular}{|l|l|}
\hline Saving Mothers Reports & Maternal Mortality Rate \\
\hline 1998 & 100 per 100000 births \\
\hline $1999-2001$ & 144 per 100000 births \\
\hline $2002-2004$ & 160 per 100000 births \\
\hline
\end{tabular}

- Much of the practice of midwives in governed by the South African Nursing Council regulations (Government Notice R2598 of 30 November 1984 as amended: No R387 as amended by No R866 and No R2190; No R2488 of 26 October 1990), which are out of date and supported by an Act and have not addressed the major issue of HIV and Aids, Sexually Transmitted Infections, Tuberculosis and domestic violence issues. The new Nursing Act (2005) has no new regulations that apply to midwives to date (Jan 2008).

- HIV prevalence in KwaZulu-Natal has risen exponentially from $24 \%$ to $39 \%$ since the last maternity guidelines were developed.

- $\quad$ No comprehensive and integrated policy and guidelines for antenatal (ANC) and postnatal care (PNC) are currently in use in KwaZulu-Natal to guide integrated routine maternity care and practice for pregnant and postnatal women.

- Many of the practices undertaken by nurses at primary health care level in the care of pregnant women are traditional rather than evidence-based.

- In KwaZulu-Natal antenatal and postnatal care is task-oriented rather than client-oriented, leading to impersonal and incomplete care, as well as making a contribution to staff burn-out.

- Many women who die during pregnancy, during labour and in the postnatal period do not attend antenatal care (23.8\% Saving Mothers Report 2002 - 2004)

- Mothers who do not attend antenatal care services are more likely to have stillborn infants (Perinatal Problem Identification Programme data).

- Only $28 \%$ of women attend antenatal care before 13 weeks of pregnancy (DHIS: 2006/07). Women in KwaZulu-Natal attend Antenatal care late during their pregnancies, diminishing the access to HIV testing for possible antiretroviral treatment, prevention of complications of previously diagnosed or undiagnosed medical conditions eg cardiac disease; and complete treatment of sexually transmitted infections, syphilis in particular. It has been noted in the Saving Mothers report (2001 to 2003) that women under 18 years of age are less likely to attend antenatal clinics.

- Areas such as screening for tuberculosis and domestic violence, cervical cancer and sexually transmitted infections (except for syphilis) are not routinely screened for, and have not been included in routine antenatal or postnatal care.

- Postnatal care has not been formally addressed. More women die in the postnatal period than any other time of pregnancy (75.4\% Saving Mothers Report 1999 - 2001 pp 213 update to 2002 - 2004).

- Postnatal care after the immediate puerperium has centred on the baby (and this is not in a focused or targeted manner), rather than the mother and baby unit. 
- Postnatal care and access to care has not been monitored or evaluated in KwaZulu-Natal.

- Limited health education and planning for the birth take place at the antenatal visits. There has been no concerted effort to bring community, family and partner participation into the holistic care of pregnant women and new mothers. 


\section{Justification for an Integrated Antenatal and Postnatal Policy with Guidelines}

a. The HIV and Aids pandemic is causing many deaths among women during pregnancy and the postnatal period. In the Saving Mothers Report (2002 - 2004), it was found that 49\% of maternal deaths were caused by HIV and Aids-related conditions.

b. No screening for TB is routinely done during pregnancy, yet the disease has reached epidemic proportions in the province.

c. Domestic violence is common and $26 \%$ of women attending antenatal care in 12 clinics in Umlazi, KwaZulu-Natal had experienced violence during their pregnancies (MIM study: 2004).

d. The National Maternity Guidelines $\left(20022^{\text {nd }} \mathrm{Ed}\right)$ do not outline antenatal care and postnatal care in an integrated and holistic manner. Prevention of mother to child transmission of HIV services have been added on, rather than integrated into the documents.

e. Much research is available to inform the policy and guidelines to ensure an improved, integrated client and familycentred service to pregnant women and their families.

f. In the public service most of the antenatal and postnatal care is rendered at primary health care level, where many service are overcrowded and understaffed. These guidelines aim to help clinics to work more efficiently, while delivering a quality service.

g. Focused education of the pregnant woman and family must be made available at antenatal and postnatal clinic visits.

h. The postnatal period is a strategic time at which HIV and Aids and STI prevention, infant feeding and family planning information should be reinforced.

i. Many women access services outside their areas ie rural woman may travel to access antenatal and delivery services, even though these services are offered in their domicile areas. 


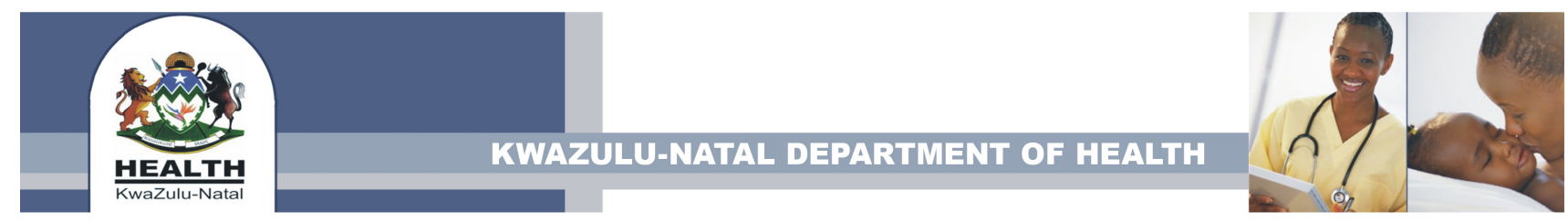

\section{Vision}

Provision of antenatal and postnatal care in a client and family-centred manner to all women in KwaZulu-Natal to ensure the maintenance of health of the mother, the birth of a healthy baby, and support of the mother and baby in the six weeks postpartum to build a foundation for a healthy life, through evidence-based care within the primary health care approach to health service delivery. 


\section{Goals}

\subsection{Reduction in mortality}

- Reduction of maternal deaths indirectly caused by inadequate antenatal and postnatal care.

- Reduction in perinatal mortality.

\subsection{Provision of a therapeutic environment}

- Ensuring an environment conducive to providing holistic, integrated health services (privacy, equipment, supplies, space, appropriately trained staffing requirements).

\subsection{Access to antenatal services}

- Initiating a targeted base for five essential antenatal care visits at primary care level for women with normal, uncomplicated pregnancies.

- Improving access to quality antenatal care (prevention of delays, reducing waiting periods, appropriate referral, hours of service, mobile clinics).

- Establishing targeted screening and early referral for medical, social, obstetric and neonatal causes that endanger the health of the mother and baby.

\subsection{Family and community care}

- Promoting and sustaining a partnership between the health care providers and the communities to ensure meaningful community involvement in mother and child health care programmes.

- Encouraging all community members to be involved in the promotion and support of mother and child health by making information accessible, involving communities in decision making and giving feedback to communities.

- Creating an individual, family and community- friendly maternal health service in order to promote access to and appropriate utilisation of services

- Establishing basic information about pregnancy, birth and the postpartum period for families to ensure they are ready for a new child.

- Laying the foundation to ensure that each child is a planned child.

- Improving maternal and newborn health by engaging community members in community-owned integrated processes and strategies aimed at ensuring safe pregnancy, healthy mothers and healthy babies. 


\subsection{Establish structured postnatal care}

- Establishing postnatal care, which includes the mother, baby and family, in a structured framework.

- Monitoring of postnatal services at local, district and provincial level.

\subsection{Monitoring and evaluation}

- Strengthening data collection and monitoring and evaluation (M\&E) processes.

- Support local service-level monitoring.

- Support action from local monitoring and information analysis.

- Support sharing of information with communities. 


\section{Indicators to be Measured}

\begin{tabular}{|c|c|}
\hline Indicator & Data Source \\
\hline Maternal mortality rate & Maternal death reports and assessments \\
\hline Antenatal coverage rate & District Health Information System \\
\hline $\begin{array}{l}\text { Percentage of women accessing antenatal care before the } 20^{\text {th }} \text { week of } \\
\text { pregnancy or attending for confirmation of pregnancy }\end{array}$ & District Health Information System \\
\hline Percentage of antenatal women tested for HIV & District Health Information System \\
\hline $\begin{array}{l}\text { Percentage of HIV-positive women accessing medication to limit HIV } \\
\text { transmission to the baby }\end{array}$ & District Health Information System \\
\hline Prevalence of syphilis in pregnant women & District Health Information System \\
\hline $\begin{array}{l}\text { Percentage of women who complete their treatment for syphilis before } \\
\text { delivery }\end{array}$ & $\begin{array}{l}\text { Record audits } \\
\text { Sentinel sites }\end{array}$ \\
\hline Percentage of women tested for syphilis in pregnancy & $\begin{array}{l}\text { District Health Information System } \\
\text { Record audits }\end{array}$ \\
\hline Percentage of HIV-positive pregnant women on dual therapy & District Health Information System \\
\hline $\begin{array}{l}\text { Proportion of HIV-positive women having CD4 counts done during pregnancy } \\
\text { and postpartum }\end{array}$ & District Health Information System \\
\hline Number of women requiring antiretroviral treatment during pregnancy & $\begin{array}{l}\text { Sentinel sites/ ARV database } \\
\text { District Health Information System }\end{array}$ \\
\hline $\begin{array}{l}\text { Number of hospitals and clinics undertaking clinical audits of antenatal and } \\
\text { postnatal care }\end{array}$ & $\begin{array}{l}\text { Provincial Saving Mothers } \\
\text { Recommendation Implementation Reports } \\
\text { Audit reports from Basic Antenatal Care } \\
\text { sites (BANC) }\end{array}$ \\
\hline Number of women accessing antiretroviral treatment in the postnatal period. & $\begin{array}{l}\text { Sentinel sites } \\
\text { District Health Information System }\end{array}$ \\
\hline Perinatal mortality and morbidity & $\begin{array}{l}\text { District Health Information System } \\
\text { Perinatal Problem Identification } \\
\text { Programme }\end{array}$ \\
\hline Early neonatal mortality & $\begin{array}{l}\text { District Health Information System } \\
\text { Perinatal Problem Identification } \\
\text { Programme }\end{array}$ \\
\hline $\begin{array}{l}\text { Number of deliveries in facilities (trained personnel) } \\
\text { Number of births without a trained healthcare worker }\end{array}$ & $\begin{array}{l}\text { District Health Information System } \\
\text { Periodic community surveys (eg IMCI) }\end{array}$ \\
\hline
\end{tabular}




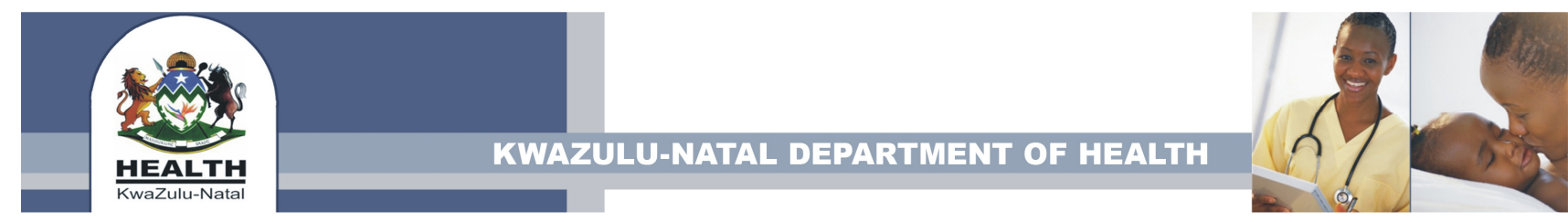

\begin{tabular}{|c|c|}
\hline Indicator & Data Source \\
\hline Percentage of clinics with client suggestion and compliant system & $\begin{array}{l}\text { Supervision reports } \\
\text { Maternal reviews } \\
\text { Quality assurance data }\end{array}$ \\
\hline Client waiting times & $\begin{array}{l}\text { Local monitoring } \\
\text { Supervision reports }\end{array}$ \\
\hline Client satisfaction rate & $\begin{array}{l}\text { Client satisfaction surveys } \\
\text { Client complaints }\end{array}$ \\
\hline Number of companioned visits for antenatal care & Sentinel sites (periodic) \\
\hline Number of women requesting termination of pregnancy & Sentinel sites (periodic) \\
\hline Percentage of hospitals providing first trimester terminations of pregnancy & District Health Information System \\
\hline $\begin{array}{l}\text { Percentage of hospitals providing second trimester terminations of } \\
\text { pregnancy }\end{array}$ & District Health Information System \\
\hline $\begin{array}{l}\text { Percentage of community health centres providing first trimester } \\
\text { terminations of pregnancy }\end{array}$ & District Health Information System \\
\hline Percentage of clinics accredited as youth-friendly services. & Accreditation database \\
\hline $\begin{array}{l}\text { Number of women who confirmed/initiated antenatal care with a private } \\
\text { practitioner }\end{array}$ & Sentinel sites (periodic) \\
\hline Percentage of women being discharged before six hours post delivery & $\begin{array}{l}\text { District Reports } \\
\text { Sentinel sites }\end{array}$ \\
\hline $\begin{array}{l}\text { Percentage of women attending a postnatal service within six days post } \\
\text { delivery }\end{array}$ & New (District Health Information System) \\
\hline Percentage of women attending a postnatal clinic by six weeks post delivery & New (District Health Information System) \\
\hline $\begin{array}{l}\text { Number of clinics and hospitals which have shared maternal and neonatal } \\
\text { information with communities }\end{array}$ & $\begin{array}{l}\text { Service reports/ supervision reports } \\
\text { Maternal Health Reviews }\end{array}$ \\
\hline Number of awareness events covering maternal health issues & District Reports \\
\hline $\begin{array}{l}\text { Number of sub-districts with Integrated Management of Child hood Illness } \\
\text { (IMCI) community component projects addressing Pregnancy Care Key } \\
\text { Family Practice }\end{array}$ & $\begin{array}{l}\text { Six-monthly Integrated Management of } \\
\text { Childhood Illness (IMCI) District Reports } \\
\text { Project reports and baseline surveys }\end{array}$ \\
\hline $\begin{array}{l}\text { Number of customer satisfaction surveys targeting pregnant and postnatal } \\
\text { women }\end{array}$ & Survey results \\
\hline $\begin{array}{l}\text { Number of services undertaking evaluations of antenatal and postnatal } \\
\text { services, which include clients and communities as well as health service } \\
\text { providers. }\end{array}$ & Reports from districts (annual) \\
\hline
\end{tabular}




\section{8. $\quad$ Guiding Principles}

8.1 The policy and guidelines acknowledge that safe and healthy pregnancy and safe delivery of a healthy child are human rights issues.

8.2 The principles embodied in Batho Pele ("people first") of the South African Public Service are fundamental to the delivery of quality antenatal and postnatal services to the communities in KwaZulu-Natal.

8.3 In keeping with the principle of Batho Pele that clients have the right to being served by a named service provider, and a principle of humane continuum of care, as far as possible the same service provider (or small team of three people) should render care to the client throughout their pregnancy and post partum period. Tasks, contained in the antenatal care schedule, should be rendered by no more than three people who work in a team, ie two nurses and one lay counsellor will do the total antenatal care for one women, rather than having five nurses and a lay counsellor all doing a task toward care. This is advocated to ensure that a nurse-client relationship is established to promote compliance and influence behaviour. It will also enhance job satisfaction and areas of responsibility for the service providers.

8.4 The norms and standards of the Primary Health Care Package and District Hospital Package are upheld by this policy and guidelines.

8.5 All routine services to pregnant women in the antenatal and postnatal periods should be available at the same facility. Antenatal care should be available daily, especially for early first antenatal visits.

8.6 Partnership, co-ordination and joint programming among stakeholders, including communities, should be promoted in the implementation of community interventions. The principles of the Integrated Management of Child hood Illness Community Component, Youth-friendly Services and other community development models in engaging communities in care of pregnant women and the newborn babies should be followed.

8.7 Key players and stakeholders including women and their partners or significant others, traditional health practitioners, community leaders, non-governmental organisations, civic and faith-based organisations, and men's and youth groups should be identified at a local service level, in order to clarify their roles and responsibilities in maternal and newborn health, in each sub-district or service delivery area. 


\section{Underlying Assumptions}

\subsection{Quality care can only be rendered where the following exist:}

9.1.1 Regular and participatory reviews, customer satisfaction surveys and evaluation of the services delivered to pregnant women and postnatal women are undertaken. Medical, nursing staff, community members and clients participate in these evaluations and feedback is made available to groups.

9.1.2 Management at all levels pay attention to staffing and caseloads to ensure quality can be maintained

9.1.3 Equipment according to Facilities Planning and Commissioning Service.

9.1.4 Nurses and doctors rendering the service are qualified to offer basic midwifery or obstetric care.

9.1.5 All staff offering antenatal and postnatal care are orientated to the service, and offered an appropriate inservice training opportunity at least annually.

9.1.6 Rotation of nurses and doctors is limited to contain erosion of the established skills base, to offer continuation of care to the woman by the same service provider and to enhance job satisfaction of the health care providers.

9.1.7 Staff complement is adequate to provide a service within a reasonable waiting time.

9.1.8 Safety - both physical and emotional - of staff and clients is upheld by the Provincial Health Department as fundamental to quality service delivery. The Department is committed to staff safety and takes every step possible to ensure it while on they are duty.

9.2. A clear understanding of traditional and cultural norms and practices, perceptions, and health-seeking behaviours of individuals, families, and communities in relation to maternal and child health exists to avoid substituting for existing community resources and initiatives.

9.3. The right to have a companion (partner or another significant other) during all antenatal care, labour and postnatal care is acknowledged. This person should be actively involved in the health education as well as taught some home care of the mother and baby.

9.4. Gender equity, open communication, transparency and accountability in accessing health services and information as well as in planning, implementation, monitoring and evaluation of community-based initiatives are promoted. 
9.5 Appropriate rapid tests are available at clinics and hospitals to reduce clients' waiting times for results and appropriate treatment. For example: HIV, Rhesus factor, syphilis testing (RPR), haemoglobin.

9.6. Clear written referral routes are available at all levels of care and updated annually, and districts appraise the referral system at least twice a year. 


\section{Strategies for Implementation}

\subsection{Increasing the knowledge base for all health care providers}

This includes:

- Professional scope of practice according to current legislation, with extension orders of the staff nurses and enrolled nursing assistants.

- The scope of practice of other health care providers in the team eg lay HIV and Aids councillors.

- Basic information about sexual and reproductive health, including sexuality, safer sex practices, contraception, voluntary sterilisation, termination of pregnancy and infertility.

- Health care providers should be well versed in the physiological changes, occurring during the menstrual cycle, pregnancy and puerperium so as to be able to prevent and detect abnormalities/complications as soon as possible.

- Breast feeding, the physiology of sustaining breast feeding and solutions to breast feeding problems.

- Understanding of the complexity of the choices HIV-positive women have to make about feeding their newborn babies.

- Understanding of the transmission of HIV infection from mother to child, and current interventions to prevent transmission.

- Knowledge of provisions of the Sexual Offences Act and Domestic Violence Act.

- Knowledge of community resources.

\subsection{Increasing the skills base for all health care providers}

This must include:

- Counselling skills, including managing requests for termination of pregnancy commencing provider initiated HIV counselling and testing and provide basic genetic counselling.

- General medical assessment, history taking and examination skills: assessment of the cardiac system, urinary system and female genital tract.

- Updated general midwifery or medical obstetric skills to offer basic ante and postnatal care

- Techniques for the rapid tests available: rhesus factor, syphilis, HIV, etc.

- Group health education health skills.

- Skills to develop youth-friendly services and in the community component of $I \mathrm{MCl}$.

- Counselling and communication skills to management adolescents. 


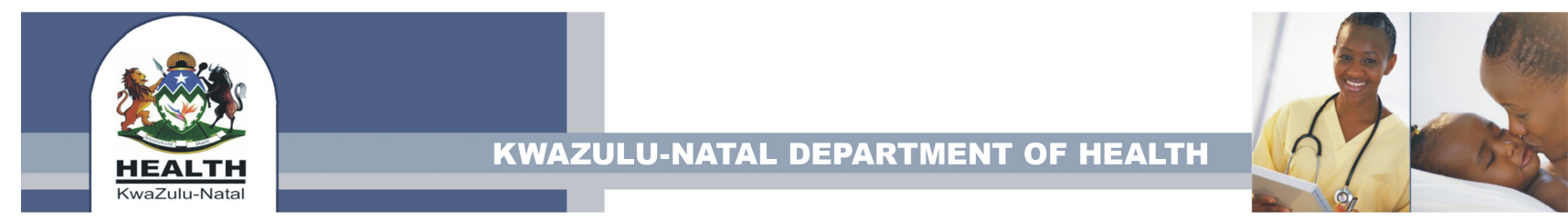

\subsection{Strategies for pre-pregnancy care}

Through youth-friendly services, family planning services including treatment of sexually transmitted infections, management of chronic conditions, community-based projects and outreach, as well as comprehensive sexual and reproductive health services must be available to enable women and their partners to plan pregnancies.

Groups at risk such as adolescents, women with chronic diseases, families affected by genetic disorders and couples with infertility problems need to be approached with care and understanding.

The following services must be available to enable families to plan their next child, and maintain:

- Provision of a comprehensive Sexual and Reproductive Health Service, including contraceptive, infertility interventions, termination of pregnancy and sexuality education.

- Basic genetic counselling, referral and testing for affected families.

- $\quad$ Screening and management for infection eg TB, HIV and Aids, STIs, malaria, schitozimasis and intestinal helminths infestations.

- Screening for and management of medical conditions such as diabetes, cardiac diseases and hypertension.

- Provision of basic counselling on infertility and referral to specialist clinic as required.

- $\quad$ Rehabilitation services with services to prepare families with disabled members for pregnancy, child birth and childcare.

\subsection{Strategies for integrated and holistic antenatal care}

\subsubsection{Nutrition}

- Basic nutrition information on dietary needs during pregnancy and breast feeding.

- Provision of routine iron and folic acid supplements, with follow-up counselling, monitoring of haemoglobin and checking for compliance at each visit.

- $\quad$ Extra supplements for HIV-positive women, as prescribed in protocols.

- Identification of pregnant women who need food supplementation, using a nutritional assessment tool for pregnant women.

\subsubsection{HIV testing}

- Access to HIV counselling and testing for all women and their partners attending antenatal and postnatal clinics and family planning services and other medical services. And repeat testing after the window period.

- All pregnant women are educated about safer sexual practises during pregnancy and breast feeding, and about interventions available to limit transmission to unborn babies through the media, in groups and individual counselling.

- Assessment of HIV-positive women for entry to ART by examining them to determine the clinical stage of the HIV infection at each visit.

- Counselling of all HIV-positive women about the need for a CD4 count every six months and the benefits of antiretroviral therapies as soon as they have been found to be HIV-positive. 
- Targeted counselling and education of HIV-negative pregnant women and the implementation of practises to maintain a negative status at all antenatal, postnatal and family planning visits.

\subsubsection{Antiretroviral therapy}

- Women with CD4 counts less than $200 \mathrm{mmo} / \mathrm{l}$ are referred to the nearest antiretroviral centre. These women should be fast tracked to obtain treatment before 36 weeks of pregnancy.

- Compliance with ARV medication is checked at every antenatal and postnatal visit, and side effects explained and managed.

- Attendance early in pregnancy is required to ensure that women are assessed fully before delivery.

\subsubsection{Management of prevention of mother to child transmission of HIV (PMTCT)}

- Current interventions in terms of counselling and medication (including mineral and vitamin supplements), infant feeding choice counselling, safer sexual practises, and general nutrition are an integral part of the service to pregnant women.

\subsubsection{Five targeted visits during pregnancy}

- Early attendance during pregnancy is required for full assessment and management during the antenatal period.

- $\quad$ Routine antenatal care is contained in five targeted visits for women who present with no risk factors and whose expected pregnancy outcome is normal. Risks are assessed at each visit.

- All visits include targeted health education and individual counselling top ensure preparation for emergencies, birth preparedness, improved compliance with care appointments.

- Supplements and treatment. Health education can be given to small groups or individual or couples.

- Visits are scheduled as below.

\begin{tabular}{|l|l|}
\hline Visit & Weeks of pregnancy \\
\hline 1 & Before 13 weeks \\
\hline 2 & 20 to 24 weeks \\
\hline 3 & 26 to 32 weeks \\
\hline 4 & 34 to 36 weeks \\
\hline 5 & 40 weeks \\
\hline
\end{tabular}

\subsubsection{Health screening during pregnancy}

- Health screening is undertaken with information about the tests and interventions available and counselling on the individual circumstance and implications of the screening and interventions.

- Screening to exclude of the following medical conditions through a through history and medical examination: diabetes, cardiac conditions, hypertension, liver disease, urinary tract infection or impairment, depression, mother mental illness asthma and epilepsy.

- All women should have a cervical smear taken during pregnancy to exclude in situ cancer, or if the cervix appears abnormal during examination.

- Rhesus factor, syphilis and other sexually transmitted infections, HIV infection (as mentioned), anaemia, hookworm and tuberculosis are screened for routinely. Rapid tests must be prioritised so that results can be 
- obtained at the visit, and in high-prevalence areas for the screening of malaria and intestinal helminths, especially hook worm.

- Genetic conditions through taking an adequate history.

- $\quad$ For HIV-positive women, the HIV infection must be staged using WHO staging procedure, regardless of CD4 count status, and CD4 counts must be done every six months.

- Obtaining a comprehensive reproductive and obstetric assessment through comprehensive history taking and examination, and assessment of risks in the pregnancy, with appropriate referral to a relevant level of service.

\subsection{Strategies for postnatal care}

- Each woman should be clinically assessed within the first hour post-delivery, and during the first six hours of the postnatal period. In addition she should also be clinically assessed at six hours post-delivery, within six days postdelivery and within six weeks post-delivery. An additional visit at six months is also advocated to address infant feeding, family planning, other women's health issues such as cervical cancer screening.

- This policy advocates that every woman be retained in the facility for six hours post-delivery to rest, to reduce the risk of post partum haemorrhage and infection, to receive assistance with breast feeding where necessary and to monitor any increase in blood pressure.

\subsubsection{Provision of health care information}

Post delivery patients, their partners, and families have a right to accessible information regarding:

\section{Self care}

- Personal hygiene especially of the vulval area and nutrition, signs of infection of the genital tract, urinary tract, incision (caesarean, sterilisation or episiotomy), breast inflammation.

- Emotional changes during the postnatal period.

- $\quad$ Expected physical changes during the postnatal period.

\section{Baby care}

- Infant feeding, especially about sources of information or advice should problems occur.

- Availability of clinic services and the utilisation of services, including growth monitoring, immunisation and Vitamin A supplementation; and developmental screening.

- $\quad$ Signs of illness in a newborn baby according to $\mathrm{IMCl}$ criteria.

- General baby care.

\section{Sexual and reproductive health care}

- Resumption of sexual relations, safer sexual practises, and contraception availability.

- Identifications, management and treatment of sexually transmitted infections.

- Counselling and referral for sterilisation once family is complete.

- Sexuality education and counselling, 


\subsection{Strategies for the community component}

The community-based carer network is essential to keep communities informed about care in pregnancy and the post partum period, and to provide a first level referral system.

- To promote and sustain the partnership between the health care providers and the communities and to ensure support and meaningful community involvement in mother and child health care programmes.

- Consult key figures in the community and discuss key practices to gain their support and promotion of health and safe practices.

- Create two-way feedback mechanisms that provide opportunities for communities, families and individuals to voice their ideas about services provided and receive response from the health system and vice versa.

- $\quad$ Provide health information and health education to institutions, communities and individuals with the view to improve health-seeking behaviours (eg press conferences, community talks, local coalitions, etc.).

- To create an individual, family and community-friendly maternal health service in order to promote access to and appropriate utilisation of services.

- Inform the community about what, when and how to access services, including their rights and responsibilities.

- $\quad$ Provide awareness campaigns about pregnancy care, male involvement, community support for pregnant women and their infants, companionship in pregnancy and labour and breast feeding and care of new mother and baby.

- Develop and distribute user-friendly IEC (information, education and communication) materials with appropriate messages in local languages.

- $\quad$ Promote male participation in the promotion of mother and child health and the concept of companionship including male partners as well as significant others.

Guidelines are included to provide basic and general guidance on interventions to provide during antenatal and postnatal care at primary care level and district hospital level. 


\section{Implementation Plan}

The policy will be advocated as a whole through workshops. Implementation will be phased, with each phase lasting 24 months. Districts may wish various strategies to be implemented earlier than the overall plan and district health needs will dictate the speed and actual strategies to be implemented. Final and total implementation should be achieved by 2013 (ie over five years). The activities are suggested and districts and services will need to evaluate what activities will enable them to achieve the indicators.

\begin{tabular}{|c|c|c|c|}
\hline Strategies and activities & $\begin{array}{l}\text { Activities for } \\
\text { Phase } 1\end{array}$ & $\begin{array}{l}\text { Activities for } \\
\text { Phase } 2\end{array}$ & $\begin{array}{l}\text { Activities for } \\
\text { Phase } 3\end{array}$ \\
\hline $\begin{array}{l}\text { Increase the knowledge } \\
\text { base of health care } \\
\text { providers working in } \\
\text { midwifery and obstetric } \\
\text { settings }\end{array}$ & $\begin{array}{l}\text { Explore the possible roles } \\
\text { of staff nurses and } \\
\text { enrolled nursing } \\
\text { assistants. } \\
\text { Develop training } \\
\text { materials for all cadres. } \\
\text { Annual in-service training } \\
\text { for all doctors in } \\
\text { obstetrics and midwives. } \\
\text { Commence marketing } \\
\text { and implementation of } \\
\text { perinatal education } \\
\text { programme or other in- } \\
\text { service training packages } \\
\text { in each district. }\end{array}$ & $\begin{array}{l}\text { Provide training for staff } \\
\text { nurses and nursing } \\
\text { assistants, especially } \\
\text { birth preparedness } \\
\text { education, HIV and } \\
\text { PMTCT and breast } \\
\text { feeding counselling. } \\
\text { Develop and test a } \\
\text { handguide for } \\
\text { community-based } \\
\text { workers. } \\
\text { Annual in-service } \\
\text { training for all doctors } \\
\text { in obstetrics and } \\
\text { midwives } \\
\text { Continue perinatal } \\
\text { education programme. }\end{array}$ & $\begin{array}{l}\text { Evaluate health } \\
\text { education on birth } \\
\text { preparedness. } \\
\text { Training of community- } \\
\text { based workers to use } \\
\text { guide. } \\
\text { - Annual in-service } \\
\text { training for all doctors in } \\
\text { obstetrics and midwives. } \\
\text { Continue perinatal } \\
\text { education programme. }\end{array}$ \\
\hline
\end{tabular}




\begin{tabular}{|c|c|c|c|}
\hline Strategies and activities & $\begin{array}{l}\text { Activities for } \\
\text { Phase } 1\end{array}$ & $\begin{array}{l}\text { Activities for } \\
\text { Phase } 2\end{array}$ & $\begin{array}{l}\text { Activities for } \\
\text { Phase } 3\end{array}$ \\
\hline $\begin{array}{l}\text { Increase the skills of all } \\
\text { health care providers } \\
\text { working in midwifery } \\
\text { and obstetric settings }\end{array}$ & $\begin{array}{l}\text { Counselling skills training for } \\
\text { PHC clinic- based nurses, } \\
\text { concentrating on HIV, } \\
\text { breastfeeding and domestic } \\
\text { violence. } \\
\text { - General medical assessment } \\
\text { history taking and } \\
\text { examination skills for } \\
\text { professional nurses. } \\
\text { Perinatal education } \\
\text { programme. } \\
\text { Increase basic antenatal } \\
\text { care sites (BANC). } \\
\text { Health education skills in } \\
\text { nursing assistants and } \\
\text { enrolled nurses. }\end{array}$ & $\begin{array}{l}\text { Continue training in } \\
\text { perinatal education } \\
\text { programme. } \\
\text { BANC sites. } \\
\text { Continue increasing } \\
\text { countinue training on } \\
\text { Develop an in-service } \\
\text { training programme to } \\
\text { address the needs of } \\
\text { adolescent pregnant } \\
\text { women. }\end{array}$ & $\begin{array}{l}\text { Continue perinatal } \\
\text { education programme. } \\
\text { continue increasing BANC } \\
\text { sites. } \\
\text { Implement an in-service } \\
\text { training programme to } \\
\text { address the needs of } \\
\text { adolescent pregnant } \\
\text { women. }\end{array}$ \\
\hline
\end{tabular}




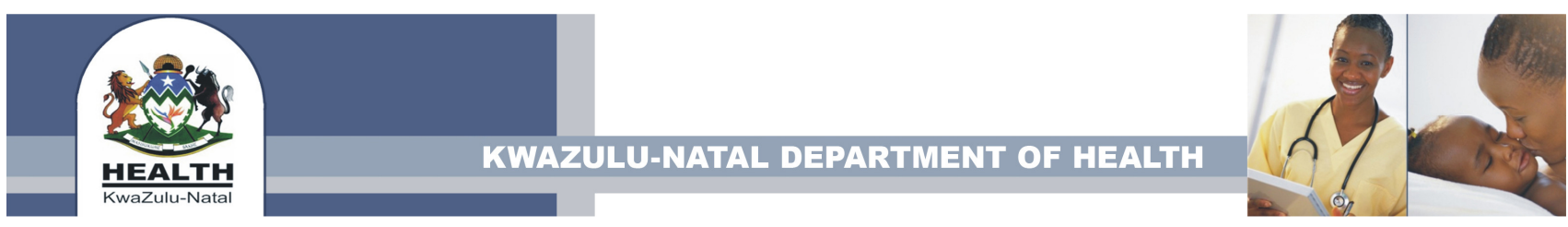

\begin{tabular}{|c|c|c|c|}
\hline Strategies and activities & $\begin{array}{l}\text { Activities for } \\
\text { Phase } 1\end{array}$ & $\begin{array}{l}\text { Activities for } \\
\text { Phase } 2\end{array}$ & $\begin{array}{l}\text { Activities for } \\
\text { Phase } 3\end{array}$ \\
\hline $\begin{array}{l}\text { Develop pre-pregnancy } \\
\text { care through family } \\
\text { planning services, youth- } \\
\text { friendly services, } \\
\text { consultations for STIs, HIV } \\
\text { counselling and treatment } \\
\text { for chronic diseases }\end{array}$ & $\begin{array}{l}\text { Increase youth-friendly } \\
\text { services in each district to } \\
\text { 30\% of all clinics, which } \\
\text { will also ensure quality } \\
\text { assurance in clinics. } \\
\text { Commence planning } \\
\text { what knowledge and skill } \\
\text { base is required for each } \\
\text { cadre in each setting to } \\
\text { provide adequate pre- } \\
\text { pregnancy care in various } \\
\text { settings. } \\
\text { Develop appropriate IEC } \\
\text { material. } \\
\text { Develop formal referral } \\
\text { system for infertile } \\
\text { couples. } \\
\text { Develop and print one } \\
\text { message for target } \\
\text { groups on pre- pregnancy } \\
\text { care. } \\
\text { Advocacy workshops for } \\
\text { managers on termination } \\
\text { of pregnancy. } \\
\text { professional nurses to } \\
\text { pregnancy intrict. }\end{array}$ & $\begin{array}{l}\text { Intensify youth-friendly } \\
\text { clinic development to } \\
\text { target at } 50 \% \text { of facilities. } \\
\text { Development training } \\
\text { materials and commence } \\
\text { training opportunities for } \\
\text { various cadres to provide } \\
\text { pre- pregnancy care in } \\
\text { various settings, basic } \\
\text { human genetics must also } \\
\text { be covered. } \\
\text { Develop a booklet suitable } \\
\text { for first time readers on } \\
\text { sexual and reproductive } \\
\text { health and available } \\
\text { services. } \\
\text { Develop two essential } \\
\text { messages for each target } \\
\text { area with appropriate } \\
\text { leaflet for counselling/ } \\
\text { information to clients. } \\
\text { Implement and monitor } \\
\text { infertility referrals through } \\
\text { the referral system } \\
\text { services providing } \\
\text { termination of pregnancy. }\end{array}$ & $\begin{array}{l}\text { Intensify youth-friendly } \\
\text { clinic development to } \\
\text { target at } 60 \% \text { of } \\
\text { facilities. } \\
\text { Continue training for } \\
\text { knowledge and skill } \\
\text { gaps. } \\
\text { Introduce booklet on } \\
\text { sexual and reproductive } \\
\text { health through } \\
\text { community based } \\
\text { workers and pre } \\
\text { pregnancy care and } \\
\text { ABET. } \\
\text { Develop two essential } \\
\text { messages for each } \\
\text { target area with an } \\
\text { appropriate leaflet for } \\
\text { counselling/ } \\
\text { information to clients. } \\
\text { Monitor infertility } \\
\text { referrals through the } \\
\text { referral system. } \\
\text { Increase number of } \\
\text { services providing } \\
\text { second trimester } \\
\text { terminations of } \\
\text { pregnancy. }\end{array}$ \\
\hline
\end{tabular}




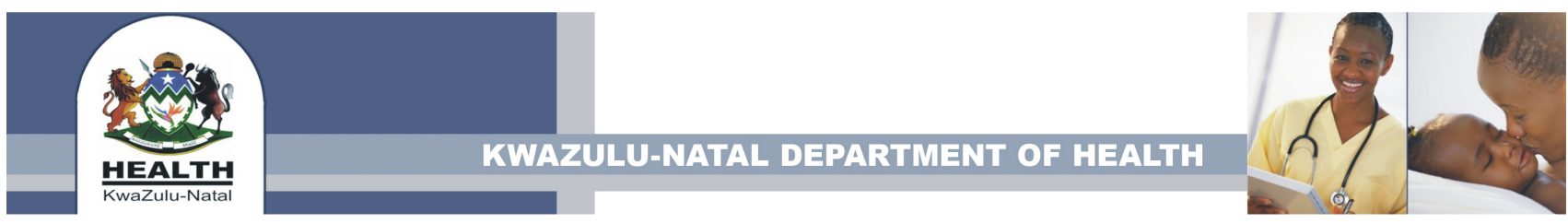

\begin{tabular}{|c|c|c|c|}
\hline Strategies and activities & $\begin{array}{l}\text { Activities for } \\
\text { Phase } 1\end{array}$ & $\begin{array}{l}\text { Activities for } \\
\text { Phase } 2\end{array}$ & $\begin{array}{l}\text { Activities for } \\
\text { Phase } 3\end{array}$ \\
\hline $\begin{array}{l}\text { Integrated and holistic } \\
\text { antenatal care using the } \\
\text { five essential antenatal } \\
\text { visits as a point of } \\
\text { integration }\end{array}$ & 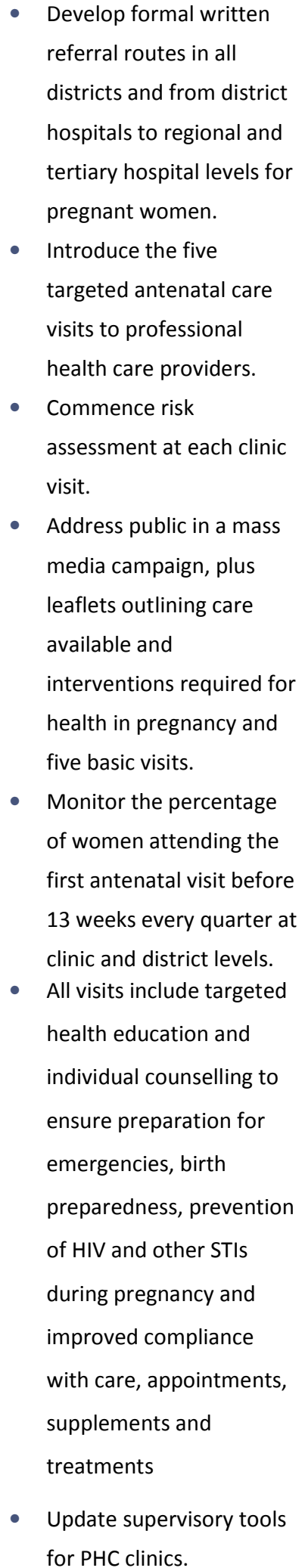 & $\begin{array}{l}\text { Monitor referral systems } \\
\text { for pregnant women at } \\
\text { district level. } \\
\text { Commence lobbying for } \\
\text { rapid on-site syphilis } \\
\text { testing. } \\
\text { Continue perinatal } \\
\text { education programme } \\
\text { training or other targeted } \\
\text { in-service training. } \\
\text { Improve staffing } \\
\text { according to Service } \\
\text { Transformation Plan at } \\
\text { clinic. } \\
\text { Maintain the publicity of } \\
\text { the new targeted visits. } \\
\text { Introduce companioned } \\
\text { visits in high volume pilot } \\
\text { sites in each district. } \\
\text { Introduce nutritional } \\
\text { advisors to care of } \\
\text { pregnant women and } \\
\text { active and participatory } \\
\text { health education } \\
\text { principles and methods. } \\
\text { supitontor compliance of } \\
\text { and appointments of } \\
\text { clients. } \\
\text { - }\end{array}$ & $\begin{array}{l}\text { Evaluate referral systems at } \\
\text { district and provincial level, } \\
\text { and review referral systems } \\
\text { and criteria. } \\
\text { - Train all nursing staff to use } \\
\text { the rapid syphilis tests and } \\
\text { to management positive } \\
\text { cases according to essential } \\
\text { drug list protocols. } \\
\text { Monitor treatment of } \\
\text { positive syphilis pregnant } \\
\text { women through BANC and } \\
\text { audits system. } \\
\text { Market companioned visits } \\
\text { in all services. } \\
\text { Continue all monitoring } \\
\text { processes commenced in } \\
\text { previous two phases. } \\
\text { Evaluate the use of the } \\
\text { antenatal and postnatal } \\
\text { supervisory tools. }\end{array}$ \\
\hline
\end{tabular}




\begin{tabular}{|c|c|c|c|}
\hline Strategies and activities & $\begin{array}{l}\text { Activities for } \\
\text { Phase } 1\end{array}$ & $\begin{array}{l}\text { Activities for } \\
\text { Phase } 2\end{array}$ & $\begin{array}{l}\text { Activities for } \\
\text { Phase } 3\end{array}$ \\
\hline $\begin{array}{l}\text { As part of integrated and } \\
\text { holistic care: Identify those } \\
\text { families that require } \\
\text { supplementation and } \\
\text { improve nutritional status } \\
\text { of pregnant women } \\
\text { through counselling and } \\
\text { education }\end{array}$ & $\begin{array}{l}\text { Education on basic } \\
\text { nutrition information on } \\
\text { dietary needs during } \\
\text { pregnancy and breast } \\
\text { feeding. } \\
\text { Introduce the } \\
\text { nutritional assessment } \\
\text { tool for assessing } \\
\text { pregnant women. } \\
\text { Continue lobbying for } \\
\text { nutritional advisers at } \\
\text { PHC level. } \\
\text { Commence BANC } \\
\text { auditing in all districts. } \\
\text { Monitor the } \\
\text { prescription of } \\
\text { supplements at service } \\
\text { level through BANC and } \\
\text { audit routine } \\
\text { supervision. } \\
\text { Monitor the } \\
\text { haemoglobin testing } \\
\text { and remedial inventions } \\
\text { through an audit } \\
\text { system. }\end{array}$ & $\begin{array}{l}\text { Continue training of } \\
\text { nurses to use the } \\
\text { nutritional assessment } \\
\text { tools } \\
\text { Commence monitoring } \\
\text { of application of } \\
\text { nutrition assessment } \\
\text { tool for pregnant } \\
\text { women through the } \\
\text { audit system. } \\
\text { Commence training of } \\
\text { nutritional advisors as } \\
\text { soon as they are } \\
\text { appointed. } \\
\text { Strengthen the } \\
\text { monitoring of } \\
\text { haemoglobin in } \\
\text { pregnancy, through } \\
\text { training and correct use } \\
\text { of meters } \\
\text { Monitor the use of the } \\
\text { nutritional assessment } \\
\text { tools through BANC } \\
\text { audit tools } \\
\text { enrolled nursing } \\
\text { assistants on education } \\
\text { of nutritional } \\
\text { requirements during } \\
\text { pregnancy. }\end{array}$ & $\begin{array}{l}\text { - Continuation of } \\
\text { monitoring systems at } \\
\text { provincial, district and } \\
\text { local levels. } \\
\text { - Continue with the } \\
\text { training of nutritional } \\
\text { advisors. } \\
\text { Continue training staff } \\
\text { nurse and nursing } \\
\text { assistants. }\end{array}$ \\
\hline
\end{tabular}




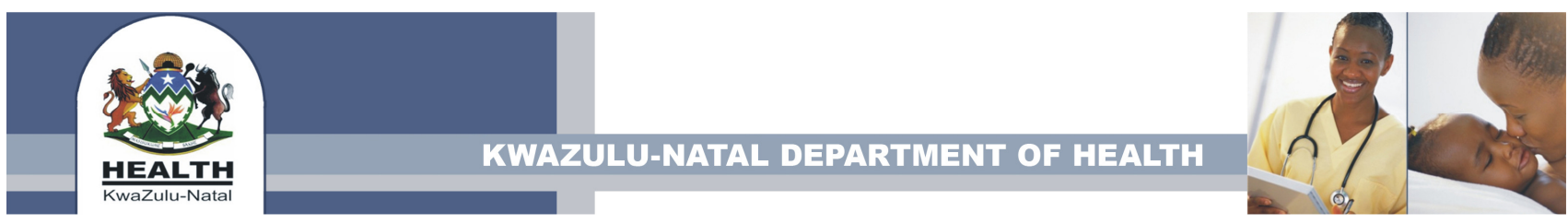

\begin{tabular}{|c|c|c|c|}
\hline Strategies and activities & $\begin{array}{l}\text { Activities for } \\
\text { Phase } 1\end{array}$ & $\begin{array}{l}\text { Activities for } \\
\text { Phase } 2\end{array}$ & $\begin{array}{l}\text { Activities for } \\
\text { Phase } 3\end{array}$ \\
\hline $\begin{array}{l}\text { As part of integrated and } \\
\text { holistic care: Improve } \\
\text { access to counselling and } \\
\text { HIV testing for pregnant } \\
\text { and postnatal women and } \\
\text { other prevention strategies }\end{array}$ & $\begin{array}{l}\text { - All services have } \\
\text { sufficient lay } \\
\text { counsellors. } \\
\text { Universal access to HIV } \\
\text { testing during } \\
\text { pregnancy at all PHC } \\
\text { and hospital clinics. } \\
\text { Offer counselling and } \\
\text { HIV testing commencing } \\
\text { with provider initiated } \\
\text { counselling. } \\
\text { Targeted counselling } \\
\text { and education of HIV- } \\
\text { negative pregnant } \\
\text { women and maintaining } \\
\text { a negative status at all } \\
\text { antenatal visits. }\end{array}$ & $\begin{array}{l}\text { - Commence training of } \\
\text { nurses in HIV } \\
\text { counselling skills } \\
\text { Training of all lay } \\
\text { counsellors on couple } \\
\text { counselling. } \\
\text { Increase local } \\
\text { monitoring and quality } \\
\text { improvement } \\
\text { programmes. }\end{array}$ & $\begin{array}{l}\text { Continue monitoring } \\
\text { from other phases. } \\
\text { rates and HIV } \\
\text { prevalence in pregnancy } \\
\text { with communities to } \\
\text { keep people informed } \\
\text { and to seek joint } \\
\text { solutions and action. }\end{array}$ \\
\hline $\begin{array}{l}\text { As part of integrated and } \\
\text { holistic care: Assessment of } \\
\text { HIV-positive pregnant } \\
\text { women for entry to } \\
\text { antiretroviral therapy }\end{array}$ & $\begin{array}{l}\text { Develop policy circular } \\
\text { for CD4 testing and fast } \\
\text { tracking of pregnant } \\
\text { women through the ARV } \\
\text { preparation and } \\
\text { improve rapid access to } \\
\text { ARVs. } \\
\text { CD4 count taken as part } \\
\text { of antenatal care for } \\
\text { HIV-positive women } \\
\text { Increase Mothers-to- } \\
\text { Mothers sites to support } \\
\text { access to ARVs. }\end{array}$ & $\begin{array}{l}\text { Local monitoring of care } \\
\text { of HIV-positive women. } \\
\text { Mass media education } \\
\text { programmes about } \\
\text { testing and CD4 counts } \\
\text { during pregnancy, and } \\
\text { need for ARV's during } \\
\text { pregnancy. } \\
\text { Review all referral } \\
\text { criteria for different } \\
\text { levels. } \\
\text { Introduce wellness } \\
\text { monitoring for HIV- } \\
\text { positive pregnant and } \\
\text { postpartum women. }\end{array}$ & $\begin{array}{l}\text { Provincial evaluation of } \\
\text { the assessment of } \\
\text { pregnant women who } \\
\text { have HIV infection. } \\
\text { Monitor wellness } \\
\text { monitoring for HIV- } \\
\text { positive pregnant and } \\
\text { postpartum women. } \\
\text { Continue monitoring of } \\
\text { all indicators through } \\
\text { DHIS or sentinel sites. }\end{array}$ \\
\hline
\end{tabular}




\begin{tabular}{|c|c|c|c|}
\hline Strategies and activities & $\begin{array}{l}\text { Activities for } \\
\text { Phase } 1\end{array}$ & $\begin{array}{l}\text { Activities for } \\
\text { Phase } 2\end{array}$ & $\begin{array}{l}\text { Activities for } \\
\text { Phase } 3\end{array}$ \\
\hline & $\begin{array}{l}\text { Clinical training of } \\
\text { midwives to undertake the } \\
\text { WHO HIV staging } \\
\text { examination. } \\
\text { - Fast track pregnant HIV- } \\
\text { positive women to obtain } \\
\text { treatment before } 36 \text { weeks } \\
\text { of pregnancy. } \\
\text { Monitor speed of } \\
\text { commencement of ARVs in } \\
\text { pregnant and postnatal } \\
\text { women at service and } \\
\text { district level. } \\
\text { Training courses on ARV } \\
\text { therapies for PHC and } \\
\text { hospital staff in obstetric } \\
\text { and midwifery units. }\end{array}$ & $\begin{array}{l}\text { Evaluate Mothers- to- } \\
\text { Mothers Programme in } \\
\text { terms of increasing the } \\
\text { number and compliance } \\
\text { of pregnant women } \\
\text { receiving ARVs. } \\
\text { Continue ARV therapy } \\
\text { training courses for } \\
\text { various cadres of } \\
\text { workers. }\end{array}$ & \\
\hline $\begin{array}{l}\text { As part of integrated and } \\
\text { holistic care: Improve } \\
\text { health screening during } \\
\text { pregnancy }\end{array}$ & $\begin{array}{l}\text { Commence perinatal } \\
\text { education programme or } \\
\text { other in-service training } \\
\text { programmes in every } \\
\text { district. } \\
\text { Mortality meetings at } \\
\text { services as part of quality } \\
\text { improvement. } \\
\text { Provincial maternal } \\
\text { mortality data analysis. } \\
\text { Review all referral criteria } \\
\text { for different levels. } \\
\text { Screening for STls through } \\
\text { careful history taking and } \\
\text { examination }\end{array}$ & $\begin{array}{l}\text { Continue training of } \\
\text { professional nurses. } \\
\text { through the audit } \\
\text { system used in BANC } \\
\text { and the maternal death } \\
\text { assessments and } \\
\text { reports. } \\
\text { Continue outreach and } \\
\text { mass media to } \\
\text { encourage early } \\
\text { attendance at antenatal } \\
\text { clinics. } \\
\text { Review all referral } \\
\text { criteria for different } \\
\text { levels. } \\
\text { Introduce the concept } \\
\text { of enquiring about and } \\
\text { looking for cases of } \\
\text { domestic violence into } \\
\text { antenatal clinics. }\end{array}$ & $\begin{array}{l}\text { Continue training of } \\
\text { professional nurses. } \\
\text { continue developing BANC } \\
\text { sites. } \\
\text { Review all referral criteria } \\
\text { for different levels. } \\
\text { Evaluate adherence to } \\
\text { protocols at PHC and } \\
\text { hospital level. } \\
\text { Monitor the numbers of } \\
\text { women reporting domestic } \\
\text { violence. } \\
\text { With Social Welfare } \\
\text { Department, develop } \\
\text { referral mechanisms for } \\
\text { survivors of domestic } \\
\text { violence. }\end{array}$ \\
\hline
\end{tabular}




\begin{tabular}{|c|c|c|c|}
\hline Strategies and activities & $\begin{array}{l}\text { Activities for } \\
\text { Phase } 1\end{array}$ & $\begin{array}{l}\text { Activities for } \\
\text { Phase } 2\end{array}$ & $\begin{array}{l}\text { Activities for } \\
\text { Phase } 3\end{array}$ \\
\hline $\begin{array}{l}\text { As part of integrated and } \\
\text { holistic care: Management } \\
\text { of РMTCT. }\end{array}$ & 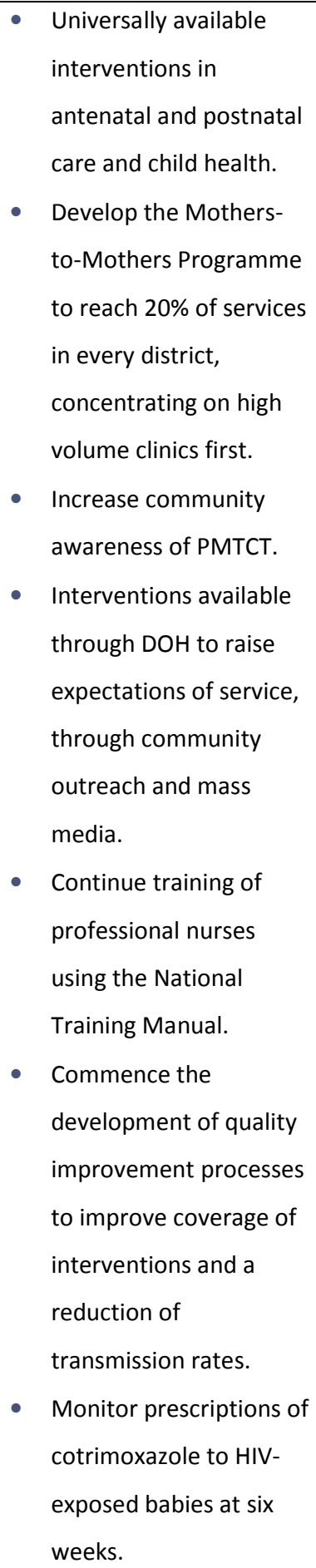 & $\begin{array}{l}\text { Universally available } \\
\text { interventions in } \\
\text { antenatal and postnatal } \\
\text { care and child health. } \\
\text { Universal access of all } \\
\text { pregnant HIV-positive } \\
\text { women. } \\
\text { Commence quality- } \\
\text { improvement } \\
\text { programmes in all } \\
\text { districts. } \\
\text { Develop Mothers-to- } \\
\text { Mothers sites to cover } \\
\text { 35\% of services in all } \\
\text { districts. } \\
\text { Continue creating } \\
\text { interventions at clinics } \\
\text { and hospitals. } \\
\text { sommunity awareness } \\
\text { of PMTCT interventions. } \\
\text { Develop messages for } \\
\text { fathers of HIV-exposed } \\
\text { children to ensure } \\
\text { participation in } \\
\text { supponitoring and } \\
\text { the mother and the } \\
\text { baby } \\
\text { - }\end{array}$ & $\begin{array}{l}\text { Continue monitoring at } \\
\text { all levels. } \\
\text { continue quality } \\
\text { and progress. } \\
\text { - Share transmission and } \\
\text { coverage rates with } \\
\text { communities to jointly } \\
\text { work to ward } \\
\text { improvement. } \\
\text { Continue to develop and } \\
\text { sustain Mothers-to- } \\
\text { Mothers sites. } \\
\text { Continue and reinforce } \\
\text { training of PHC and } \\
\text { hospital personnel. } \\
\text { Monitor and evaluate } \\
\text { supervision. }\end{array}$ \\
\hline
\end{tabular}




\begin{tabular}{|c|c|c|c|}
\hline Strategies and activities & $\begin{array}{l}\text { Activities for } \\
\text { Phase } 1\end{array}$ & $\begin{array}{l}\text { Activities for } \\
\text { Phase } 2\end{array}$ & $\begin{array}{l}\text { Activities for } \\
\text { Phase } 3\end{array}$ \\
\hline $\begin{array}{l}\text { Introduction and } \\
\text { development of formal } \\
\text { postnatal care, using the six } \\
\text { hours, six days and six } \\
\text { weeks approach }\end{array}$ & $\begin{array}{l}\text { Perinatal education } \\
\text { programme or other in- } \\
\text { service training } \\
\text { programmes. } \\
\text { Formal the referral } \\
\text { criteria and routes for } \\
\text { postnatal care. } \\
\text { Introduction to the visits } \\
\text { and actions through } \\
\text { workshops and training } \\
\text { sessions. } \\
\text { Implement the six hours } \\
\text { and six days visits in all } \\
\text { hospitals and clinics. } \\
\text { Market the six days visit } \\
\text { through mass media, } \\
\text { awareness days, health } \\
\text { education and discharge } \\
\text { plans. } \\
\text { Lobby for inclusion of } \\
\text { the postnatal data } \\
\text { collection through } \\
\text { District Health } \\
\text { Information System. }\end{array}$ & 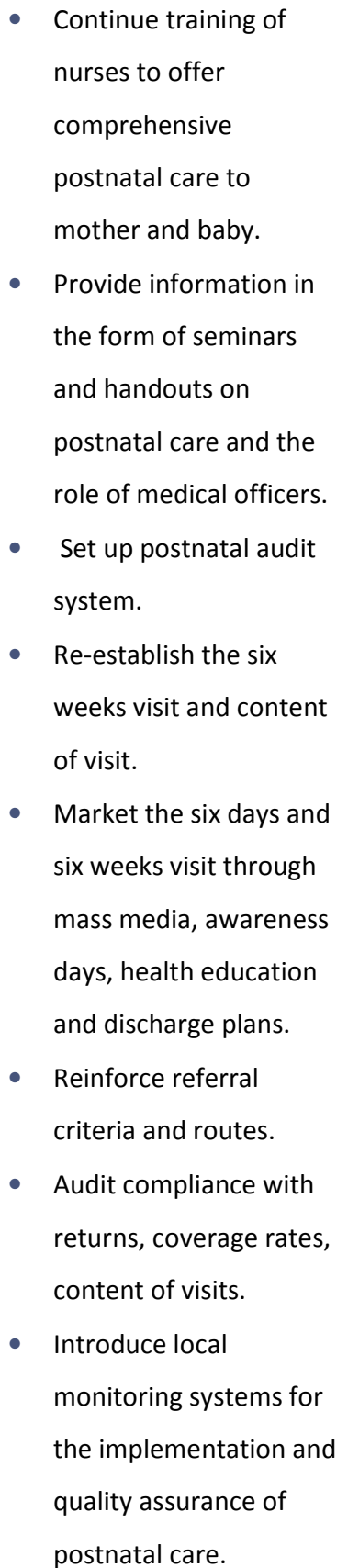 & $\begin{array}{l}\text { Develop the postnatal } \\
\text { care messages in the } \\
\text { Health Promoting } \\
\text { Hospitals initiative, for } \\
\text { community and home- } \\
\text { based carers and nurses } \\
\text { at clinics. } \\
\text { Update medical doctors } \\
\text { in obstetric care of the } \\
\text { postnatal woman and } \\
\text { her baby. } \\
\text { Develop an Internet } \\
\text { programme on } \\
\text { postnatal care. } \\
\text { Monitor the postnatal } \\
\text { care system at } \\
\text { provincial and district } \\
\text { levels. }\end{array}$ \\
\hline
\end{tabular}




\begin{tabular}{|c|c|c|c|}
\hline Strategies and activities & $\begin{array}{l}\text { Activities for } \\
\text { Phase } 1\end{array}$ & $\begin{array}{l}\text { Activities for } \\
\text { Phase } 2\end{array}$ & $\begin{array}{l}\text { Activities for } \\
\text { Phase } 3\end{array}$ \\
\hline $\begin{array}{l}\text { Develop and strengthen the } \\
\text { community component for } \\
\text { antenatal and postnatal } \\
\text { care to empower } \\
\text { communities and families, } \\
\text { and raise expectations for } \\
\text { service delivery }\end{array}$ & $\begin{array}{l}\text { Increase the } \\
\text { community-based carer } \\
\text { network. } \\
\text { Link community-based } \\
\text { care and Mothers to } \\
\text { Mothers to form teams } \\
\text { in active sites. } \\
\text { Develop postnatal } \\
\text { messages on danger or } \\
\text { early warning signs. } \\
\text { Use mass media to } \\
\text { publish these advocacy } \\
\text { workshops for } \\
\text { community IMCI which } \\
\text { include antenatal and } \\
\text { postnatal care at home, } \\
\text { and danger signs which } \\
\text { require urgent referral. } \\
\text { Commence } \\
\text { development of care } \\
\text { and support within } \\
\text { communities for women } \\
\text { in domestic violence } \\
\text { situations through a } \\
\text { multi-sectoral platform } \\
\text { as well as local NGOs. }\end{array}$ & $\begin{array}{l}\text { Provision of health care } \\
\text { information to } \\
\text { communities and } \\
\text { community leaders, and } \\
\text { negotiate joint plans of } \\
\text { action to improve } \\
\text { postnatal care. } \\
\text { Increase Mothers to } \\
\text { Mothers sites. } \\
\text { Monitor the number of } \\
\text { outreach meetings, } \\
\text { awareness days or press } \\
\text { releases regarding the } \\
\text { information on } \\
\text { antenatal and postnatal } \\
\text { care which directly } \\
\text { keeps communities } \\
\text { informed about the } \\
\text { content, challenges, } \\
\text { progress and outcomes } \\
\text { of antenatal and } \\
\text { postnatal care. } \\
\text { commence active } \\
\text { figures in each service } \\
\text { area. } \\
\text { consultation with key } \\
\text { compliant and } \\
\text { - ofion system for }\end{array}$ & $\begin{array}{l}\text { Assess community IMCI } \\
\text { sites. } \\
\text { Develop household } \\
\text { and postnatal care } \\
\text { targeted at } \\
\text { grandmothers and male } \\
\text { family members. } \\
\text { Undertake custom } \\
\text { satisfaction surveys } \\
\text { among companions and } \\
\text { partners or fathers } \\
\text { determine clients and } \\
\text { health system user } \\
\text { needs. } \\
\text { Firmly establish the } \\
\text { forum within the service } \\
\text { area to support } \\
\text { survivors of domestic } \\
\text { violence. }\end{array}$ \\
\hline
\end{tabular}




\begin{tabular}{|c|c|c|c|}
\hline Strategies and activities & $\begin{array}{l}\text { Activities for } \\
\text { Phase } 1\end{array}$ & $\begin{array}{l}\text { Activities for } \\
\text { Phase } 2\end{array}$ & $\begin{array}{l}\text { Activities for } \\
\text { Phase } 3\end{array}$ \\
\hline & $\begin{array}{l}\text { Ensure that supervisors, } \\
\text { clinic and other } \\
\text { managers keep } \\
\text { communities informed } \\
\text { about the content, } \\
\text { challenges and } \\
\text { outcomes of antenatal } \\
\text { and postnatal care in } \\
\text { their communities. } \\
\text { Begin active } \\
\text { consultation with key } \\
\text { figures. }\end{array}$ & $\begin{array}{l}\text { Undertake custom } \\
\text { satisfaction surveys and } \\
\text { focus groups to } \\
\text { determine client and } \\
\text { health system user } \\
\text { needs. }\end{array}$ & \\
\hline
\end{tabular}




\section{Introduction to the Antenatal and Postnatal Care Policy Guidelines}

The guidelines support the changes to the practice of service delivery for antenatal and postnatal clients as outlined in the policy.

The policy and guidelines stress the individual approach to each client and actively encourage continuity of care by the same provider or small (maximum of three) groups of providers. This will increase the likelihood of establishing a two-way nurse-client relationship, improve follow-up care of individual clients with health problems, encourage antenatal and postnatal attendance and provide a platform for behaviour change communication.

The guidelines inform the daily practices in antenatal and postnatal services. They must be used in conjunction with the National Maternity Guide Essential Drug List and local protocols and referral criteria, which will provide management protocols.

The referral system must be reviewed annually and each clinic must have a clear list of criteria for referral and to where the client should be referred. For example, a family requiring genetic counselling and investigation will be unlikely to source the service at the district hospital, so how to make appointments and pre-investigation requirements must be documented and reviewed annually.

\subsection{Antenatal care policy guidelines}

\subsubsection{Guidelines for care at each antenatal visit}

Each visit should be undertaken by the same service providers in a team of no more than three to provide continuity of care.

Time schedule for visits

\begin{tabular}{|l|l|}
\hline Visit & Weeks of pregnancy \\
\hline 1 & Before 13 weeks \\
\hline 2 & 20 to 24 weeks \\
\hline 3 & 26 to 32 weeks \\
\hline 4 & 34 to 36 weeks \\
\hline 5 & 40 weeks \\
\hline
\end{tabular}

Please remember that if any risk factors occur, book antenatal visits closer together to increase monitoring.

The guidelines outline routine antenatal care for women without risk factors or complications.

The guidelines indicate what should be included in antenatal care to ensure an integrated and quality service to each pregnant women and her unborn child. 
Putting the client (and companion) at ease is essential to obtaining a history from the client:

- Greet client by name.

- Make client (and partner) comfortable.

- Maintain privacy and confidentiality.

- Allow for two-way communication, answer questions in lay language, check understanding, and answer question honestly.

- $\quad$ Explain all examinations, tests undertaken and medication given as the visits progress.

- Ensure that individual counselling and education addresses individual needs.

Obtaining a history is fundamental to quality antenatal care.

- Confirm details of the history given at the previous visit, and reconfirm dates of last menstrual period and or first foetal movements felt at each visit to establish expected date of delivery (EDD).

Review all previous obstetric history and notes for risk factors:

- Review all previous history notes for risk factors. Ask the woman for clarity about any issues.

- Past obstetric history: note any conditions that indicate that a hospital delivery should be planned, eg previous caesarean, precious baby, previous assisted delivery, Rhesus-negative, etc.

- Check that HIV test has been done, if not, discuss the benefits for the woman and her child. Explain the interventions available to limit HIV transmission.

- Review results of all laboratory tests done at first visit. Follow up as needed eg commence treatment syphilis, counsel on need for CD4 count if HIV-positive, counsel on compliance for iron and folic acid supplementation, check haemoglobin if it was low the last visit.

- $\quad$ Review medical history from the notes and ask for clarity.

- $\quad$ Check if tetanus toxoid immunisation was given and when the next dose is due. 
History

ASK:

- About any changes in the contact details, habits or social circumstance.

- About any new health problems, common complaints of pregnancy eg constipation, frequency of urine (last trimester) morning sickness, etc.

- About signs of pre-eclampsia at every visit, ie severe and persistent frontal headaches, visual disturbances, epigastria discomfort or pain, nausea and vomiting, generalised oedema (especially of face and hands).

- About physical changes to breasts, oedema, any dyspnoea, varicose veins.

- About signs of TB such as a persistent cough, productive cough, blood stained sputum, night sweats, fevers, chest pains, tiredness, loss of appetite and weight loss.

- If there are TB contacts in the household

- About signs of HIV infection, even if HIV test result is available, eg fatigue, night sweats, fevers, persistent or recurrent diarrhoea difficulty in swallowing, loss of taste.

- About other medical consultations, sick leave, and hospitalisation since the last visit. Record significant answers on the antenatal card. Ask about visits to traditional healer.

- About any medication the woman is taking: prescribed, traditional or non-prescribed.

- About compliance with medication given eg iron and folic acid, or other medication.

- If the woman has shared her HIV status with her partner, family or companion?

- If the woman has been able to discuss safer sexual practises with her partner?

- To assess social issues: here are some examples of questions to ASK:

D "Is your partner supporting you during this pregnancy?"

$>$ "How is the pregnancy being accepted by the family?"

$>$ "Who will help you with the new baby?"

> "Who will care for the other children when you come to hospital/clinic for this birth?"

> "Are there any problems at home that can affect you or your baby?"

- Check whether the woman has an identity document or whether she knows how to obtain one.

If the woman is HIV-positive; undertake WHO clinical staging at every visit

- Check cotrimoxazole has been commenced, compliance with extra supplements.

- $\quad$ Check when the last CD4 count was taken. CD4 count must be done every six months.

- If on ARVs, ask about compliance, side effects and next appointment. 
Observations: Measure and record all of the following at EVERY visit:

\begin{tabular}{|c|c|}
\hline - Weight & $\begin{array}{l}\text { - Stable, decrease, small or excessive weight gain - assess nutritional status. } \\
\text { - Look for generalised oedema. }\end{array}$ \\
\hline $\begin{array}{l}\text { Blood pressure } \\
\text { (right size cuff especially for } \\
\text { obese women) } \\
\text { Take (two readings) with a rest } \\
\text { period of } 30 \text { minutes between. } \\
\text { Ask women not to smoke or } \\
\text { drink coffee between readings. }\end{array}$ & $\begin{array}{l}\text { - 140/90mmHg on second reading or diastolic or systolic readings increased by } \\
>10 \mathrm{mmHg} \text { since previous visit - refer to high-risk clinic. } \\
\text { - Refer urgently if there are any signs of pre-eclampsia or if diastolic blood } \\
\text { pressure is above } 100 \mathrm{~mm} / \mathrm{Hg} \text {. }\end{array}$ \\
\hline - $\quad$ Pulse & $\begin{array}{l}\text { Pulse of } 100 \mathrm{bpm} \text {, if arrhythmia is noted on the radial pulse - then listen to } \\
\text { apex beat for one minute for arrhythmia. If arrhythmia is present check for } \\
\text { other cardiac signs, if no cardiac signs, refer to the next high-risk clinic. If } \\
\text { cardiac signs present immediately to district hospital. } \\
\text { - Refer if pulse constantly above } 100 \text { after checking for any infections. }\end{array}$ \\
\hline - Respiration & - $>20$ respirations per minute (refer urgently if dyspnoeic) \\
\hline - Temperature & $\begin{array}{l}\text { - } 37.4 \text { degrees centigrade look for source of infection. Check for Malaria in } \\
\text { Malaria areas. Check history for sign of TB. }\end{array}$ \\
\hline
\end{tabular}

Conduct the following examinations

\begin{tabular}{|l|l}
\hline $\begin{array}{l}\text { General } \\
\text { Look for: Signs (JACCOL) }\end{array}$ & $\begin{array}{l}\text { - Refer immediately for any signs of jaundice, synosis or dyspnoea. } \\
\circ \quad \text { Jaundice }\end{array}$ \\
$\circ$ Anaemia & $\begin{array}{l}\text { Check Haemoglobin if there are signs for anaemia or this was low at previous } \\
\text { visits, and manage accordingly. }\end{array}$ \\
$\circ$ Clubbing of fingers & $\begin{array}{l}\text { Clubbing of fingers: check all medical history for TB, asthma, and cardiac } \\
\text { illness: refer for medical assessment. Look for another cardiac signs, if }\end{array}$ \\
$\circ$ Cyanosis or dyspnoea & present refer immediately. \\
$\circ$ Enlarged Lymph Nodes & $\begin{array}{l}\text { Enlarged lymph nodes: check for infections eg ear and throat infections or } \\
\text { cellulites and treat or refer; check HIV status and WHO Clinical Staging to } \\
\text { exclude need for ARV referral. Check for TB again. }\end{array}$
\end{tabular}




\begin{tabular}{|c|c|}
\hline $\begin{array}{l}\text { Listen to the apex heart } \\
\text { beat for arrhythmias: } \\
\text { Listen for one minute }\end{array}$ & $\begin{array}{l}\text { - Refer any arrhythmias for a medical opinion. If any other cardiac sign, if } \\
\text { present refer immediately. }\end{array}$ \\
\hline $\begin{array}{l}\text { - Look for skin rashes, } \\
\text { sores }\end{array}$ & $\begin{array}{l}\text { Treat sores and rashes as per Essential Drug List; refer to medical officer if } \\
\text { they do not clear. Check that nutrition is adequate. Consider extra } \\
\text { supplementation. } \\
\text { - Consider HIV infection if rashes and stores do not heal. }\end{array}$ \\
\hline $\begin{array}{l}\text { - Examine for unexplained } \\
\text { bruises and injuries }\end{array}$ & $\begin{array}{l}\text { - Teach mothers to count foetal kicks. } \\
\text { - Ask about home circumstances; refer to social worker or NGO for care and } \\
\text { support. See the women more often in pregnancy and immediate postnatal } \\
\text { period to support her. }\end{array}$ \\
\hline $\begin{array}{l}\text { Obstetrical examination: } \\
\text { Breast examination as for } \\
\text { first visit } \\
>\text { Abdominal examination } \\
\text { Inspection } \\
\text { Palpation }\end{array}$ & $\begin{array}{l}\text { - Uterus larger or smaller than expected for dates, shape and scars (especially } \\
\text { new scars or bruises). } \\
\text { - Note lie of foetus and estimate the size of foetus: record you findings }\end{array}$ \\
\hline $\begin{array}{l}\text { Symphysis pubis-to- } \\
\text { fundal height } \\
\text { measurement, chart on } \\
\text { foetal monitoring chart } \\
\text { (centile chart) }\end{array}$ & $\begin{array}{l}\text { - Height of fundus discrepancy with expected date of delivery - refer to the } \\
\text { advanced midwife/visiting doctor or high-risk antenatal care clinic. } \\
\text { - If growth is below the tenth centile, refer to high-risk antenatal care clinic. }\end{array}$ \\
\hline $\begin{array}{l}\text { Auscultation for foetal } \\
\text { heart sounds }\end{array}$ & $\begin{array}{l}\text { - If the foetal heart not heard with foetoscope, use sonic aid of CTG to confirm. } \\
\text { Refer if no foetal heart can be found at clinic. }\end{array}$ \\
\hline $\begin{array}{l}\text { Inspect the vulva, check } \\
\text { for vaginal discharge, } \\
\text { genital sores, dysuria, } \\
\text { vulval itching, swollen } \\
\text { lymph nodes, abdominal } \\
\text { pain or tenderness. }\end{array}$ & $\begin{array}{l}\text { - If sexually transmitted infection is found - use protocols for diagnosis and } \\
\text { treatment as per Essential Drug List. } \\
\text { - Check for lesions, and vaginal bleeding. }\end{array}$ \\
\hline $\begin{array}{l}\text { Do full vaginal } \\
\text { examination if any sores } \\
\text { or discharge present }\end{array}$ & $\begin{array}{l}\text { - If bleeding per vagina, estimate the amount of bleeding - do not attempt a } \\
\text { digital or vaginal examination - refer for speculum exam by experienced } \\
\text { advanced midwife or medical officer. } \\
\text { - If NOT bleeding per vagina and on examination the cervix appears abnormal, } \\
\text { take a Pap smear. Refer to high risk antenatal care clinic if smear is abnormal }\end{array}$ \\
\hline
\end{tabular}


Screening tests

\section{Routine interventions at every antenatal visit}

- Continue with iron and folic acid, increase dosage according to the Essential Drug List, if haemoglobin indicates.

- $\quad$ Continue with any other prescribed medication eg cotrimoxazole (until the last trimester), TB drugs, epileptic medication, etc.

- Continue or commence with food supplements and micro-nutrients for under-nourished women, monitor weight at least every two weeks

- Tetanus toxoid 2, if four weeks after the first dose and Tetanus toxoid 3, if six months after the second dose.

- $\quad$ Refer to high-risk clinics according to local referral protocols.

\section{Risk assessment}

- Consider risk factors in each woman: Risk assessments are done at each

- NB: Review record for risk factors from history and first visit

\begin{tabular}{|c|c|}
\hline Risk factors & Action (Referral) \\
\hline $\begin{array}{l}\text { - Abnormal cervical smear eg HSIL: CIN, CIS HSIL: } \\
\text { High-grade squamous intraepithelial lesion; } \\
\text { CIN: Cervical intraepithelial neoplasia ; CIS : } \\
\text { carcinoma in situ }\end{array}$ & $\begin{array}{l}\text { - Refer to high risk antenatal clinic. } \\
\text { - Counsel woman in need attend. }\end{array}$ \\
\hline - Antepartum haemorrhage & - Resuscitate if needed. Establish an intravenous line. \\
\hline - History of antepartum haemorrhage & $\begin{array}{l}\text { - Use National Maternity Guidelines for Emergency Treatment } \\
\text { - Urgent transfer to hospital by EMRS } \\
\text { - Educate the mother and companion about signs of } \\
\text { haemorrhage during pregnancy, check family emergency plan, } \\
\text { monitor client more frequently. }\end{array}$ \\
\hline - Cardiac : dyspnoea, arrhythmias & $\begin{array}{l}\text { High-risk clinic as soon as any signs occur; assist to plan for a } \\
\text { hospital birth. }\end{array}$ \\
\hline
\end{tabular}




\begin{tabular}{|c|c|}
\hline Risk factors & Action (Referral) \\
\hline - Epilepsy & $\begin{array}{l}\text { - Next high-risk clinic for medication adjustment otherwise } \\
\text { clinic for routine antenatal care. } \\
\text { - Monitor seizures as part of care. If services increase, refer for } \\
\text { re-assessment. }\end{array}$ \\
\hline $\begin{array}{l}\text { - Symptomatic HIV - testing refused or testing } \\
\text { done and symptomatic, including low CD4 }\end{array}$ & $\begin{array}{l}\text { - Monitor and prescribe symptomatic treatment. } \\
\text { - Refer to ARV site if positive and has a low CD4 or/ and is } \\
\text { - Plan with client and family for a hospital delivery. } \\
\text { - Educate about PMTCT interventions, especially infant } \\
\text { feeding. }\end{array}$ \\
\hline $\begin{array}{l}\text { Intra-uterine growth retardation: } \\
\text { Foetal movements good or poor }\end{array}$ & $\begin{array}{l}\text { Teach woman how to use maternal monitoring using foetal } \\
\text { movement chart (foetal kick chart), ask her to return within } \\
\text { the week to check foetal movements. Monitor more } \\
\text { carefully, this woman needs monthly or fortnightly } \\
\text { monitoring. } \\
\text { - Check for foetal heart with CTG or sonic aid. If no heart } \\
\text { sounds refer to district hospital for obstetric assessment. }\end{array}$ \\
\hline - Malaria & $\begin{array}{l}\text { - Urgent referral to hospital. } \\
\text { - Use local protocols for urgent first-line treatment before } \\
\text { urgent referral; do not treat at primary level. }\end{array}$ \\
\hline - Malnutrition: no or poor weight gain & $\begin{array}{l}\text { - Continue to manage in clinic with micronutrient and food } \\
\text { supplements with help from dietician. } \\
\text { - Check for any infection or chronic disease, TB or HIV } \\
\text { infection }\end{array}$ \\
\hline $\begin{array}{l}\text { - Medical conditions eg symptomatic asthma, } \\
\text { enlarged thyroid }\end{array}$ & $\begin{array}{l}\text { - Refer to next high-risk clinic or appropriate medical clinic. } \\
\text { - Plan with woman and family for hospital birth }\end{array}$ \\
\hline - Mental illness : not previously identified & $\begin{array}{l}\text { - High-risk clinic, refer to psychiatric clinic. } \\
\text { - Encourage the involvement of family, companioned visits are } \\
\text { recommended. }\end{array}$ \\
\hline - Multiple pregnancy: suspected & $\begin{array}{l}\text { - High-risk clinic for ultrasound diagnosis. } \\
\text { - Plan with woman and family for a hospital birth. }\end{array}$ \\
\hline $\begin{array}{l}\text { - } \quad \text { Rhesus negative: un-sensitised } \\
\text { - } \quad \text { Sensitised }\end{array}$ & $\begin{array}{l}\text { - Monitor. Plan with client and family for hospital birth. } \\
\text { - Next high-risk clinic. Teach mothers to use foetal kick chart. }\end{array}$ \\
\hline $\begin{array}{l}\text { Severe illness: fever, abdominal pain, severe } \\
\text { diarrhoea, shortness of breath, persistent } \\
\text { diarrhoea, severe asthma }\end{array}$ & $\begin{array}{l}\text { - Treat and stabilise. Refer urgently. } \\
\text { - Arrange for emergency transport to hospital. }\end{array}$ \\
\hline
\end{tabular}




\begin{tabular}{|c|c|}
\hline Risk factors & Action (Referral) \\
\hline $\begin{array}{l}\text { - Sexually transmitted infections: Positive RPR } \\
\text { - Others: eg vaginal discharge, vaginal thrush } \\
\text { - Herpes }\end{array}$ & $\begin{array}{l}\text { - Counsel about safer sex practices. Treat according to } \\
\text { protocols. } \\
\text { - Syndromic diagnosis and management in clinic. } \\
\text { - Refer any suspected herpes cases to next high-risk antenatal } \\
\text { clinic. Plan for hospital birth. }\end{array}$ \\
\hline $\begin{array}{l}\text { Skeletal abnormalities: spinal, pelvic, hip } \\
\text { disease/deformities, para or quadriplegia }\end{array}$ & $\begin{array}{l}\text { - Antenatal care at clinic. } \\
\text { - High-risk clinic for assessment at } 36 \text { weeks. } \\
\text { - Plan with client and family for hospital delivery. }\end{array}$ \\
\hline - Substance abuse: alcohol, narcotic & $\begin{array}{l}\text { Refer for counselling to appropriate NGO and to next high- } \\
\text { risk clinic for genetic counselling. Hospital delivery is } \\
\text { required for narcotic users, so baby has adequate care. } \\
\text { Follow-up of mother and baby after is essential. }\end{array}$ \\
\hline - Tobacco & $\begin{array}{l}\text { Clinic management counsel and support client to stop. } \\
\text { Assess foetal growth carefully. Teach mother to monitor } \\
\text { foetal kicks } \\
\text { - Involve family in care }\end{array}$ \\
\hline $\begin{array}{l}\text { Suspected intra-uterine death: Mother has not } \\
\text { felt foetal movement, no foetal heart heard with } \\
\text { soniacid and Symphsis pubis to fundus height < } \\
20 \mathrm{~cm}\end{array}$ & $\begin{array}{l}\text { - Next high-risk clinic for ultrasound assessment and } \\
\text { management plan. } \\
\text { Advise the woman that she should be accompanied by a } \\
\text { member of family for this visit. }\end{array}$ \\
\hline - $\quad \mathrm{TB}$ - positive sputum & $\begin{array}{l}\text { Continue with DOTS in clinic. Medications given as } \\
\text { prescribed by Medical Officer. Referral to next high-risk } \\
\text { clinic. Increase antenatal visits for treatment and support. }\end{array}$ \\
\hline $\begin{array}{l}\text { - Uterus large for dates ( }>90 \text { th centile of symphosis } \\
\text { pubis to fundus height) } \\
\text { Uterus small for dates (< } 10 \% \text { centile of } \\
\text { symphosis pubis to fundus height) }\end{array}$ & $\begin{array}{l}\text { - Check expected date of delivery (EDD) again. } \\
\text { Refer to next high-risk clinic for continuation of care and } \\
\text { hospital delivery. } \\
\text { - Ultrasound assessment is essential. }\end{array}$ \\
\hline $\begin{array}{l}\text { Complicated, abdominal pain, uterine } \\
\text { contractions, severe fever, etc. }\end{array}$ & $\begin{array}{l}\text { Refer immediately to visiting doctor in clinic or to district } \\
\text { hospital for antibiotic prescription. Prescribe antibiotics } \\
\text { according to essential drug list. } \\
\text { - Take mid-stream urine for culture and sensitivity. } \\
\text { - Transfer urgently to hospital after stat treatment (Essential } \\
\text { Drug List). Transport via ambulance. }\end{array}$ \\
\hline
\end{tabular}




\section{No antenatal care visit is complete without group and individual education.}

\section{Education and counselling (key messages)}

\section{Group education}

- Danger signs in pregnancy, which need urgent admission to health centre/hospital.

- Emergency planning and readiness, this must be discussed with family, especially the woman's partner

- Safer sexual practices and condom use during pregnancy and breast feeding

- Nutrition requirements, during pregnancy and breast feeding.

- $\quad$ Avoiding all alcohol, drugs, smoking and non-prescribed drugs, including traditional herbal remedies.

Individual education and counselling (Incorporate companion if present and acceptable to client)

- Voluntary counselling and testing: If HIV status unknown, and client and partner did not respond at first visit encourage to participate at this visit.

- Preparation for breastfeeding and review feeding options if mother HIV-positive

- Give client a return date for the next visit; remember cases that require follow up for treatments and monitoring (increase antenatal visit frequency where risk factors indicate).

\section{Maintain complete records}

- $\quad$ Clinic and patient's antenatal care card.

- Advise to bring antenatal care card on all visits or to take to the referral centre. Ensure that the woman understands that the antenatal care card is a confidential medical document, and she should keep it in a safe place.

- Record results of laboratory and rapid tests received on the antenatal care card. Explain to the mother what results appear on the card.

- Ensure the visit is recorded in the clinic register and tally sheets.

- Detail all medication prescribed, including supplements such as iron, STI treatments and PMTCT medication, in the daily clinic register. 


\subsubsection{Guidelines for the first antenatal visit $<13$ weeks (up to 20 weeks)}

The first visit is the most important. It is recommended that women attend before the 13th week of pregnancy. However, if a woman comes after 13 weeks, all the tests, examinations, counselling and education as listed below must still be completed. Call women who come later in their pregnancies back at more frequent intervals, until they catch up with the regime.

Companioned visits must be encouraged, ie the pregnant woman is accompanied by her partner or any significant other. All services should have strategies in place to encourage women to come early in the pregnancy. The percentage of first antenatal visits must be monitored in each clinic, as well as district and provincial level.

First visits are important as they provide a baseline on the health status of the woman; it may be the first time this woman attends clinic and it is the beginning of a new midwife-client relationship, which should be meaningful for both parties.

\begin{tabular}{|c|c|}
\hline Put the client at ease & Aims of the visit \\
\hline $\begin{array}{l}\text { - Greet client by name. } \\
\text { - Make client (and partner) comfortable. } \\
\text { closed. } \\
\text { - Allow for two-way communication. Ask if the client } \\
\text { has any questions or concerns. }\end{array}$ & $\begin{array}{l}\text { - Introduce the service and providers to the expectant } \\
\text { mother. } \\
\text { - Outline expectations of this and subsequent visits. } \\
\text { Obtain an overall history of each woman and her } \\
\text { situation. } \\
\text { - Obtain specific obstetric history from each woman. } \\
\text { - Identify any health problems or obstetric risks through a } \\
\text { risk assessment. } \\
\text { - Identify any social challenges for intervention and } \\
\text { - support. } \\
\text { - Refer when appropriate. } \\
\text { - } \text { Record findings. }\end{array}$ \\
\hline
\end{tabular}

These policy and guidelines require that as far as possible the same health provider or small team of providers (maximum of three people) attend to the woman during her pregnancy and postnatal period in order to ensure continuity of care, confidentiality, building of trust and to give job satisfaction to the midwife through total job allocation. 
Take a comprehensive history at this visit: Write you findings clearly on the antenatal card.

ASK:

- About personal details.

- Name and contact address.

- Whether the person has an identity document if she is a South African resident. If the woman has no identity document refer to the Department of Home Affairs; explain the benefits of the document for child care support, etc. If the person is not a South African resident continue with the antenatal care.

- Obtain contact details of the client: next of kin for emergencies, and birth companion once selected.

- Social circumstances in order to take into consideration difficult circumstances eg domestic violence, economical support, partner/expectant father available for support.

- Employment status and occupation to assess environmental safety and educate about maternity and paternity leave.

- Habits and daily activities, including smoking, pica, drug use and alcohol.

- Access to health care facility: walk, bus, taxi.

- Telephone number or contact where a message can be left.

Assess the level of education of the client during the history taking and tailor the individual messages to ensure a good understanding of self care and signs of emergencies.

Ensure clients know where Termination of Pregnancy is available, give information about adoption options and relevant phone numbers eg clinic, hospital, EMRS 10177.

ASK about:

- The personal 'medical' history, to assess general health and identify health issues that may cause complications during pregnancy.

ASK about:

- $\quad$ Allergies, especially to medication

- Asthma, breathlessness, persistent cough (longer than three weeks), any known heart problems, diabetes mellitus in both the client and the client's family, recurrent diarrhoea, epilepsy, hypertension, TB previous or current mental illness any previous illness or present treatment, orthopaedic problems, surgery, other major illnesses.

ASK especially about:

- $\quad$ Constant fatigue, fevers, night sweats, unexplained weight loss, severe headaches, difficulty swallowing.

- $\quad$ The signs and symptoms of TB. Take a sputum test for TB if signs and symptoms are present.

- $\quad$ Problems falling pregnant or sub-fertility and infertility treatment.

- $\quad$ Previous contraception used, what were the reasons for discontinuing the method of contraception.

- Previous gynaecological problems, surgery, if over 30 years ask when she last had last cervical examination and smear. 
- Signs of sexually transmitted diseases and her knowledge of prevention.

- $\quad$ HIV status and whether she has been tested before. If HIV-positive find out when the last CD4 count was done and the result.

- Medication: Is she taking any medication at present? Is it prescribed, over the counter medication, or traditional medication; Ask about the reasons.

ASK about the family history (family includes the partner):

- Any bleeding tendency in the family, congenital or genetic defects. Counsel about genetic disorders if necessary.

- Multiple births.

- Diabetes mellitus, hypertension, mental health problems.

- $\quad T B$ in a family member.

- Partner's HIV status and any treatment for sexually transmitted infections.

As a practising midwife it is essential to gain insight into previous pregnancy or pregnancies to undertake a risk assessment and refer if required, and to provide information to the woman and her family:

ASK about past pregnancies:

- How many previous pregnancies (parity) including ectopic, miscarriages, previous termination and still births.

- Any problems that occurred during the pregnancies, delivery or post partum.

- $\quad$ Specific complications in past and present pregnancies and post partum, and management.

- Modes of delivery of all previous children, especially assisted deliveries and previous caesarean sections.

- $\quad$ Place of delivery and specific intrapartum complications and management

- The health of the children now, and any neonatal problems, or congenital abnormalities.

- $\quad$ Are the children all alive now, do they have any health problems, and whether they were breastfed.

- If any of the births were pre or post-term, are the birth weights of each child known?

- Previous PMTCT participation and whether the medication was taken during delivery (make a note of the gap between this previous dose and this next birth). 
Now ASK about this pregnancy:

- First day last normal menstrual period (LNMP) and whether it was a "normal" period for her - calculated Estimated Date of Delivery (EDD) ie First day of LMP + seven days + nine months).

- Discuss the expected date of delivery with the woman.

- If the woman is attending after 13 weeks ASK about the date foetal movement was felt - this assists estimating gestational age (gestational age is confirmed by physical examination [ultrasound if needed and available to service]).

- Current obstetric problems eg vaginal bleeding, vaginal discharge, lower abdominal pain, morning sickness, persistent headaches.

- Other minor ailments of pregnancy eg frequency of urine, constipation, tenderness of breasts, etc.

\section{Examination}

- General examination: please ensure that every woman is fully examined; existing medical conditions are a preventable cause of maternal deaths in KwaZulu-Natal, if managed well in pregnancy.

Look: your powers of observations are essential:

- Observe the gait. Look for limps, deformities, especially skeletal, and, posture, abnormalities, that may cause complications in labour.

- Fully assess the nutritional state using the nutritional assessment tool for pregnant women. Note wasting, recent weight loss, or obesity.

- Undertake the routine of JACCOL (observing for jaundice, anaemia, cyanosis, clubbing, oedema, swollen lymph glands).

- $\quad$ Actively look for bruises, scars at different stages of healing which may be signs of abuse. Gently ask questions about whether the partner is supporting her, is the family happy to be expecting a new baby, etc.

- Scars from surgery or injury, ask about the reason.

- Interaction with partner (if present).

- While taking the history and examination note any sadness, expression of hopelessness, disorientation, and general acceptance of the pregnancy. Undertake a full mental health status if there is any suspicion of depression.

- Varicose veins, leg ulcers. 


\begin{tabular}{|c|c|}
\hline Abdominal examination & Abnormal findings \\
\hline $\begin{array}{l}\text { Inspection (uterus only visible } \\
\text { abdominally after } 12 \text { weeks) } \\
\text { Palpation (only possible to feel } \\
\text { uterus after } 12 \text { weeks) } \\
\text { Symphosis pubis fundal height } \\
\text { measurement accurate from } 20 \\
\text { weeks onwards } \\
\text { Auscultation of foetal heart when } \\
\text { uterus becomes an abdominal } \\
\text { organ } \\
\text { Use sonic-aid if foetal heart not } \\
\text { heard with foeto-scope }<20 \\
\text { weeks. } \\
\text { Do an ultrasound after } 20 \text { weeks } \\
\text { (if this is routinely available in } \\
\text { your service). } \\
\text { Examine the vulva: inspect and } \\
\text { digital examination }\end{array}$ & $\begin{array}{l}\text { Foetal heart not heard with a sonic aid. } \\
\text { Refer for ultrasound if warranted. } \\
\text { Refer to advanced midwife if foetal heart is not heard. } \\
\text { Lesions, abnormal discharges, pain, vaginal bleeding: manage according } \\
\text { to protocols and maturity of the pregnancy, refer to advanced midwife } \\
\text { or doctor. } \\
\text { Signs of physical violation (possible sexual assault): consider counselling } \\
\text { and post exposure prophylaxis and referral. Refer to a crisis clinic if } \\
\text { sexual assault has occurred, Do not examine at clinic, unless there is a } \\
\text { trained nurse or doctor to collect evidence. }\end{array}$ \\
\hline
\end{tabular}

\begin{tabular}{|l|l|}
\hline Vaginal examination & Abnormal findings \\
\hline $\begin{array}{l}\text { Vaginal, cervical, bimanual } \\
\text { examinations }\end{array}$ & $\begin{array}{l}\text { Treat sexually transmitted infections as per syndromic diagnosis and } \\
\text { treatment in Essential Drug List. } \\
\text { Insection and digital } \\
\text { examination vagina } \\
\text { Speculum examination of the } \\
\text { cervix can be postponed to } \\
\text { second visit, unless there is } \\
\text { bleeding or a discharge or seen } \\
\text { lesion }\end{array}$ \\
\end{tabular}




\begin{tabular}{|l|l|}
\hline Urine screening test & Abnormal findings/risk factors/referral \\
\hline $\begin{array}{l}\text { Urine (clean, recent specimen; the } \\
\text { specimen should be passed at the clinic) }\end{array}$ & $\begin{array}{l}\text { Urine is routinely tested every visit: for glucose, protein and leucocytes } \\
\text { and nitrites. }\end{array}$ \\
$\begin{array}{l}\text { Protein } \\
\text { Glucose }\end{array}$ & $\begin{array}{l}\geq 1+\text { (Check for signs of pre eclampsia and urinary tract infection), if there } \\
\text { are no signs of infection or pre-eclampsia, request that the woman } \\
\text { attends in two weeks for monitoring, give education of danger signs in } \\
\text { pregnancy and check her emergency plan. }\end{array}$ \\
$\begin{array}{l}\text { Nitrites and leucocytes } \\
\text { Pregnancy test to confirm }\end{array}$ & $\begin{array}{l}\geq 1+\text { (If any sugar present, do a random blood sugar using a glucometer in } \\
\text { the clinic). }\end{array}$ \\
pregnancy & $\begin{array}{l}\text { Present. Treat with first-line antibiotic for a urinary tract infection. Refer } \\
\text { for treatment if significant bacteria or if infected. }\end{array}$ \\
& Commence first antenatal visit if pregnancy confirmed. \\
\hline
\end{tabular}

\begin{tabular}{|l|l|}
\hline Routine screening tests & Abnormal findings/risk factors/referral \\
\hline $\begin{array}{l}\text { Haemoglobin } \\
\text { Haemoglobin meter used, ensure } \\
\text { the haemoglobin meter is calibrated } \\
\text { regularly and batteries are strong. } \\
\begin{array}{l}\text { Send a specimen to the laboratory if } \\
\text { any degree of anaemia is noted. } \\
\text { Routinely first, third and fourth visit } \\
\text { (More often as indicated). }\end{array}\end{array}$ & $\begin{array}{l}\text { Haemoglobin from 8-10g/dl Mild anaemia (Treated in clinic, increase Iron } \\
\text { Haemoglobin less than } 8 \mathrm{~g} / \mathrm{dl} \text { follow up with full blood count at laboratory; }\end{array}$ \\
\hline $\begin{array}{l}\text { Random blood glucose (using the } \\
\text { clinic glucometer). Measure this if } \\
\text { there is any previous history of } \\
\text { diabetes or gestational diabetes, or } \\
\text { if there is any glucose in the urine. }\end{array}$ & If more and $10 \mathrm{mmol} / \mathrm{l}$ gestational diabetic. Refer high-risk clinic. \\
\hline
\end{tabular}




\begin{tabular}{|c|c|}
\hline Routine screening tests & Abnormal findings/risk factors/referral \\
\hline $\begin{array}{l}\text { HIV test only if test was previously } \\
\text { negative, it is not necessary to re- } \\
\text { test HIV-positive people. All women } \\
\text { should be counselled about the } \\
\text { benefits of an HIV test to her and } \\
\text { her baby. Testing can only be } \\
\text { undertaken if the woman gives } \\
\text { informed consent and this can only } \\
\text { be done after counselling. The } \\
\text { counselling must include infant } \\
\text { feeding information. }\end{array}$ & $\begin{array}{l}\text { If the first test is positive, do the confirmatory test. } \\
\text { When both rapid tests are positive, counsel the woman on the need to } \\
\text { check the CD4 count. Try to prevent delays in taking CD4 counts in } \\
\text { pregnant women - ideally the CD4 count should be done on the same day. } \\
\text { If the HIV test is negative, test again in three months (even in the } \\
\text { postnatal period). Retest if tested negative more than three months ago. }\end{array}$ \\
\hline $\begin{array}{l}\text { For HIV-positive women: Take a CD4 } \\
\text { count every six months. Ensure all } \\
\text { women who are HIV-positive are } \\
\text { clinically staged using the WHO } \\
\text { clinical staging guidelines. }\end{array}$ & $\begin{array}{l}\text { If known to be HIV-positive and has had a CD4 count, and is higher than } \\
\text { 200, counsel about PMTCT interventions. If the CD4 count was done more } \\
\text { than six months ago, take a CD4 count at this first visit and make an } \\
\text { appointment for her to come back for the results. Consult latest PMTCT } \\
\text { and ARV protocols for referral criteria and intervention. }\end{array}$ \\
\hline $\begin{array}{l}\text { Rhesus factor: at the first visit, use } \\
\text { the rapid card test. }\end{array}$ & $\begin{array}{l}\text { If Rhesus-negative take blood for antibodies, if no antibodies continue } \\
\text { routine antenatal care. } \\
\text { Advise all Rhesus-negative women to deliver in hospital. } \\
\text { If antibodies are present: Monitor the client in clinic with maternal blood } \\
\text { specimen every four weeks for antibodies, and refer to the high-risk clinic } \\
\text { at } 28 \text { weeks. }\end{array}$ \\
\hline $\begin{array}{l}\text { Take blood for syphilis serology (RPR) } \\
\text { using a rapid test if available. }\end{array}$ & $\begin{array}{l}\text { First and fourth visits routine tests. } \\
\text { Treat as per sexually transmitted infections protocol, including partner } \\
\text { notification and counselling on condom use. Counsel on the need for HIV } \\
\text { testing if the woman has not tested. }\end{array}$ \\
\hline - $\quad$ Pap smear (cervical smear) & $\begin{array}{l}\text { First or second visits (according to KZN protocol), or if cervix has a lesion. } \\
\text { If the result of the smear is not normal refer for second opinion. } \\
\text { Remember cervical cells are changed in pregnancy, it is therefore } \\
\text { ESSENTIAL to state the pregnancy on the laboratory form. }\end{array}$ \\
\hline $\begin{array}{l}\text { - Sputum } \\
\text { If any signs of TB: Take sputum - two } \\
\text { specimens on consecutive days for } \\
\text { TB. Follow National TB Guidelines. }\end{array}$ & $\begin{array}{l}\text { TB bacilli (AFB) present: } \\
\text { Initial treatment prescribed by MO and followed up in clinic or } \\
\text { community-based care for directly-observed treatment. } \\
\text { (Refer to National TB Guidelines) }\end{array}$ \\
\hline
\end{tabular}




\section{Specimens and tests at referral district hospital or community health centre}

(These are usually done in the high-risk clinic)

Client referred for any of the following:

- $\quad A B O$ blood group incompatibility, especially if previous children were affected. This may not be fully understood by the client; however a history of prolonged treatment of jaundice of a previous newborn child may give an indication.

- $\quad$ Genetic screening eg triple screen for Down syndrome and neural tube defects, according individual risk.

- Rubella serology - if client has been in contact with a case of Rubella.

- Ultrasound - both screening and diagnostic, and where the expected date of delivery is not congruent with the size of uterus.

\section{Interventions at the first visit}

- Immunisation

- Tetanus toxoid (TT) first dose (Follow up with TT2 after four weeks and TT3 six months later in primi gravida or if immunisation status unknown). Refer to National EPI Guidelines

- $\quad$ Routine medications

- Ferrous sulphate - oral $-200 \mathrm{mg}$ daily with food, if multiple pregnancy double the dose ie $200 \mathrm{mg}$ twice a day

- Folic acid - oral - 5mg daily

- Prenatal Forte for HIV-positive women

- Counsel carefully about compliance to prevent anaemia

- Treatment interventions in clinic:

- Mild anaemia (Haemoglobin $8-10 \mathrm{~g} / \mathrm{dl}$ ): Ferrous sulphate $200 \mathrm{mg} 3 \mathrm{X}$ daily and retest at next visit. This client may require more antenatal visits to intensify monitoring.

- Malnourished clients: Food supplementation, (KZN Guidelines for Nutrition Intervention, 2005).

- Infections (refer to Essential Drug List and various National Guidelines) eg sexually transmitted infections, including syphilis, urinary tract infections, infected scabies, etc.

- HIV-positive clients: manage according to National PMTCT and ARV guidelines.

- Refer to high-risk clinic according to referral protocols within the province and district, and from the district hospital. 


\section{Education and counselling}

\section{Group education}

- Introduce the women to the team providing midwifery services at this facility.

- Benefits of HIV testing during pregnancy and outline of the PMTCT interventions, including use of cotrimoxazole, access to ARVs, early testing of baby and early access to ARVs for HIV-positive babies.

- $\quad$ Avoid alcohol, drugs and non-prescribed medicines, even herbal and traditional medicines.

- Introduce the women to the five focused visits, outline why it is important to attend every visit, and what tests and examinations take place at each visit.

- Nutritional requirements in pregnancy, and the need for iron and folic acid supplementation.

- $\quad$ Danger signs during pregnancy.

\section{Individual education and counselling}

- Clarify progress of pregnancy and all examination and tests done and treatment given.

- Discuss benefits of knowing the HIV status of mother to protect child and safe sexual practices in pregnancy.

- Consider termination of pregnancy if unwanted pregnancy or any other clinical reason and pregnancy is less than 20 weeks. (Make sure women in your clinic know where the service can be accessed).

- If at risk for giving birth to an abnormal baby, due to previously affected child or infection, or maternal age, counsel on benefit of attending genetic counselling clinic.

- $\quad$ Ask her to record date the first foetal movements felt and when this should be expected.

- If employed, advise on maternity leave and pay (Unemployment Insurance Fund)

- If she will require Tetanus Toxoid 2 - ask her to return in four weeks (written date and time).

- If any laboratory tests were done make an appointment for a date when results are expected back.

- Provide relevant printed material to take home.

- Danger signs in pregnancy must be explained to every mother at every visit.

- $\quad$ Educate the mother about signs of sexually transmitted infections.

\section{Determine if eligible for midwifery care clinic}

- $\quad$ Risk screening through history, examination and test results.

- $\quad$ Refer to risk assessment at first visit.

\section{Maintain complete records}

- Clinic and clients ANC card.

- $\quad$ Advise to bring ANC card on all visits or take to referral centre.

- Ensure that the visit is entered in the clinic register and tally sheet.

- Keep a record of tests sent to laboratories and enter results when these become available (ensure that it is noted when the client has been given the results).

- Schedule second visit at 20 to 24 weeks - written date and time, encourage the client to bring her partner or a companion with her 


\section{Risk assessment at first visit}

Identification of antenatal risk factors from history

\begin{tabular}{|c|c|}
\hline Risk factors from obstetric history & Action (Referral) \\
\hline - Previous ante partum haemorrhage & $\begin{array}{l}\text { Monitor in clinic. If hemorrhage recurs urgent transfer to } \\
\text { hospital. } \\
\text { - Increase visits to monitor more closely. }\end{array}$ \\
\hline - Birth defect in previous neonate & $\begin{array}{l}\text { - Refer to high-risk clinic. Genetic screening needed. } \\
\text { - Ultra sound required if physical defect occurred. }\end{array}$ \\
\hline - Birth weight of last baby: $<2000 \mathrm{~g} \geq 4500 \mathrm{~g}$ & $\begin{array}{l}\text { Monitor in a clinic and refer to high-risk clinic if poor foetal } \\
\text { growth. Measure fundul-symphosis height accurately. } \\
\text { - Increase antenatal visits. } \\
\text { - Refer to High-risk clinic for assessment for diabetes. }\end{array}$ \\
\hline - Previous caesarean section & $\begin{array}{l}\text { Refer to high-risk clinic for } 34 \text { to } 36 \text { week visit and delivery } \\
\text { plan. Discuss with client that delivery should take in a } \\
\text { hospital. }\end{array}$ \\
\hline - Consecutive miscarriages $\geq 3$ & - District hospital for obstetric referral. \\
\hline $\begin{array}{l}\text { - Genital tract surgery: myomectomy, removal } \\
\text { of septum, cone biopsy, classical caesarean } \\
\text { section }\end{array}$ & - Refer to high-risk clinic for opinion and plan for care. \\
\hline $\begin{array}{l}\text { - Intra uterine growth retardation: in a } \\
\text { previous pregnancy }\end{array}$ & $\begin{array}{l}\text { - Monitor in clinic, may need more than the five visits to } \\
\text { increase monitoring. Use the centile chart to monitor. } \\
\text { - If this recurs refer to high-risk clinic. }\end{array}$ \\
\hline $\begin{array}{l}\text { - Multiple pregnancy: in previous pregnancy or } \\
\text { suspected in the pregnancy }\end{array}$ & $\begin{array}{l}\text { - Monitor in clinic and refer to high-risk clinic if suspected. } \\
\text { shere multiple pregnancies are confirmed, the woman } \\
\text { transport and birth. }\end{array}$ \\
\hline $\begin{array}{l}\text { Perinatal deaths: previous mid-trimester, } \\
\text { abortion, stillbirth, neonatal death }\end{array}$ & $\begin{array}{l}\text { Refer to high-risk clinic for } 20 \text { weeks visit. May be referred } \\
\text { back to clinic to continue care. Advise to deliver in hospital. } \\
\text { Increase antenatal visits. } \\
\text { - Teach client how to use the kick count chart. }\end{array}$ \\
\hline - Post partum haemorrhage & $\begin{array}{l}\text { - Routine antenatal care at clinic but must deliver in hospital. } \\
\text { - Assist family to plan transport and birth }\end{array}$ \\
\hline
\end{tabular}




\begin{tabular}{|c|c|}
\hline Risk factors from obstetrics history & Action (Referral) \\
\hline $\begin{array}{l}\text { Pre-eclampsia or eclampsia previously. } \\
\text { Especially if developed before } 28 \text { weeks in last } \\
\text { pregnancy }\end{array}$ & $\begin{array}{l}\text { - Monitor carefully especially from } 20 \text { weeks onwards. } \\
\text { - } \text { - Introduce nutrition supplements if situation warrants it. } \\
\text { - Refer to high-risk clinic if clinical signs develop. Reschedule } \\
\text { subsequent visits as needed, these clients may need closer } \\
\text { visits for monitoring than the five targeted visits suggested } \\
\text { in these guidelines. }\end{array}$ \\
\hline $\begin{array}{l}\text { Preterm labour in a previous pregnancy. } \\
\text { Especially if delivered before } 28 \text { weeks in last } \\
\text { pregnancy }\end{array}$ & $\begin{array}{l}\text { Monitor carefully especially from } 20 \text { weeks onwards. Refer } \\
\text { to high-risk clinic if clinical signs develop. Empower client to } \\
\text { self-monitor and to attend health centre if premature } \\
\text { rupture of membranes occurs. } \\
\text { - Discourage sexual intercourse after } 20 \text { weeks. }\end{array}$ \\
\hline $\begin{array}{l}\text { - Puerperal psychosis in or after previous } \\
\text { pregnancy. }\end{array}$ & $\begin{array}{l}\text { - Refer to hospital for delivery and postnatal monitoring } \\
\text { - Involve the family to support the mother. } \\
\text { - Companioned visits must be encouraged. }\end{array}$ \\
\hline - Rhesus-D negative - sensitised & $\begin{array}{l}\text { Refer to high-risk clinic. Advise to deliver in a hospital. Assist } \\
\text { family to plan for transport and birth. }\end{array}$ \\
\hline - Sub-fertility or infertility treatment & $\begin{array}{l}\text { - Refer to high-risk clinic for assessment. } \\
\text { - Closer monitoring and more frequent antenatal visits may } \\
\text { be required }\end{array}$ \\
\hline $\begin{array}{l}\text { Vacuum or forceps delivery in previous } \\
\text { pregnancy }\end{array}$ & - Plan with mother and family for hospital delivery. \\
\hline
\end{tabular}


Risk factors on examination at first ANC visit $<13$ weeks (to $<20$ weeks)

NB: Review factors from history

\begin{tabular}{|c|c|}
\hline Risk factors current pregnancy & Action (Referral) \\
\hline $\begin{array}{l}\text { HIV: Tested positive or known HIV-positive or } \\
\text { known HIV-positive on treatment or symptomatic } \\
\text { - testing refused }\end{array}$ & $\begin{array}{l}\text { - Clinically stage all HIV-positive expectant mothers at each visit. } \\
\text { low enough to commence ARVs, explain PMTCT intervention } \\
\text { and positive lifestyle. } \\
\text { - If CD4 count is low or after WHO clinical staging, the woman is } \\
\text { staged at stage } 3 \text { or } 4 \text { refer to ARV treatment centre. } \\
\text { Monitor all HIV-positive women and those who are } \\
\text { symptomatic and refuse testing for opportunistic infections } \\
\text { provide symptomatic treatment and refer to high-risk clinic for } \\
\text { medical opinion. }\end{array}$ \\
\hline - Abnormal pap smear & $\begin{array}{l}\text { Pap smear as part of routine antenatal care in clinic. Refer to } \\
\text { medical officer if abnormal eg HSIL: CIN, CIS. }\end{array}$ \\
\hline $\begin{array}{l}\text { - Pelvic mass found on palpation eg ectopic } \\
\text { pregnancy, ovarian tumour, etc. }\end{array}$ & $\begin{array}{l}\text { - Transfer to next high-risk clinic. } \\
\text { - If acute abdomen urgent transfer to hospital using EMRS, } \\
\text { establish an intravenous line and monitor patient carefully. } \\
\text { Provide oxygen. }\end{array}$ \\
\hline $\begin{array}{l}\text { - Rhesus-negative: Un-sensitised } \\
\text { - Sensitised }\end{array}$ & $\begin{array}{l}\text { Monitor. Refer to high-risk clinic as needed. Plan with client } \\
\text { and family for hospital birth. } \\
\text { All clients with antibodies must be referred to high-risk clinic. } \\
\text { Hospital birth is advised. }\end{array}$ \\
\hline $\begin{array}{l}\text { Sexually transmitted infections } \\
\text { Syphilis (RPR positive) } \\
\text { - Other sexually transmitted infections }\end{array}$ & $\begin{array}{l}\text { Treat syphilis in clinic as per EDL guidelines ensure treatment } \\
\text { is completed. } \\
\text { - Ask about vaginal discharge at all antenatal and postnatal } \\
\text { visits. Repeat RPR for syphilis if any sexually transmitted } \\
\text { infection occurs. Counsel about HIV testing if a sexually } \\
\text { transmitted infection occurs. }\end{array}$ \\
\hline & $\begin{array}{l}\text { Syndromic diagnosis and management in clinic - National } \\
\text { Sexually Transmitted Infections Guidelines or Essential Drug } \\
\text { List. Refer all cases that do not respond to treatment. }\end{array}$ \\
\hline
\end{tabular}


12.1.3 Guidelines for the second antenatal visit: 20 to 24 weeks

(Adjust if first visit delayed)

Special risk areas during this time of pregnancy

- Hypertension may develop

- Threatened abortion

- Intra-uterine growth retardation or intra-uterine death may be identified.

- Signs of cardiac disease may become evident as the pregnancy continues.

\section{Review records}

- History taken during the first visit with the client.

- $\quad$ Reconfirm date of the last menstrual period and expected date of delivery (EDD) at each visit.

- Check if tetanus toxoid immunisation was given, and when the next dose is required.

\section{History}

- $\quad$ ASK and record date first foetal movements felt, this will help to refine the expected date of delivery (EDD).

- $\quad$ ASK the mother If she has an identify document. If not, advise on benefits and how to apply for this document.

Allow some time for questions from the client and her companion about pregnancy and general health.

\section{Routine examination}

\section{Carry out all the requirements as per the "Every Antenatal Visit Schedule" to ensure quality and integrated} Antenatal Care.

\section{Observations}

Undertake the following observations at all second antenatal visits, plus those from the every antenatal care visit schedule:

- $\quad$ Observe mental health state.

- Check common HIV symptoms: such as: oral thrush, fatigue, fever, night sweats, difficulty swallowing, persistent diarrhoea, dyspnoea on extension, severe headaches.

- Check common symptoms of TB-swollen glands, weight loss, night sweats, and a 14-day persistent cough. 
Physical examination abnormal findings and guidelines

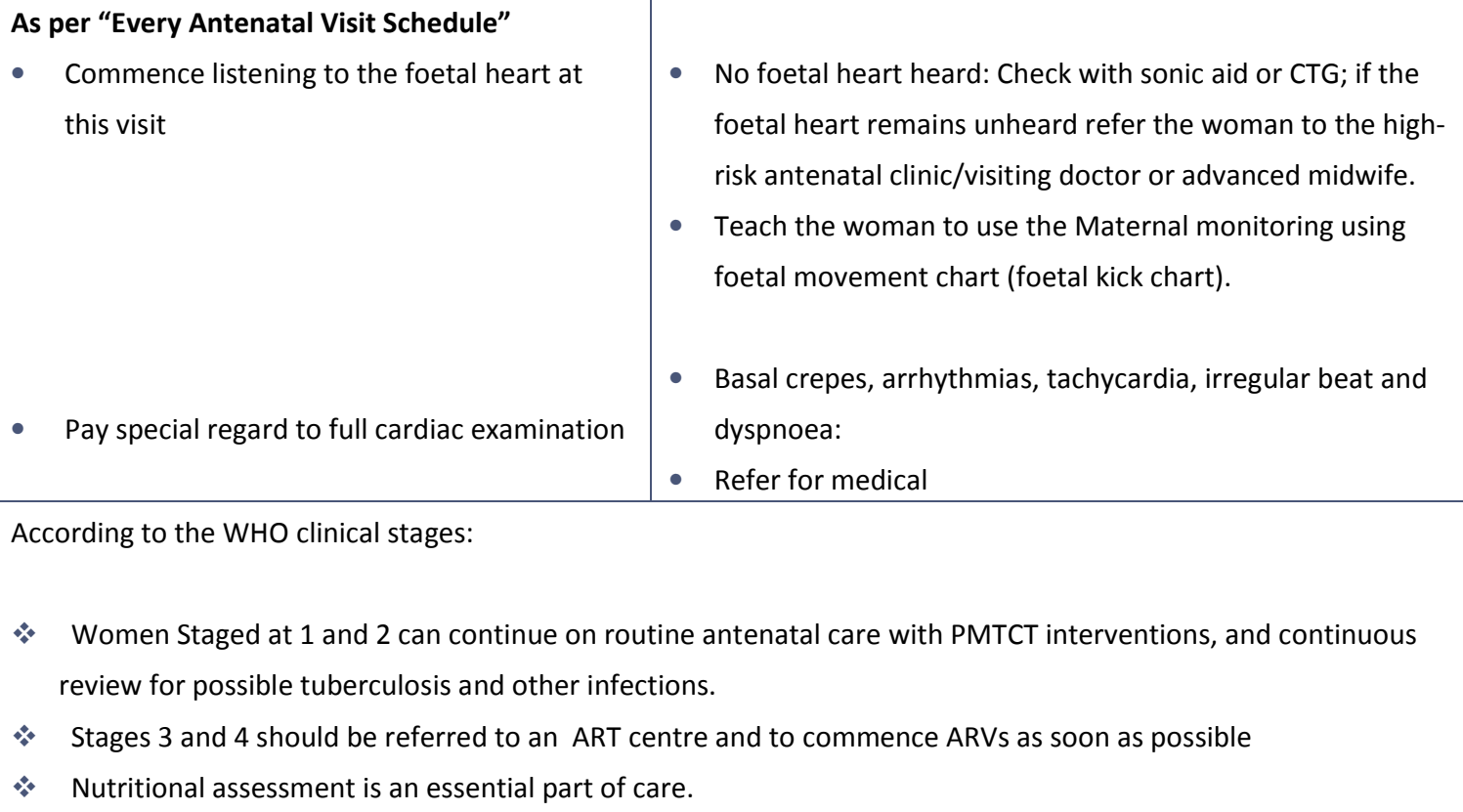

- Commence listening to the foetal heart at this visit

- Pay special regard to full cardiac examination

- No foetal heart heard: Check with sonic aid or CTG; if the foetal heart remains unheard refer the woman to the highrisk antenatal clinic/visiting doctor or advanced midwife.

- Teach the woman to use the Maternal monitoring using foetal movement chart (foetal kick chart).

- Basal crepes, arrhythmias, tachycardia, irregular beat and dyspnoea:

- Refer for medical

According to the WHO clinical stages:

* Women Staged at 1 and 2 can continue on routine antenatal care with PMTCT interventions, and continuous review for possible tuberculosis and other infections.

* Stages 3 and 4 should be referred to an ART centre and to commence ARVs as soon as possible

* Nutritional assessment is an essential part of care.

\section{Screening tests}

- Do tests as per "Every Antenatal Care Visit Schedule"

- $\quad$ Check for results of the syphilis test, commence treatment if required.

- $\quad$ Check for PAP smear results.

\section{Interventions at the second antenatal visit}

\section{Carry out the interventions on the "Every Antenatal Care Visit Schedule"}

- $\quad$ Prescribe supplements according to National Maternity Guideline schedule.

- If second visit is delayed beyond 32 weeks and the woman is HIV-positive prescribe PMTCT medication to prevent Mother to Child Transmission of HIV infection - see latest PMTCT guidelines.

- If the woman is HIV-positive, check for CD4 test and results, and WHO clinical staging of HIV infection to assess the need for ARV referral.

\section{Education and counselling}

\section{Group education (key messages)}

Include the key messages from "Every Antenatal Visit Schedule" PLUS

- Preparation for breastfeeding, importance of the first feed, exclusive breast feeding, protected sex during breastfeeding

- Benefits of companionship in pregnancy and labour 
- Preparation for new baby in family, including sibling rivalry, financial planning, obtaining documents for child care grants.

- Nourishing diet for health and healthy baby during pregnancy

- Signs of Sexual Transmitted Infection, and when to come to the clinic for treatment

Individual education and counselling

- Explain all examinations, tests undertaken medications given, with special emphasis on the supplementation with Iron and folic acid.

- Teach the woman (and companion) to use maternal foetal movement chart (foetal kick chart).

- If HIV status unknown, and client and partner did not respond and test at first visit: encourage clients to participate at this visit by informing the couple or person about the benefits of knowing the HIV status to protect the woman and unborn child.

- $\quad$ For HIV-positive women re-enforce messages on infant feeding choices and assessment, and safer sexual practises. Schedule third visit between 28 to 32 weeks (written and time) unless need to return sooner for more monitoring, or for test results, or treatment.

Risk assessment

DETERMINE IF ELIGIBLE TO CONTINUE ANTENATAL CARE AT PRIMARY HEALTH CARE LEVEL USING THE RISK FACORS IN THE "EVERY ANTENATAL VISIT SCHEDULE" AND SPECIAL RISK FACTORS AT THE SECOND VISIT (20 TO 24 WEEKS). 


\section{Risk factors at second ANC visit: 20 to 24 weeks}

NB: Consider risk factors from history and first visit results.

\section{Review the history}

\begin{tabular}{|c|c|}
\hline Risk Factors & Action/Referral/Intervention \\
\hline - Abuse - sexual or domestic & $\begin{array}{l}\text { Next high-risk clinic, police, social services, support group, } \\
\text { or NGO. } \\
\text { More frequent visits may give some measure of support for } \\
\text { this woman. }\end{array}$ \\
\hline - Anaemia $\mathrm{Hb}<8 \mathrm{~g} / \mathrm{dl}$ & $\begin{array}{l}\text { Take a full blood count and refer to medical officer or high- } \\
\text { risk antenatal clinic. }\end{array}$ \\
\hline - $\mathrm{Hb} 8$ to $10 \mathrm{~g} / \mathrm{dl}$ & $\begin{array}{l}\text { Take a full blood count, if no abnormalities, then monitor at } \\
\text { clinic; check compliance with supplements, increase dosage } \\
\text { as per Essential Drug List / National Maternal Guidelines. } \\
\text { - If in an area with high Hook worm prevalence, refer to } \\
\text { medical officer for medication. }\end{array}$ \\
\hline - Symptomatic HIV and woman refuses HIV testing & $\begin{array}{l}\text { Provide symptomatic treatment as required screen for TB. } \\
\text { - Explain the benefits of HIV testing and knowing the HIV } \\
\text { status during pregnancy and breast feeding. } \\
\text { - Refer to next high-risk antenatal clinic if she is symptomatic } \\
\text { and refuses testing for HIV infection. } \\
\text { - Counsel about safer sexual practices to protect baby } \\
\text { - Plan with client and family for a hospital delivery. }\end{array}$ \\
\hline $\begin{array}{l}\text { Suspected intrauterine death : Mother has not } \\
\text { felt foetal movement, no foetal heart heard with } \\
\text { sonicacid and Symphisis pubis to fundus height < } \\
20 \mathrm{~cm}\end{array}$ & $\begin{array}{l}\text { Refer to next high-risk antenatal clinic for ultrasound } \\
\text { assessment and management plan } \\
\text { Request that the woman is accompanied by the a family } \\
\text { member for this visit to the high-risk clinic }\end{array}$ \\
\hline - Signs of cardiac disease & $\begin{array}{l}\text { Assess fully; may need immediate referral or referral to next } \\
\text { high-risk antenatal clinic }\end{array}$ \\
\hline - Signs of threatened abortion & - $\quad$ Refer urgently \\
\hline
\end{tabular}

Continue the risk assessment as per "Every Antenatal Care Visit Schedule"

\section{Maintain complete records}

As stipulated in the "Every Antenatal Care Visit Schedule" 


\subsubsection{Guidelines for the third antenatal visit: 28 to 32 Weeks}

This is an important visit for both maternal and foetal health and especially for preventing transmission of HIV infection to the baby and for the assessment of anaemia.

\section{Special risk areas during this time of pregnancy}

Serious complications can occur at this stage of pregnancy:

- Pre-eclampsia

- $\quad$ Pre term-labour with transmission of HIV

- Anaemia

- Intra uterine growth retardation

Undertake all contained in the "Every Antenatal Visit Schedule" and add the following special items for the third visit at 28 to 32 weeks

\section{History}

\section{ASK:}

- When maternity leave will commence if employed, provide the woman with the required letter or document.

- $\quad$ About compliance with medication given, especially iron and folic acid

- If foetal movements (foetal kick count monitoring) diminished or no longer felt. Use sonic aid if not heard, with foetoscope. If foetal heart not heard do CTG recording. If non-reactive trace or no Foetal Heart refer to hospital (non-urgent).

\section{Routine examination}

As Per "Every Antenatal Visit Schedule" PLUS:

\section{Do not forget to examine all HIV-positive women using WHO clinical staging and refer for ART if stage 3 or 4.}

- $\quad$ Carefully check the woman for signs of cardiac disease and anaemia at this visit (repeat haemoglobin).

- $\quad$ Repeat the nutritional assessment at this visit and manage according to protocols.

Do not forget to examine all HIV- positive women using WHO clinical staging and refer for ART if stage 3 or 4.

- $\quad$ Carefully check the woman for signs of cardiac disease and anaemia at this visit (repeat haemoglobin).

- Repeat the nutritional assessment at this visit and manage according to protocols. 


\section{Routine screening tests}

\begin{tabular}{|c|c|}
\hline Investigation & Abnormal results and action \\
\hline Urine & $\begin{array}{l}\text { - Nitrites leucocytes: Present } \\
\text { - Take a clean mid stream specimen for culture (MC\&S). } \\
\text { - } \quad \text { Refer for treatment if significant bacteria or if infected. } \\
\text { - If signs of complicated urinary tract infection - Refer. }\end{array}$ \\
\hline $\begin{array}{l}\text { Haemoglobin blood test: (using a haemoglobin } \\
\text { meter) } \\
\text { This is an essential test at this time of pregnancy } \\
\text { do not miss this test }\end{array}$ & $\begin{array}{l}\text { If result is } \mathrm{Hb} 8-10 \mathrm{~g} / \mathrm{dl} \text { (mild anaemia) and no abnormal } \\
\text { results from any previous full blood count. Adjust iron } \\
\text { supplement as needed: check Essential Drug List. Women } \\
\text { with previous abnormal results must be referred to high- } \\
\text { risk clinic. } \\
\text { If result is } \mathrm{Hb}<8 \mathrm{~g} / \mathrm{dl} \text { (severe anaemia) follow up with full } \\
\text { blood count and refer to next high-risk clinic. }\end{array}$ \\
\hline Random blood sugar using glucometer & $\begin{array}{l}\text { - }>11 \mathrm{mmol} / / \text { gestational diabetes. Refer to high-risk } \\
\text { clinic. }\end{array}$ \\
\hline
\end{tabular}

\section{Interventions}

\section{Continue with all the interventions contained in the "Every Antenatal Visit Schedule"}

If the woman is HIV-positive and on the PMTCT programme, dispense current medication to mother and counsel on safe storage and self-administration. If the woman is on full ARV, check compliance and give assurance, there is no need for extra medication.

\section{Education and counselling}

\section{Group education (key messages)}

- $\quad$ Explain the PMTCT interventions and benefits to mother and baby, especially access to ARVs.

- Teach all mothers how to do and interpret the maternal monitoring using foetal movement chart (foetal kick chart).

- Explain why iron and folic acid must be taken

- Discuss the need for child spacing and contraception.

- Educate women to come to a health facility if they think that labour has commenced prematurely. 
- $\quad$ Birth preparedness: Preparation for admission in labour:

- Knowledge of signs of onset of labour: "show", regular contractions.

- (Differentiate from Braxton-Hicks), rupture of membranes.

○ Timing of admission i.e. when to leave home for admission: how long does labour take.

- Women must be made aware that if premature labour occurs they should go to hospital soon as possible.

- Organisation of other children at home when admitted for birth, some information on sibling rivalry.

Knowledge of what to bring in to labour ward, snack, clothes, etc.

- Organisation of transport for delivery, especially if an emergency occurs

- Advise on birth plan - place of delivery, companion in labour, delivery and postnatal period

- Choices in labour: positions, mobility, relaxation and breathing techniques.

- Introduction to the importance of primary health services for children eg Vitamin A, immunisation, growth monitoring.

Individual education and counselling

- Discuss protected sex and sexual activity during pregnancy.

- $\quad$ Reinforce preparation for breastfeeding (Consider HIV status and social circumstances).

- Educate or counsel women at particular risk. In particular, if intra-uterine growth retardation is suspected, teach her how to undertake monitoring using foetal movement chart (foetal kick chart). She must report immediately if diminished significantly according to clinic protocol.

- If at risk for ante-partum haemorrhage or preterm labour avoid penetrative sexual activities.

- If the woman is HIV-positive.

- $\quad$ Review feeding options; discuss the options with the woman, and her partner if available.

- If the PMTCT interventions are to be followed, then review education on PMTCT medication or counsel about adherence to medication protocol.

- Discuss opportunistic infections such as oral thrush, cough, persistent diarrhoea, etc.

- Encourage compliance with medications eg ARVs, cotrimoxazole and supplements.

- Schedule fourth visit between 34 to 36 weeks, unless there are some tests results outstanding, the woman needs closer monitoring or medication is required, such as to complete treatment for syphilis or the tetanus toxoid regime is not complete. Give the woman a written date and time to return. 


\section{Risk assessment}

Risk screening takes place throughout the history taking, examination and assessment of Test results; it is not a separate task.

* Use all the RISK FACTORS in Every Antenatal Visit Schedule, as well as these below:

- SPECIAL RISK FACTORS AT THIRD ANTENATAL VISIT: 28 TO 32 WEEKS

NB Review risk factors from history and first and second antenatal visit

\begin{tabular}{|c|c|}
\hline Risk Factors & Action \\
\hline $\begin{array}{l}\text { - Ante-partum haemorrhage } \\
\text { - History of ante-partum haemorrhage }\end{array}$ & $\begin{array}{l}\text { - } \text { Resuscitate if needed. } \\
\text { - } \text { For protocols use National Maternity Guidelines. } \\
\text { - Immediate transfer to hospital by EMRS. }\end{array}$ \\
\hline - Large foetus felt on palpation & $\begin{array}{l}\text { At clinic - check expected date of delivery. Screen for } \\
\text { diabetes by doing random blood sugar if } \geq 11 \mathrm{mmol} / \mathrm{l} \text { refer } \\
\text { to high-risk clinic }\end{array}$ \\
\hline $\begin{array}{l}\text { Intra-uterine death : soft, non-tender uterus } \\
\text { no foetal heart if associated with ante-partum } \\
\text { haemorrhage }\end{array}$ & $\begin{array}{l}\text { - Referral to high-risk clinic for management and plan. } \\
\text { If signs of ante-partum haemorrhage, Urgent transfer to } \\
\text { hospital by ambulance and manage according to National } \\
\text { Maternity Guidelines. }\end{array}$ \\
\hline $\begin{array}{l}\text { - Intra-uterine growth retardation } \\
\text { - If foetal movements are good }\end{array}$ & $\begin{array}{l}\text { Maternal monitoring using foetal movement chart (foetal } \\
\text { kick chart) and refer to next high-risk antenatal clinic for } \\
\text { assessment. }\end{array}$ \\
\hline - If foetal movements are poor or diminishing & - Transfer to hospital immediately. Provide supportive care. \\
\hline - Mental health problems : mental illness & $\begin{array}{l}\text { - Assessment and stabilisation at hospital. } \\
\text { - Routine care at clinic, especially encourage compliance with } \\
\text { medication. Plan delivery at hospital }\end{array}$ \\
\hline - Multiple pregnancy: suspected or confirmed & $\begin{array}{l}\text { - Refer to high-risk clinic if a multiple pregnancy is suspected. } \\
\text { - Assist the family to plan for hospital delivery. } \\
\text { - Check that the family has an emergency plan. }\end{array}$ \\
\hline
\end{tabular}




\begin{tabular}{|c|c|}
\hline Risk Factors & Action \\
\hline - Polyhydramnios found on palpation & $\begin{array}{l}\text { - Refer to next high-risk clinic. Check for foetal heart. } \\
\text { - Assist the family to plan for a hospital delivery. } \\
\text { - Check that the family has an emergency plan. }\end{array}$ \\
\hline - Premature rupture of membranes (PROM) & $\begin{array}{l}\text { Check for prolapsed cord and signs of labour and manage } \\
\text { appropriately. } \\
\text { Immediate transfer to hospital, unless the cord is prolapsed } \\
\text { and the foetal heart is present, which will mean an urgent } \\
\text { transfer to hospital. Check National Maternity Guidelines for } \\
\text { management protocols. Ensure infection control measure } \\
\text { during examination. }\end{array}$ \\
\hline - Preterm labour & $\begin{array}{l}\text { Do cervical score if premature labour suspected, via gentle } \\
\text { speculum examination. Ensure infection control measures. } \\
\text { - Commence management in clinic (National Maternity } \\
\text { Guidelines). } \\
\text { - Urgent transfer to hospital. }\end{array}$ \\
\hline
\end{tabular}




\subsubsection{Guidelines for the fourth antenatal visit: $\mathbf{3 4}$ to $\mathbf{3 6}$ weeks}

Undertake all contained in the "Every Antenatal Visit Schedule"

\begin{tabular}{|l|l|}
\hline Put the client at ease & Aims of the visit \\
\hline - Greet the client by name & - Preparation for emergency \\
- Make client (and partner) comfortable & - Preparation for birth \\
- Maintain privacy and confidentiality & - Assess general health status \\
- Allow two-way communication, ask about \\
any questions from the last visit
\end{tabular}

\section{History}

Personal details reviewed, especially any changes.

Personal medical history

- Review all previous history consider any chronic conditions that may be worsen by pregnancy.

- Confirm that a HIV test has been done. Ask the client if she has been able to share the results with her partner, family or significant other.

- Ask about new health problems, including any injuries; note any sick leave, hospitalisation, medication since last visit. Visits to traditional healer and traditional medication.

- Re-identify all medication being taken; use this opportunity to motivate the client to take the Iron and Folic acid. If HIV-positive, to take the cotrimoxazole and/or ARVs.

\section{Past obstetric history}

- Note any conditions that indicate that a hospital delivery should be planned, eg previous caesarean, previous assisted delivery.

- Review all previous history and notes for risk factors.

\section{Current pregnancy}

- $\quad$ Review expected delivery date (EDD) and gestational age, discuss the dates and preparation with the client.

- Ask about foetal movements: have these decreased, is she still feeling them? Use the sonic aid if they are diminished or have ceased.

- Ask about any notable changes since the last visit, especially vaginal bleeding, painful contractions, liquor draining, severe or persistent headaches, blurred vision, severe or persistent diarrhoea. Transfer urgently if any of these signs are present.

- Ask client and companion about any body changes noted, especially changes in physical capacity, breathlessness, and oedema. If oedema present check for other signs of pre-eclampsia. 


\section{Routine examinations required}

\section{Do not forget to clinically stage all women who have tested HIV-positive and to check all women for signs of TB.}

General

- Check for signs of jaundice, oedema, anaemia, swollen lymph glands, breathlessness, malnutrition, bruising and injury that may indicate domestic violence.

- Observe mental status; ask about family support, plans for the future.

- Undertake a nutritional assessment at this visit.

- Ask about symptoms of TB, HIV, Sexually transmitted infections and pre-eclampsia.

- Common signs of HIV infection: Fatigue, night sweats, difficulty swallowing, persistent diarrhoea, dyspnoea, severe headaches, enlarged lymph nodes.

- Common signs of TB: Cough for longer than two weeks, production of sputum (maybe blood stained), breathlessness, chest pain, loss of weight and appetite, malaise and tiredness, night sweats and fever, enlarged lymph nodes.

- Sexually transmitted infections: Ask about: vaginal discharge, dysuria, vulval itch or burning, lower abdominal pain, genital sores swollen lymph nodes in the femoral or inguinal areas.

- Imminent eclampsia: Ask about: severe or persistent frontal headaches, visual disturbances, epigastric pain or discomfort, nausea or vomiting, widespread oedema, especially oedema of the face and hands.

Measure and record: Criteria

1. Weight

2. Blood pressure: use the correct cuff especially for obese women If raised, take two readings ten minutes apart and mother to rest between.

3. Pulse: take the pulse for at least one minute

Vulvo-vaginal and cervical examination: DO
NOT UNDERTAKE vaginal examination if any
vaginal bleeding is reported or observed.

$>$ Do a pelvic assessment at this visit if this is a first delivery, or a large baby, or if any suspect of cephalo-pelvic disproportion.
Findings considered abnormal: use these to make decisions about care: Check these against the "eligibility criteria for midwifery care".

1. Decrease of weight, small or no weight gain or excessive weight gain.

2. Readings above $140 / 90 \mathrm{~mm}$ Hg or increase in the Diastolic BP or Systolic BP by 20 or more since the third visit.

3. Any arrhythmia or a pulse of 100 or more must be referred immediately.

Check arrhythmias by using a stethoscope listen for at least one minute.

Look for any lesions, sores, and discharges: treat sexually transmitted infections as per protocol or Essential Drug List. Ensure counselling about partner notification and safer sexual practises.

Vaginal bleeding: refer urgently to doctor or advanced midwife.

Do cervical score if premature labour suspected. And transfer urgently. If contract pelvis is suspected refer to advanced midwife or doctor, for decision about place of delivery and management. 


\section{Screening tests}

\begin{tabular}{|c|c|}
\hline $\begin{array}{l}\text { Urine: must be clean fresh } \\
\text { specimen }\end{array}$ & $\begin{array}{l}\text { Protein present: check for urinary tract infection, check for other signs of } \\
\text { pre-eclampsia. } \\
\text { - Glucose present: do random blood sugar using heamoglobinometer, } \\
\text { if above ten refer to next high-risk clinic. } \\
\text { - Nitrites and leucocytes present: send mid-stream urine specimen for } \\
\text { micro-culture and sensitivity: manage according to Essential Drug List } \\
\text { - If signs of urinary tract infection are severe, eg fever, abnormal pain, pain } \\
\text { on micurination. Check for signs of preterm labour and refer immediately. }\end{array}$ \\
\hline $\begin{array}{l}\text { Blood tests: } \\
\text { Haemoglobin must be done at } \\
\text { this visit. }\end{array}$ & $\begin{array}{l}\text { Haemoglobin below } 8 \mathrm{~g} / \mathrm{dl} \text { : take full blood count, and refer to high-risk } \\
\text { clinic within the week. } \\
\text { Haemoglobin between } 8 \mathrm{~g} / \mathrm{dl} \text { and } 10 \mathrm{~g} / \mathrm{dl} \text { and pregnancy less than } 36 \\
\text { weeks: } \\
\text { Check compliance with iron and folic acid medication. If pregnancy over } \\
36 \text { weeks, refer to next high-risk clinic for medical opinion and } \\
\text { managements plan. } \\
\text { Haemoglobin } 10 \mathrm{~g} / \mathrm{dl} \text { and pregnancy over } 36 \text { weeks: take full blood count, } \\
\text { check compliance with iron and folic acid medication. Refer to next High- } \\
\text { risk clinic for an opinion. }\end{array}$ \\
\hline $\begin{array}{l}\text { Repeat syphilis test: preferably } \\
\text { rapid on site PRP. } \\
\text { HIV testing after counselling if } \\
\text { this has not been done before } \\
\text { or it is three months after first } \\
\text { test. }\end{array}$ & $\begin{array}{l}\text { If Positive RPR test, management as per sexually transmitted infections } \\
\text { protocol in the Essential Drug List, ensure counselling about partner } \\
\text { notification and treatment, and protected sexual visits course. } \\
\text { - If negative counsel about protected sex relations during pregnancy and } \\
\text { breastfeeding to protect the baby and herself. }\end{array}$ \\
\hline $\begin{array}{l}\text { If HIV-positive, check when last } \\
\text { CD4 count was done, if six } \\
\text { months ago redo at this visit }\end{array}$ & $\begin{array}{l}\text { - If positive commence PMTCT regime, explaining the use of medication to } \\
\text { protect baby, counsel about choices of infant feeding, and commence } \\
\text { cotrimoxazole until } 36 \text { weeks. Take a CD4 count, and commence } \\
\text { preparation counselling for ARVs. } \\
\text { - Counsel for disclosure to partner, family or significant other to ensure } \\
\text { support in labour, and for infant feeding choices. } \\
\text { If CD4 count: } \\
\checkmark \text { Lower than recommended level refer to nearest ART clinic, ensure the } \\
\text { details are entered on the antenatal card. Commence planning for } \\
\text { hospital delivery with woman and family. } \\
\checkmark \text { More than ARV levels continue with antenatal care and PMTCT } \\
\text { protocols at clinic. }\end{array}$ \\
\hline
\end{tabular}




\section{Interventions}

- Check compliance with Iron and folic acid, check haemoglobin and adjust dosage, give sufficient supply until next visit.

- $\quad$ Continue with food supplements, if required.

- If HIV-positive, check when last CD4 count done, ask client if she has been able to share her status with a family member, partner or significant other. Ask her about the ARVs given to her last visit, review her understanding of compliance.

- $\quad$ Check eligibly for midwifery care, and refer to high-risk clinic if indicated

\section{Education and counselling}

Group education (includes partners/ birth companions in this education session)

- Explain the benefits of knowing one's HIV status to protect the unborn baby, the need for protected sexual intercourse during pregnancy and breastfeeding. Outline the PMTCT intervention and access to ARVs for pregnant women and babies.

- $\quad$ Reinforce all messages from previous visits, especially signs of premature labour, ante-partum haemorrhage (APH), danger signs in pregnancy.

- $\quad$ Emergency preparedness for family, birth preparedness: preparation for labour, birth companionship.

- Importance of rest for mother to ensure baby growth especially in this last part of the pregnancy.

- Discuss with group the importance of breastfeeding, putting the baby to breast as soon as after delivery as possible (remember that HIV-positive need mother to be supported in their choice of breastfeeding).

- Discuss the need for child spacing including the benefits to the parents, children and society. Discuss sterilisation and where this service is available.

- Give information and encourage discussion about resumption of sexual relations after birth and protected sexual relations.

- Warn clients that if they have not delivered by 41 weeks, one week after expected delivery date, they should report to hospital for medical opinion.

- Educate the mothers and their companions about the need to stay in the delivery facility for six hours for rest and observation, as well as support for infant feeding. Mother should bring a snack for themselves postdelivery.

- Preparation at the homestead, eg sibling preparedness, preparation of partner, preparation of environment like clothes, supply of clean water if she has chosen to formula-feed.

- Importance of postnatal care and child health services, where the service is available, what services to expect.

- Inform the clients about the need to obtain an Identity Document for the registration of the child, child care grants, etc. 
Individual counselling (Use every opportunity to provide information during the examination and history taking activities.)

- Clarify the progress of the pregnancy, the results of the tests done and management prescribed.

- Discuss the family's emergency plan, especially transport.

- Ask about the client's readiness for the birth.

- If HIV-positive, clarify infant feeding choices, reinforce when to take the medication if on ARVs to continue medication. Educate about the need for any infections to be treated quickly.

- Need for protected sexual intercourse to protect the baby during pregnancy and breastfeeding (all women need this information).

- Commence discussion of contraceptive methods for the postpartum period and need for child spacing.

- Ensure that the women know how to use the kick chart count and foetal movement count. Partners or companions can assist.

- Give a date for the next appointment: 39 to 40 weeks.

- GIVE EVERY CLIENT AN OPPORTUNITY TO ASK QUESTIONS, ANSWER HONESTLY.

\section{Risk assessment}

Determine eligibility for midwifery care: Assess risks from all previous visits and this visit.

\begin{tabular}{|c|c|}
\hline Risk factors & Action and referral \\
\hline $\begin{array}{l}\text { Age: } \\
>\quad \text { less than } 16 \text { years } \\
>\quad \text { elderly primi gravida (over age of } 40 \\
\text { years) }\end{array}$ & $\begin{array}{l}\text { Refer to next high-risk clinic, counsel woman and family } \\
\text { about delivering in hospital. } \\
\text { - Refer to next high-risk clinic, counsel woman and family } \\
\text { about delivering in hospital. }\end{array}$ \\
\hline 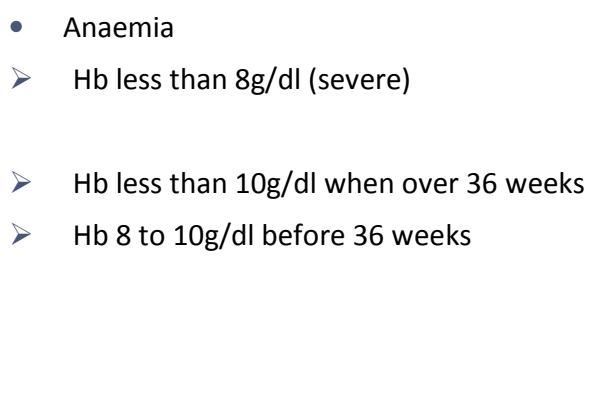 & $\begin{array}{l}\text { - Refer immediately to high-risk clinic at stage of pregnancy. } \\
\text { - Take full blood count } \\
\text { - } \text { Refer to next high-risk clinic; take full blood count } \\
\text { blood count, and } \\
\text { - give a repeat visit in one week for Haemoglobin to be } \\
\text { checked again. If not improved, refer to next high-risk clinic. }\end{array}$ \\
\hline - Antenatal haemorrhage & $\begin{array}{l}\text { Stabilise or resuscitate the woman according to the National } \\
\text { Maternity Guidelines, check status of foetus, Refer as an } \\
\text { emergency. }\end{array}$ \\
\hline
\end{tabular}




\begin{tabular}{|c|c|}
\hline Risk factors & Action and referral \\
\hline $\begin{array}{l}\text { - Bad obstetric history: previous still birth, } \\
\text { previous assisted birth, previous } \\
\text { caesarean, }\end{array}$ & $\begin{array}{l}\text { Refer to next high-risk clinic, or advanced midwife counsel } \\
\text { woman and family about delivering in hospital. }\end{array}$ \\
\hline $\begin{array}{l}\text { Big baby at } 36 \text { to } 38 \text { weeks, suspect } \\
\text { cephlo-pelvic disproportion, especially in } \\
\text { first pregnancy. }\end{array}$ & $\begin{array}{l}\text { - Undertake pelvic assessment. } \\
\text { Refer to next high-risk clinic or advanced midwife, counsel } \\
\text { woman and family about delivering in the hospital. }\end{array}$ \\
\hline - Breech or any other mal-presentation & $\begin{array}{l}\text { Refer to next High-risk clinic, counsel woman and family } \\
\text { about delivering in hospital. }\end{array}$ \\
\hline $\begin{array}{l}\text { Cardiac disease or any signs of cardiac } \\
\text { diseases. }\end{array}$ & $\begin{array}{l}\text { - Assess general health status. If condition is serious or } \\
\text { deteriorating, refer urgently. }\end{array}$ \\
\hline $\begin{array}{l}\text { Diabetes, or random blood sugar over } \\
\text { ten }\end{array}$ & $\begin{array}{l}\text { - Refer to next high-risk clinic to continuation of care and } \\
\text { hospital delivery (from } 36 \text { weeks of pregnancy). }\end{array}$ \\
\hline $\begin{array}{l}\text { - Eclampsia, imminent or severe } \\
\text { eclampsia. }\end{array}$ & $\begin{array}{l}\text { Stabilise or resuscitate according to National Maternity } \\
\text { Guidelines, arrange for emergency admission to hospital and } \\
\text { EMRS transport of appropriate level. }\end{array}$ \\
\hline - Grande multiple & $\begin{array}{l}\text { Refer to next high-risk clinic at } 34 \text { weeks, counsel about } \\
\text { delivering in hospital, counsel about health risks to herself } \\
\text { and subsequent babies if more pregnancy crisis anticipated } \\
\text { educate and counsel the women and her partner, if available, } \\
\text { about sterilisation and where this is available make } \\
\text { arrangements for post-partum sterilisation if mother } \\
\text { consents. }\end{array}$ \\
\hline
\end{tabular}




\subsubsection{Guidelines for the fifth visit: 39 to $\mathbf{4 0}$ weeks}

NB This visit will not occur in most pregnancies as the baby will have been born already. In KwaZulu-Natal, a higher than expected rate of babies weighing over $2,5 \mathrm{kgs}$ are stillborn, many of these babies are post-mature. Every woman must be educated to come to a health facility if the birth has not occurred by 41 weeks.

$>\quad$ At this visit it is important to revisit the expected date of delivery. Re-calculate to ensure that it is as accurate as possible.

$\quad$ Check carefully for signs of pre-eclampsia.

$\quad$ Check the family's birth preparedness and emergency plan.

Undertake all contained in the "Every Antenatal Visit Schedule"

\section{History}

\section{Review history by ASKING:}

Personal medical history

- Review all previous history consider any chronic conditions that may be worsen by pregnancy.

- Confirm that a HIV test has been done. Ask the client if she has been able to share the results with her partner, family or significant other; ask about her knowledge of the PMTCT interventions, correct any misunderstandings.

- Ask about new health problems, including any injuries, note any sick leave, hospitalisation, medication since last visit.

- $\quad$ Re-identify all medication being taken; use this opportunity to motivate the client to take the iron and folic acid, and continue other medications eg TB, epileptic. Ask about Traditional Medications being taken.

Past obstetric history: note any conditions that indicate that a hospital delivery should be planned, eg previous caesarean, previous assisted delivery.

\section{Current pregnancy}

- Check the results of all tests, check that no results are outstanding, especially haemoglobin, CD4 count, full blood counts, syphilis test (RPR), rhesus test.

- Carefully review expected date of delivery and gestational age, re-calculate and record.

- $\quad$ Ask about foetal movements. Use the sonic aid if they are diminished or have ceased.

- Ask about any notable changes since the last visit, especially vaginal bleeding, painful contractions, liquor draining, severe or persistent headaches, blurred vision, severe or persistent diarrhoea. Refer urgently if any of these signs are present.

- Ask client and companion about any noted body changes, especially changes in physical capacity, breathlessness, and oedema. If oedema present check for other signs of pre-eclampsia. 
Routine examinations

Do not forget to clinically stage all women who have tested HIV-positive and to check all women for signs of TB and STIs

General

- Check for signs of jaundice, oedema, anaemia, swollen lymph glands, breathlessness, bruising and injury that may indicate domestic violence.

- Observe mental state, ask about preparation for the baby, family preparedness for new baby.

- $\quad$ Ask about symptoms of TB, HIV, sexually transmitted infections and severe eclampsia.

> Common signs of HIV infection: Fatigue, night sweats, difficulty swallowing, persistent diarrhoea, dyspnoea, severe headaches, enlarged lymph nodes.

$>$ Common signs of TB: Cough for longer than two weeks, production of sputum (maybe blood stained), breathlessness, chest pain, loss of weight and appetite, malaise and tiredness, night sweats and fever, enlarged lymph nodes.

$>$ Sexually transmitted infections: Ask about: vaginal discharge/dysuria/vulval itch or burning, lower abdominal pain, genital sores swollen lymph nodes in the femoral or inguinal areas.

$>$ Eclampsia: Ask about: severe or persistent frontal headaches, visual disturbances, epigastric pain or discomfort, nausea or vomiting, widespread oedema, especially oedema of the face.

Measure and record:

1. Weight

2. Blood pressure: use the correct cuff especially for obese women, If raised take two readings ten minutes apart

3. Pulse: take the pulse for at least one minute.
Findings considered abnormal: Use these to make decisions about care. Check these against the "Eligibility criteria for midwifery care".

1. Decrease of weight, little or no weight gain or excessive weight gain. Actively look for oedema.

2. Readings above $140 / 90 \mathrm{~mm} \mathrm{Hg}$ or increase in the DBP or SBP by 20 or more since the third visit.

3. Any arrhythmia or a pulse of $\mathbf{1 0 0}$ or more is considered abnormal. Listen to Appex heartbeat with a stethoscope for a minute. 


\section{Physical examination: \\ General systems: focus \\ examination according to \\ problems noted from \\ history and previous visits. \\ Obstetrical examination: \\ - Abdominal \\ examination: \\ inspection, palpation, \\ symphosis-pubis to \\ fundal height, \\ auscultation for foetal \\ heart rate.}

Determine the foetal lie

- Vulvo-vaginal and cervical examination: DO NOT UNDERTAKE vaginal examination if any vaginal bleeding is reported or observed.

Do a pelvic assessment at this visit if this is a first delivery, or a large baby, or if any suspect of cephalo-pelvic disproportion.
Uterus larger or smaller than expected for the expected date of delivery: recheck dates, consider a multiple pregnancy. And refer for opinion.

Discrepancy of symphosis: pubis and fundal height with expected date of delivery may indicate multiple pregnancy or big foetus. Both need to be referred.

Excess or diminished liquor: refer to next high-risk clinic, counsel woman and family to plan for a hospital delivery.

Tender uterus or other abdominal pain, refer urgently to district hospital.

Foetal heart not heard, check with sonic-aid. If available, do CTG to confirm. Refer to next high-risk clinic.

Abnormal foetal lie should be referred, and counsel woman and family to plan for a hospital delivery.

Look for any lesions, sores, discharges: treat sexually transmitted infections as per protocol, ensure counselling about partner notification and condom use.

Vaginal bleeding: refer immediately to doctor or advanced midwife.

If contract pelvis is suspected refer to advanced midwife or doctor, for decision about place of delivery. 


\section{Screening tests}

\begin{tabular}{|c|c|}
\hline $\begin{array}{l}\text { Urine: must be clean fresh } \\
\text { specimen }\end{array}$ & $\begin{array}{l}\text { - Protein present: check for urinary tract infection, check for other signs of pre- } \\
\text { eclampsia. } \\
\text { - Glucose present: do random blood sugar using heamoglobinometer, if above ten } \\
\text { - Nitrites and leucocytes present: send mid-stream urine specimen for micro- } \\
\text { culture and sensitivity: manage according to Essential Drug List } \\
\text { - If signs of urinary tract infection are severe, eg fever, pain on micurination. } \\
\text { - Check for signs of preterm labour and refer immediately. }\end{array}$ \\
\hline $\begin{array}{l}\text { Blood tests: } \\
\text { HIV testing after } \\
\text { counselling if this has } \\
\text { not been done before } \\
\text { or it is three months } \\
\text { after first test. }\end{array}$ & $\begin{array}{l}\text { - If HIV-negative, counsel about protected sex relations during pregnancy and } \\
\text { breastfeeding to protect the baby. }\end{array}$ \\
\hline $\begin{array}{l}\text { If HIV-positive, check } \\
\text { when last CD4 count } \\
\text { was done, if } 6 \text { months } \\
\text { ago redo at this visit. }\end{array}$ & $\begin{array}{l}\text { If positive commence PMTCT regime, explaining the use of medication to } \\
\text { protect baby, counsel about choices of infant feeding. Take a CD4 count, and } \\
\text { commence preparation counselling for ARVs. } \\
\text { Counsel for disclosure to partner, family or significant other to ensure support } \\
\text { in labour, and for infant feeding choices. } \\
\text { If CD4 count: } \\
\checkmark \text { Is low, inform facility where delivery will take place, ensure the details are } \\
\text { entered on the antenatal card. These women should deliver in a hospital. } \\
\text { Commence ARV literacy counselling if possible. } \\
\checkmark \text { More than 200c/mm3, continue with antenatal care and PMTCT protocols at } \\
\text { clinic. }\end{array}$ \\
\hline
\end{tabular}

\section{Interventions}

- Check compliance with iron and folic acid, check haemoglobin and adjust dosage, give sufficient supply until next visit.

- Continue with food supplements, if required.

- If HIV-positive, check when the last CD4 count was done. If it was done six months ago, do again. Ask the client if she has been able to share her status with a family member, partner or significant other. Ask her about the PMTCT medication given to her review her understanding of how to take the medication.

- Check eligibility for midwifery care, and refer to high-risk clinic if indicated. 


\section{Education and counselling}

\section{Group education (Include partners/birth companions in this education session)}

Explain the benefits of knowing one's HIV status to protect the unborn baby, the need for protected sexual intercourse during pregnancy and breastfeeding. Outline the PMTCT intervention and access to ARVs for pregnant women and babies.

- $\quad$ Reinforce all messages from previous visits: especially signs of premature labour, ante-partum haemorrhage (APH), danger signs in pregnancy.

- $\quad$ Emergency preparedness for family, birth preparedness: preparation for labour, birth companionship.

- Importance of rest for mother to ensure baby growth especially in this last part of the pregnancy.

- Discuss with group the importance of breast feeding, putting the baby to breast as soon as after delivery as possible (remember that HIV-positive need mother to be supported in their choice of breastfeeding).

- Discuss the need for child spacing including the benefits to the parents, children and society. Discuss sterilisation and where this service is available.

- Give information and encourage discussion about resumption of sexual relations after birth and protected sexual relations.

- Warn clients that if they have not delivered by 41 weeks, one week after expected date of delivery, they should report to hospital for medical opinion.

- $\quad$ Educate the mothers and their companions about the need to stay in the delivery facility for six hours for rest and observation, as well as support for infant feeding. Mother should provide themselves with a snack post delivery

- $\quad$ Preparation at the homestead, eg sibling preparedness, preparation of partner, preparation of environment eg clothes, supply of clean water if she has chosen to formula-feed.

- Importance of postnatal care and child health services, where the service is available, services to expect.

- Inform the clients about the need to obtain an Identity document for the registration of the child, child care grants, etc.

Individual counselling (Use every opportunity to provide information during the examination and history taking activities.)

- Clarify the progress of the pregnancy, the results of the tests done and management prescribed.

- Discuss the family emergency plan, especially transport.

- Ask about the client's readiness for the birth.

- If HIV-positive, clarify infant feeding choices, reinforce when to take the medication if on ARVs to continue medication. Educate about the need for any infections to be treated quickly.

- Need for protected sexual intercourse to protect the baby during pregnancy and breastfeeding (all women need this information).

- Commence discussion of contraceptive methods for the post partum period and need for child spacing.

- Ensure that the women know how to use the kick chart count and foetal movement count. Partners or companions can assist.

- $\quad$ Give a date for the next appointment.

- $\quad$ GIVE EVERY CLIENT AN OPPORTUNITY TO ASK QUESTIONS. ANSWER HONESTLY. 


\section{Risk assessment}

Determine eligibility for midwifery care: Assess risks from all previous visits and this visit.

\begin{tabular}{|c|c|}
\hline Risk factors & Action and referral \\
\hline $\begin{array}{l}\text { Age: } \\
>\text { less than } 16 \text { years } \\
>\text { elderly primi gravida (over age of } 40 \\
\text { years) }\end{array}$ & $\begin{array}{l}\text { Refer to next high-risk clinic, counsel woman and family about } \\
\text { delivering in hospital. } \\
\text { Refer to next high-risk clinic, counsel woman and family about } \\
\text { delivering in hospital. }\end{array}$ \\
\hline $\begin{array}{l}\text { Anaemia } \\
>\quad \mathrm{Hb} \text { less than } 8 \mathrm{~g} / \mathrm{dl} \text { (severe) } \\
>\quad \mathrm{Hb} \text { less than } 10 \mathrm{~g} / \mathrm{dl} \text { when over } 36 \\
\text { weeks } \\
>\quad \mathrm{Hb} 8 \text { to } 10 \mathrm{~g} / \mathrm{dl} \text { before } 36 \text { weeks }\end{array}$ & $\begin{array}{l}\text { Refer immediately to high-risk clinic at stage of pregnancy; take } \\
\text { full blood count. } \\
\text { Refer to next high-risk clinic; take full blood count. } \\
\text { check compliance with the iron and folic acid, take a full blood } \\
\text { count, and give a repeat visit in one week for haemoglobin to be } \\
\text { checked again. If not improved, refer to next high-risk clinic }\end{array}$ \\
\hline - Antenatal haemorrhage & $\begin{array}{l}\text { Stabilise/resuscitate the woman according to the National } \\
\text { Maternity Guidelines, check status of foetus, and refer as an } \\
\text { Emergency. }\end{array}$ \\
\hline $\begin{array}{l}\text { Bad obstetric history: previous still } \\
\text { birth, previous assisted birth, } \\
\text { previous caesarean. }\end{array}$ & $\begin{array}{l}\text { Refer to next High-risk clinic, or advanced midwife counsel } \\
\text { woman and family about delivering in hospital. }\end{array}$ \\
\hline $\begin{array}{l}\text { Big baby at } 36 \text { to } 38 \text { weeks, suspect } \\
\text { cephalo-pelvic disproportion, } \\
\text { especially in first pregnancy. }\end{array}$ & $\begin{array}{l}\text { - Undertake pelvic assessment } \\
\text { - Refer to next high-risk clinic or advanced midwife, counsel } \\
\text { woman and family about delivering in hospital. }\end{array}$ \\
\hline - Breech or any other mal-presentation & $\begin{array}{l}\text { Refer to next high-risk clinic, counsel woman and family about } \\
\text { delivering in hospital. }\end{array}$ \\
\hline $\begin{array}{l}\text { - Cardiac disease or any signs of } \\
\text { cardiac diseases. }\end{array}$ & $\begin{array}{l}\text { - Assess general health status, if condition is serious or } \\
\text { deteriorating, refer urgently. }\end{array}$ \\
\hline $\begin{array}{l}\text { Diabetes, or random blood sugar } \\
\text { over ten }\end{array}$ & $\begin{array}{l}\text { Refer to next high-risk clinic to continuation of care and hospital } \\
\text { delivery. (From } 36 \text { weeks of pregnancy) }\end{array}$ \\
\hline $\begin{array}{l}\text { - Eclampsia, imminent or severe } \\
\text { eclampsia. }\end{array}$ & $\begin{array}{l}\text { - Stabilise/resuscitate according to National Maternity Guidelines, } \\
\text { arrange for emergency admission to hospital and EMRS } \\
\text { Transport of appropriate level. }\end{array}$ \\
\hline - Grande multiple & $\begin{array}{l}\text { Refer to next high-risk clinic at } 34 \text { weeks, counsel about } \\
\text { delivering in hospital, counsel about health risks to her self and } \\
\text { subsequent babies if more pregnancy crisis anticipated, educate } \\
\text { and counsel the women and her partner, if available, about } \\
\text { sterilisation and where this is available make arrangements for } \\
\text { postpartum sterilisation if mother consents. }\end{array}$ \\
\hline
\end{tabular}




\subsection{Postnatal care}

Many maternal deaths are occurring during the postnatal period and the neonatal mortality rate (NMR) of babies is unacceptably high in KwaZulu-Natal. This policy and guidelines seeks to establish the postnatal care system, with the goals of:

- $\quad$ Reducing maternal deaths through improved care at household and facility level

- $\quad$ Reducing neonatal deaths

- $\quad$ Supporting breast feeding

- $\quad$ Providing follow up care for HIV-positive women and HIV-exposed babies

- $\quad$ Reducing mother to child transmission of HIV infection during breast feeding

- Provide health information to ensure self care, child spacing, health services and basic child care

- Ensuring a continuum of care for the mother and child

\section{KZN guidelines: Postnatal criteria for discharge six hours after delivery}

PLEASE NOTE: All women should be retained in the facility to rest and for observation for at least six hours. Only in exceptional cases should this be reduced. Where there are any risk factors, in either the mother and/or their baby should be retained until there is a either an advanced midwife or medical officer to check the medical and obstetric condition of the baby and/or mother before discharge.

The first postnatal visit will ensure:

- Bleeding is controlled and the uterus remains contracted, in the first phase of the postnatal period.

- $\quad$ Any Hypertension is identified and referred for medical attention.

- $\quad$ Rest for the mother.

- Bonding can be encouraged.

- Breastfeeding assistance can be given. Attachment and positioning corrected. HIV-positive women who have chosen to formula feed are given education on preparation of feeds, hygiene and amounts of formula to give baby.

- Women can be educated about personal hygiene, especially vulva hygiene and what physical and emotional changes to expect during the postnatal period.

- Education about postnatal visits and why these visits are important.

- Documentation on the child's Road to Health Card and referral to well child clinic.

- Antiviral medication is delivered to HIV-exposed babies 
Routine postnatal visits need to be targeted at the following times:

Six hours after delivery

Within six days after delivery

Six weeks after delivery

The guidelines below outline care for women and their babies where there are no complicating factors

\subsubsection{First postnatal visit: six hours post-delivery}

\section{This visit takes place before discharge}

PLEASE NOTE: All women should be retained in the facility to rest and for observation for at least six hours. Only in exceptional cases should this be reduced. Only normal deliveries and where there are no risk factors for the mother or baby should be considered for discharge so soon after delivery. Where there are any risk factors, in either the mother and/or their babies should be retained until there is either an advanced midwife or medical officer to check the medical and obstetric condition of the baby and mother before discharge.

The first postnatal visit will ensure:

- Bleeding is controlled and the uterus remains contracted, in the first phase of the postnatal period.

- $\quad$ Any hypertension is identified and referred for medical attention.

- $\quad$ Rest for the mother.

- Bonding can be encouraged.

- Breastfeeding assistance can be given. Attachment and positioning corrected.

- Complete treatment for sexually transmitted infection such as syphilis.

- HIV-positive women who have chosen to formula-feed are given education on preparation of feeds, hygiene and amounts of formula to give baby.

- Antiretroviral medication is prescribed and administered to HIV-exposed babies.

- Women can be educated about personal hygiene, especially vulva hygiene and what physical and emotional changes to expect during the period and potential danger signs.

- Education about postnatal visits and why they are important.

- Documentation on the child's Road to Health Card and referral to Well Care Clinic. 
First

- Greet the mother and her companion; congratulate the family on the birth of the child.

- $\quad$ Ensure that personal details are correct. Check against the baby's band

- Explain all maternal and neonatal examinations, test and procedure and medication given.

\section{Review}

- Review the antenatal card for risk factors; consider those that may impact of the baby's health eg substance abuse. Ask again; if there were any problems during pregnancy.

- Review maternity record for any risk factors: eg excessive blood loss, hypertension, low APGAR score, prolonged labour infection.

- Review post delivery observations consider any increases, especially in blood pressure, pulse and temperature in the mother, or abnormalities.

- Review the results of the examination of the newborn,

- Review if the mother was HIV tested. If not, discuss why this should occur before discharge.

- $\quad$ For the mothers who are HIV-positive:

$\Rightarrow \quad$ Review if CD4 count has been done in the previous six months. If not prepare the mother to have this test before discharge

ASK

$$
\begin{aligned}
& \Rightarrow \quad \text { Ask if the mother has passed urine normally. If not, ask her to empty her bladder before } \\
& \text { examination. No mother should be discharged before passing urine. } \\
& \Rightarrow \quad \text { Ask if the baby passed urine and/or stool. Tell mother about the colour of the first stools } \\
& \Rightarrow \quad \text { Ask if the baby has fed from the breast if the mother has chosen to breastfed. }
\end{aligned}
$$

If not breastfeeding, ask the mother if she has attended a demonstration of how to make the formula, ask if she is clear about the appropriate amounts to make up for each feed, hygiene, and storage. Ask this in a way that assesses knowledge ie open-ended questions, NOT questions that require YES or NO answers. 
Undertake the following examinations and observations

Mother

1. If the mother had not attended antenatal care clinic then do a full first antenatal visit, including all the blood test, i.e. haemoglobin, HIV (after counselling) or CD4 count, syphilis.

2. Blood pressure, pulse and temperature: any rise should caution against early discharge, it is preferred that discharge is delayed a further six hours for observations. Repeat these observations in an hour, unless the increase in the blood pressure is above $140 / 90$ or any increase of over $20 \mathrm{mmHg}$, and/or pulse is above 90 beats per minute, then manage according to National Maternity Guidelines and local protocols, and refer for medical intervention

3. Look for signs which must delay or modify discharge eg anaemia under $8 \mathrm{mmlu}$, signs of cardiac disease, or infection.

4. Check breast for any infection of nipples, and explain care of breast.

5. Gently palpate for full bladder. If full bladder found, ask mother to empty her bladder. If she not able to empty bladder, refer.

6. Gently examine for the contraction of the uterus, demonstrate to the mother and her companion how to "rub up" the uterus to contract. Consider: does the uterus remain contracted, if not, defer the discharge for at least two hours; check again for a full bladder and whether the mother is able to pass urine satisfactorily. Check blood loss.

7. In a private setting, examine the vulva area, look for any swelling or haematomas, and check for tear, check for sutures. Delay discharge where there are swelling or tear, seek advance midwifery or medical officers advice.

8. Consider the flow of blood from the vagina, if there is excessive loss post delivery or now: defer discharge for at least another six hours to monitor bleeding. Consult Maternity Guidelines and/or local protocols for repeat doses of ergometrine/ syntocinon/ syntometrine, or referral to advanced midwifery or doctor.

9. Re-check the nutritional status of the mother, use nutritional guidelines for assessment and supplementation for pregnant and lactating women.

10. If mother is HIV-positive undertake the WHO clinical staging assessment and refer as required according to condition. Consider the CD4 count. If very low consider deferring the discharge.

11. Mental health status: should be normal, note depressed mood or abnormal behaviour and refer for assessment if any doubt. 
1. Recheck the examination of the newborn was done and was clear before discharge. It is best to examine the baby in the presence of the mother.

2. Check the body temperature of the baby. Defer discharge for six hours if the baby is cold. "Kangaroo" the baby with the mother to warm baby.

3. Observe the colour (including the tongue), the baby should be an even colour and the tongue and lips pink.

4. Observe the respiration: it should be quiet, with no rib recession or flaring of nostrils. The respiration rate should be within 50 to 60 (count or a full minute, young babies breath at unequal rate). Check that the chest movement is symmetrical.

5. Observe the movement of the baby for about a minute: Note any floppiness, irritability or jerk movements: if present, check the baby's blood glucose, and retaine the mother and baby for observation or intervention considering the condition.

6. Note the posture of the baby; it should be relaxed with flexed limbs.

7. Counts the heart rate, listen to the rhythm and rate (normal 120 to 150 beats per minute), refer immediately, if any abnormality is noted.

8. Check that the cord clamp is secure, re-clamp if required.

9. Check for any concerns noted post-delivery or from the mother.

10. It is preferable to observe a breastfeed. Observe according to IMCl guidelines over four minutes; correct any attachments and positioning problems.

11. Measure and record (on road health card) the head circumference, length and weight if this was not done at the antenatal or birth complications. Check the mother's HIV status is encoded on the baby's Road to Health card.

Treatment: Mother

Ensure mother has sufficient medication/supplements until next appointment.

- Continue with any routine treatment: asthma control treatment, daily TB medication, ARVs epileptic treatment.

- Check whether any treatment for sexually transmitted infections, including syphilis, has been commenced and need to be completed. Explain to mother any further treatment that is required and where to access medical help, if symptoms do not resolve.

- Continue iron and folic acid if there has been any anaemia during pregnancy, or if there was a heavy blood loss after delivery or and if the mother is breastfeeding. Ensure that the mother has sufficient supply for at least one month.

- $\quad$ For HIV-positive mother: supplement with iron and multivitamins (for 12 months), prescribe cotrimoxazole daily for the mother for life. 
- Although it is not recommended that mothers are given contraception at this early stage, individual counselling and assessment of the situation must be done. Contraception should NOT be denied if the mother wishes to commence at this time. Consider sterilisation.

- Give mother the postnatal vitamin A if this has not been done. Ensure that the doses are entered onto the data collection sheet.

- $\quad$ Give tetanus toxoid (TT3) dose, if not given and if six months after TT2; if not due now tell the mother when it is due and clearly write the date on the mother's carrier card.

- If the mother is Rhesus D negative, and she is NOT sensitised (no Rhesus antibodies), give anti-D immunoglobulin 100mcg IMI before discharge. Explain that this will protect the next pregnancy. (Mothers who are Rhesus D-negative should deliver in hospital )

- Women who are Para 2 or more may experience "after birth pains", explain the cause and prescribe a mild analgesic eg paracetamol or ibuprofen two tablets six hourly for three to four days.

Treatment: Baby

- $\quad$ Check the vitamin $\mathrm{K}$ was given after birth.

- $\quad$ Give BCG and Polio 0 dose before the baby leaves the facility.

- If HIV-exposed, prescribe the routine antiretroviral regime (PMTC protocols) used to prevent mother to child transmission. Plus commence vitamin supplementation (until a negative HIV test for child is recorded).

- Check mother syphilis results, and whether the baby should have treatment as per sexually transmitted infection protocols.

- If the mother has active TB and breastfeeding baby, give the baby the current prophylaxis according to the current TB protocols.

\section{Education and counselling}

Small group education is appropriate for some information. Trained staff enrolled nursing assistants can cope well with doing some education areas in small groups.

Provide counselling and education suitable for small group education

Emotional and physical changes, especially changes to lochia to be expected. Make sure each woman understands that lochia should not be profuse or foul smelling, these are danger signs and she must return to health facility as soon as possible.

- Contraception and the need for child spacing. Where services are available closest to where the family lives must be indicated.

- Commencement of sexual relations: explain the mother's body needs time to heal. It is best to explain this to her male partner as well. 
- Safer sexual practises and the use of condoms, especially while the mother is breast feeding. Discuss sexually transmitted infections, including HIV infection.

- The benefits of breastfeeding, and common problems experienced and the solutions during breastfeeding.

- Education to mothers about mastitis, the prevention and signs.

- Mothers who are formula-feeding must attend a demonstration on formula-feed preparation before discharge and practise cup feeding. Formula amounts, hygiene, storage and safety must be discussed with the mother and partner if possible.

- Demonstrate cord care, eye cleaning and bathing of baby.

- Danger signs for herself (postnatal signs) and her baby (IMCl general danger signs) that indicate when she should immediately come to a health facility.

- Need for postnatal visit within six days and six weeks post delivery, where to obtain this service and what to expect or ask for to ensure that she and her baby remains healthy.

- Well baby services in the area where she lives, what services to expect, including immunisation growth monitoring and feeding advice and the importance and use of the Road to Health card.

- Give information on where to register the birth and safe keeping of the birth certificate.

- Educate women about after-birth pains and how to manage the pain, and that it should not last longer than three days. Pain that continues must be investigated.

\section{Individual counselling and education topics}

- Discuss sterilisation individually with all women who feel their families are complete, women over 35 years and women who are Para 4. Ensure that the mother knows where this service is available. Assist her to access the service.

- Breastfeeding exclusively or formula feeding exclusively, Educate HIV-positive mothers who have chosen to formula-feed.

- If baby has not passed urine or meconium and all else is normal; ask the mother to observe when these occur and to come back immediately, if urine and stool is not passed in 24 hours.

- $\quad$ For mothers who are HIV-positive, remind them about six monthly CD4 counts for themselves and PCR test for baby at six weeks, as well as cotrimoxazole for herself for file, and for the baby from six weeks age until the baby tests negative.

- $\quad$ Reinforce the vulval hygiene principles with HIV-positive women, as well as the danger signs of temperature and offensive lochia.

Criteria for discharge: Assess carefully using all the observations and previous information from the antenatal and maternity record and your complete midwifery skills.

Use your discretion and judgement, rather act on the side of caution than jeopardise a life.

If any of the following occurred, consider delaying the discharge and getting the opinion of an advanced midwife or doctor. 
First consider all antenatal risk factors

- Presence of oedema, increase in blood pressure or pulse in the mother, mother complains of severe headaches or visual disturbances.

- Low haemoglobin in pregnancy.

- Excessive loss of blood during delivery, post delivery or now, or uterus does not remain contracted.

- $\quad$ Presence of temperature in either the mother or baby, low temperature of the baby.

- Deliveries that were prolonged or not normal vertex deliveries.

- Placenta - abnormal weight and appearance.

- Mother experiencing difficulty in passing urine, or any undue swelling or haematoma of vulva.

- Any abnormal observation of the baby: eg respiration, excessive moulding, cleft lip, poor colour or temperature, rapid heart beat.

- Baby that is not attaching to breast well, or not suckling well from breast.

- If the mother is not breast feeding, and she is not coping with formula preparation or cup feeding

- $\quad$ APGAR score $<7$ - with resuscitation needed

- $\quad$ Birth weight $<2000 \mathrm{~g}$

- If the mother is HIV-positive and has a low CD4 count, especially if she has not commenced ARVs as yet, rather rest these mothers for at least 48 hours and ensure strict hygiene to limit infection of the placental site or episiotomy; commence ARV literacy counselling as soon as possible, even before discharge.

Record

$\Rightarrow \quad$ Correct information on the Road to Health card and discharge form; plot the baby's birth weight, record the APGAR score, type of delivery, encode mother's HIV status on to the card, record immunisation and any medication given (eg antiretroviral medication).

$\Rightarrow \quad$ All prescriptions must be entered in a legal manner, full generic drug name, dated, signed, dosage, frequency.

$\Rightarrow \quad$ Write all findings on discharge in the maternity record, which will be kept at the facility.

$\Rightarrow \quad$ Enter details onto the mother's personal carrier card to ensure continuity of care, especially any medical concerns, contraception, HIV-related care (eg CD4 or when this is next due) and incomplete syphilis treatment.

$\Rightarrow \quad$ Provide the documentation for the registration of the birth.

\section{ALL WOMEN NEED CARE ON DISCHARGE WHETHER THE DISCHARGE IS DELAYED OR NOT.}




\subsubsection{The visit before the sixth day post-delivery}

With the introduction of this policy this visit is to become routine in all women.

Deaths among postnatal women in Kwazulu-Natal are increasing, and many complications with feeding and care of the baby occur in this period. It is best that all women know there this care can be obtained and what to expect, so as to request appropriate care.

\section{Ensure the following:}

- The nursing practitioner must introduce her/himself.

- Privacy, ask if the mother would like her companion to be with her during the interview and examination of the baby.

- Greet the mother and her companion; congratulate the family on the birth of the child.

- Explain all maternal and neonatal examination, tests and procedures and medication given.

- Maintain observation of the mother and baby through the consultation and examination, the relationship between the mother and baby can be assessed in this manner, as well as any obvious mental illness noted in the mother

Review history and records

- Review the antenatal, birth and postnatal history from the mother for the risk factors. Show an interest in the history the mother provides, this also gives insight into the perceptions of the mother and her understanding of health issues.

- Check all the details on the mother's carrier card provided on discharge. Look for information about ongoing medical treatment, eg TB, epilepsy, psychiatric disorder, ARVs, asthma, etc.

- Check that treatment for syphilis has been completed, the three doses of tetanus toxoid are completed (or when the baby's Road to Health card, decode the HIV information on the baby's card, explaining to mother why the information is vital for the baby's continued care at the clinic.

- Check whether immunisation was given to baby and vitamin A given to mother.

- Check mother's nutritional status in pregnancy and whether she was receiving food supplements, continue these if lactating, or if circumstances and clinical condition warrant the supplements.

- Review the record for any neonatal abnormality or genetic history of family; refer for counseling and testing if required. 
If the baby was born at home

- If mother is known HIV-positive and has chosen to formula-feed prescribe the formula-feed, and educate the mother on the formula preparation, amounts for feed, storage, cup feeding and hygiene.

- $\quad$ Give immunisations BCG and polio 0 (only give polio if before 14 days of age, as soon as to delay the polio 1 ).

- $\quad$ Ensure that the baby and mother have a full physical examination, including blood tests.

- Give the maternal dose of vitamin A to the mother.

- $\quad$ Offer HIV testing if this has not been undertaken.

ASK:

- If there are any changes in the mother or baby's health since discharge eg visit to local GP or health services. If problems were experienced - treatment given and medication prescribed, or visit to Traditional Health Practitioner.

- $\quad$ Ask about any problems the mother has experienced since discharged.

- $\quad$ Ask the mother specifically about:

- Lochia: amount, colour and offensive smell.

- Breasts especially nipples or pain or swelling,

- Pain or burning on passing urine, test urine for leucocytes and nitrates, treat for urinary tract infection.

- Genital: pain, swelling or discomfort. If sexual activity has commenced, ask about pain or discomfort.

- Problems in passing urine or stool.

- Coughing or any respiratory tract problems. Check all clients for TB at each visit.

- Undue depression or anxiety

- Relationship problems with spouse/partner or other children, give the mother an opportunity to talk about any adjustment problems.

ASK about the baby:

- $\quad$ Feeding of the baby according to choice, probe about exclusiveness of their breast or formula feeding in HIVpositive women; ask about amounts and times, challenges in making formula, etc.

- Baby's sleeping pattern, stools, wet napkins, vomiting, skin and cord.

- If HIV-positive, ask about the medication for the prevention of mother to child for the baby, and whether the mother has maintained the regime at home. Ask when the mother's next CD4 count is due. 
Mother

- Undertake the general examination of JACCOL (jaundice, anaemia, cynosis, clubbing of fingers, oedema and enlarged lymph nodes). These are serious signs except for anaemia; previous serious diagnosis and the mother must be referred urgently to hospital.

- Check the pulse and the temperature, if the temperature of above $37,5^{\circ} \mathrm{C}$ or pulse is above 90 per minute, undertake a full examination to identify the site of infection, refer if required.

- Check blood pressure if $>140 / 90 \mathrm{mmHg}$ or a rise in dystolic or systolic readings $>20 \mathrm{mmHg}$, rest the client and measure in ten minutes, if the blood pressure remains elevated refer to medical officer or advanced midwife.

- Observe respiration, note the rate: an increased rate could indicate infection, respiratory problems or anxiety. Refer as condition dictates.

- Examine breasts for any mastitis, cracked or infected nipples, or engorgement.

- Observe for any abnormal behavior, anxiety, disinterest in the baby or own health, expression of extreme sadness or despondence.

- Gently palpate the abdomen, check for fundus of uterus - it should be just above the symphosis pubis and there should be no tenderness. Lower abdominal pain is cause for concern. A soft bulky uterus may indicate an infection. Check any sutures.

- Examine the vulva area for swelling or infections, check any sutures, these should be dry and healing by this time.

- Check the amount and colour of lochia, note any offensive odour. Lochia should be scanty and non-offensive in smell. All infections of the vulva area or offensive lochia must be urgently referred. If lochia contains fresh blood, consider secondary postpartum haemorrhage and infection, and refer immediately.

- Check legs for deep vein thrombosis and oedema.

- Look for any skin rashes, especially bacterial or fungal infections. Treat appropriately.

- If HIV-positive; use WHO clinical staging to assess the mother. Consider CD4 count.

- Ask about ability to maintain safer sexual practices, recommend condoms and reassess for initiation of contraception if partner unco-operative.

Undertake the following observations and examinations

\section{Education and counselling}

\section{Group education}

- Benefits of family planning, including sterilisation.

- $\quad$ Cervical cancer screening.

- $\quad$ Safer sexual practises and protected intercourse, especially while breastfeeding. 
- Immunisation

- Infant feeding: benefits of exclusive breastfeeding.

- Child stimulation and safety.

- General danger signs in an ill child (IMCI) and the management of infant diarrhoea including the use of sugarsalt solution or home based fluids

- Birth registration.

- Protection of the Domestic Violence Act and post-exposure prophylaxis available to survivors of sexual assault.

- $\quad$ Remind mother that rest, extra kilojoules, fluid and protein are needed while breast feeding.

Topics for individual education

- Contraception and how the methods work, and the need for dual protection.

- Safer sexual practises and HIV testing, as well testing of baby if exposed and regular CD4 counts for mother.

- Crisis counselling and intervention in cases of social problems or domestic violence. Identification of safe places to escape to and action to take.

- Resumption of sexual intercourse, if this has not already occurred. Explaining any loss in libido, especially while breastfeeding. Counsel on prevention of dry painful sex.

- If HIV-positive, the need for either exclusive breast feeding or exclusive formula feeding.

- Schedule next visit in four weeks time, if all normal, otherwise according to need and health status.

Baby

- Observe feeding

$\Rightarrow \quad$ Breastfeed for four minutes, check attachment, and positioning as well as the suckling and mother's intent.

$\Rightarrow \quad$ Formula-feeding, check hygiene of cup (or bottle if in use). Observe cup feed

$\Rightarrow \quad$ Check the BCG site, and advise to keep dry and clean.

- $\quad$ Observe for jaundice; ask the mother if it is getting worse. Observe the baby for lethargy and ask about frequency of feeding. If lethargic and poor feeding refer immediately; otherwise check the jaundice in five days.

- Feel the fontanel, holding the baby at $45^{\circ}$ angle for fullness, if bulging or depressed, assess for any serious infection or reason for dehydration.

- Observe respiration, these should count from 50 to 70 per minute. The chest should be symmetrical, and there should be no signs of distress, eg flaring nostrils, or inter coastal rib recession. 
- Check cord site for any wetness or redness, treat accordingly, any redness extending from the site indicates an urgent referral.

- Check for any skin rashes (refer if many pustules are present), treat any nappy or fungal rash, advise on care as required.

- $\quad$ Check for any discharge from ears, if present refer.

Education and counselling suitable for individual counselling

- Safer sexual practises.

- Counselling for HIV testing if not recently tested, or if HIV-positive counsel mother for CD4 count testing.

- $\quad$ Formula-feeding using a cup, reinforcing mixing and hygiene principles.

- Use of contraception, or consideration of sterilisation if over 35 years, Para 4 or feels family is complete, or has a health problem that is worsened by pregnancy.

- Basic genetic counselling if family or individual has an identified problem.

- Counselling and referral about family problems, especially domestic violence. Finding women in violent domestic situations a safe place to be or find refuge when needed.

- Weigh the baby, most babies should have regained their birth weight, if the baby has not advise the mother to rest and demand feed if breastfeeding; if formula feeding: using open questions ask amounts, mixing etc. correct any misconceptions. Follow up in three days.

- Measure the head circumference, and compare with birth measurement, if greater than $3 \mathrm{~cm}$ refer:

- Observe posture of baby, this should be one of relaxed, flexion; observe the moror and rooting reflex, observe for any jitteriness or floppiness, if present check the blood sugar, provide supportive intervention and refer immediately.

- If the baby is awake, it should respond to the mother's voice.

\section{Screening tests}

- If the mother was not tested for HIV during pregnancy or after labour offer her testing at this visit. Ensure she knows the benefits of testing and knowing her status.

- If no antenatal care and was born at home, carry out all routine antenatal test: ie syphilis, HIV (after counselling), haemoglobin, Rhesus factor (although this is too late for an intervention the mother must be made aware).

- If the mother was anaemic during pregnancy or had a heavy blood loss during or post-delivery, a clinic based haemoglobin should be done, if less than $8 \mathrm{~g} / \mathrm{dl}$ refer; between $10 \mathrm{~g} / \mathrm{dl}$ and $8 \mathrm{~g} / \mathrm{dl}$ treat according to Essential Drug List. 
- If any signs of urinary tract infection test for protein, leucocytes and nitrites treat according to Essential drug List and follow up in ten days.

- If the mother is HIV-positive take CD4 count if the last one was taken more than six months ago.

\section{Education and counselling}

Many subjects can be addressed in small groups by a well-trained and mentored nursing assistant or staff nurse.

\section{Education and counselling suitable for small group sessions:}

- The benefits of exclusive breastfeeding.

- $\quad$ Signs of infection or serious illness in babies (IMCl danger signs)

- General baby care such as hand washing before feeding, care of the nappy area, suitable stimulation for age eg singing.

- $\quad$ Remind mother about birth registration.

- $\quad$ Schedule next visits for 5 weeks time ( 6 weeks after birth of baby) emphasising the need for the infant's growth to be monitored and to continue with immunisation.

- Educate the mother about simple pelvic floor exercises and the reason for doing these regularly for the next five weeks.

- Sexual and reproductive health:

- Reinforce education given on safer sexual practises. Condoms and conception.

- Family relationship such as sibling rivalry and coping mechanism, commencement of sexual relations, changing partnership with spouse/partner.

\subsubsection{KZN guidelines: six week postnatal clinic visit}

Low-risk mother and baby

All women and babies with risk factors should be examined by either an advanced midwife or medical officer at this visit, especially where long-term interventions may be required.

Ensure the following:

- $\quad$ Privacy for the mother and her companion if the mother wishes the companion to be present during the consultation. Examinations should not be done with the companion present.

- Greet client. The nurse practitioner must introduce herself by name.

- Ask the mother how she and her baby are, and if there are many problems. It is important to address the mothers concerns first to ensure good co-operation.

- Check the personal details of the family and mother according to the Carrier cards. 
Review

- Review the information on the carrier cards, ie mothers' and Road to Health cards. Note any presence of medical conditions in the mother or baby.

- $\quad$ Check details of the antenatal and birth with the mother, listen carefully to her history to clarify misconceptions and educate the mother. Review the information available from the six days postnatal visit.

- Decode the HIV status on the mother's and Road to Health Card; explain why it is necessary to obtain the information and why continuum of care is especially important.

ASK:

- Note any changes in the mothers or baby's health since discharge and the six days postnatal visit, eg visit to local GP or health services if experience problems - treatment given and medication prescribed, or visit to traditional health practitioner.

- Ask about any problems the mother has experienced since discharge and the six days postnatal visit.

- Ask the mother specifically about:

- Lochia: amount, colour and smell.

- Breast especially nipples or pain or swelling,

- Problems in passing urine, test urine for leucocytes and nitrates, treat for urinary tract infection.

- Genital: pain, swelling or discomfort. If sexual intercourse has been resumed, ask about pain or discomfort.

- Coughing or any respiratory tract problems. Check all clients for TB at each visit.

- Undue depression or anxiety, observe mother during the consultation, postnatal blues should have subsided.

- Relationship problem with: Spouse/partner or other children, give the mother an opportunity to talk about any adjustment problems.

Ask about the baby:

- Feeding of the baby according to choice, probe about exclusiveness of either breast, or formula feeding in HIVpositive women; ask about amounts and times, challenges in making formula, etc.

- Baby's sleeping pattern, stools, wet napkins, vomiting, skin, acceptance into the family.

- Ask about smiling and cooing, looking towards voice of mother and other family members. 
If the baby was born at home or not in health facility, or the mother did not attend antenatal care clinic:

- Ensure that mother and baby are afforded a full physical examination including blood tests, eg syphilis, HIV.

- Give the maternal dose of vitamin A to the mother. Check that the mother has had the required Tetanus Toxiod doses.

Undertake the following observations and examinations

Mother

- Undertake the general examination of JACCOL (jaundice, anaemia, cyanosis, respiratory problems or anxiety.

- Check the pulse and temperature, if the temperature of above $370 \mathrm{C}$ or pulse is above 90 per minute, undertake a full examination to identify the site of infection. Treat according to findings.

- Check blood pressure if $>140 / 90 \mathrm{mmHg}$ or a rise in dystolic or systolic readings $>20 \mathrm{mmHg}$, rest the client and measure in 10 minutes, if the blood pressure remains elevated refer to medical officer or advanced midwife.

- Observe respirations, note that an increased rate could indicate infection, respiratory problems or anxiety.

- $\quad$ Examine breast for any mastitis, cracked or infected nipples. Treat or refer.

- Observe for any normal behavior, anxiety, disinterest in the baby or own health. Expression of extreme sadness or despondence. Refer if required.

- Gently palpate the abdomen, the uterus should not be palpable and there should be no tenderness.

- Examine the vulva area for swelling or infections; check suture lines, these should be well healed by this time.

- Check the amount and color of lochia or discharge, note any offensive odour. Lochia should be scanty dry, only smears and non offensive in smell. All infections of the vulva area or offensive lochia must be urgently referred. If lochia remains fresh blood, consider secondary postpartum haemorrhage and infection, and refer immediately.

- If HIV-positive; use WHO clinical staging to assess the mother. Consider CD4 count.

- $\quad$ Check the mother's nutritional status and supplement if required.

Exclude common problems such as:

- Backache

- Frequent headaches

- Haemorrhoids

- Constipation

- Anxiety

- $\quad$ Extreme tiredness 
Undertake the following observations and examinations

Baby:

- Observe baby's general condition:

- Baby should be warm, active, good muscle tone, respond to mother's voice and face when awake. Limbs are flexed and bilateral movements when active. Check that the baby is gaining a measure of head when lifted.

- $\quad$ Feel the fontanel for fullness or sunkeness - do a full assessment if present, manage according to conditions.

- Examine the mucosa of the mouth for cyanosis, jaundice or paleness, if any present the baby should be referred for a medical opinion.

- $\quad$ Check the palms for pallor; take clinic based haemoglobin if suspected.

- Check for oral thrush, treat according to IMCI protocols.

- Look for discharge from the ears or eyes. Treat and refer according to IMCI.

- Examine the skin for rashes, bruises, etc.

- Check the umbilicus, this should be completely dry and healed.

- Weigh the baby without clothes on, birth weight should have been regained and the baby should be growing according to the growth curve; if not do a feeding assessment, counsel and recall in 14 days. Babies not growing well may need to be referred due to poor general condition.

- Measure the baby's head circumference and compare to birth and six days visit measurement; refer to medical officer, if growth is noted. Comparing these measurements on a head circumference growth percentile is ideal.

\section{Screening tests}

Mother

- Undertake clinic-based haemoglobin for each mother. Laboratory-based tests should be undertaken for mothers with severe blood loss or with anaemia during pregnancy that required blood transfusion.

- If a mother has not tested for HIV during pregnancy or postnataly offer to test her now after full counseling, explain the benefits of knowing one's status.

- If mother is HIV-positive: take a CD4 count, if one has not been taken in the last six months. Remind the mother when the next is due.

- $\quad$ Sputum for TB if cough history indicates. 
Baby

- Undertake the PCR test using dry blood spots from all HIV-exposed babies; tell the mother when the results are expected back. If the mother feels unprepared, keep offering the benefit of each test at each Well Baby visit, explaining the benefits for the baby. If the mother refuses testing of the baby at this visit commence cotrimoxazole until there is a negative test.

Note it should be mother who gives consent for the PCR test for the baby, other family members, unless the mother has died should not be able to consent for the test or obtain the results.

- Undertake a clinic base hemoglobin if palmar pallor is present and treat according to IMCI protocols.

\section{Prescribe the following interventions or treatment}

Mother

- Continue with iron if the mother's hemoglobin has not returned to over ten.

- Administer tetanus toxoid if the schedule is not completed.

- Continue with all routine medications required for asthma, epilepsy, TB ARVs, etc.

- If the mother is HIV-positive, continue with Vitamin supplements and cotrimoxazole prophylaxis.

- Following the required examination, history taking and education, offer the mother the range of contraception available to her.

- Drescribe the contraceptive requested by the mother if it is not medically excluded.

Baby

- Immunise the baby with the consent of the mother according to the Expanded Programme of Immmunisation schedule.

- $\quad$ For HIV exposed babies:

- Prescribe infant formula to those whose mothers have chosen formula-feed.

- Cotrimoxazole, until a negative HIV test is obtained. Demonstrate how to give infant oral medication.

- Treat any minor ailments such as oral thrush, nappy rash. 


\section{Education and counselling}

Suitable for group education

- Benefit of a family planning, including sterilisation.

- Cervical cancer screening.

- Safer sexual practices and protected intercourse, especially while breastfeeding.

- Immunisation.

- Infant feeding: benefits of excusive breastfeeding.

- Child stimulation and safety.

- General danger signs in all ill children (IMCI) and the management of infant diarrhea including the use of sugar-salt solution or home based fluids.

- Birth registration

- Protection of the Domestic Violence Act and post-exposure prophylaxis available to survivors of sexual assault.

- Remind mothers that rest, extra kilojoules, fluids and protein are needed while breastfeeding.

Topics for individual education and counselling

- Contraception and how the methods work and the need for dual protection.

- Safer sexual practices and HIV testing, as well as testing of baby if exposed and regular CD4 counts for mother.

- Crisis counseling and intervention in cases of social problems or domestic violence. Identification of safe places to escape to and action to take.

- Resumption of sexual intercourse, if this has not already occurred. Explaining any loss in libido, especially while breastfeeding. Counsel on prevention of dry, painful sex.

- If HIV-positive, the need for either exclusive breast feeding or exclusive formula feeding.

- Schedule next visit in four weeks time if all normal, otherwise according to need and health status. 